University of Nebraska - Lincoln

DigitalCommons@University of Nebraska - Lincoln

\title{
Annual Report to the Nation on the Status of Cancer, 1975-2004, Featuring Cancer in American Indians and Alaska Natives
}

\author{
David K. Espey \\ Centers for Disease Control and Prevention, david.espey@ihs.gov \\ Xiao-Cheng Wu \\ North American Association of Central Cancer Registries, xwu@lsuhsc.edu \\ Judith Swan \\ Louisiana State University \\ Charles Wiggins \\ University of New Mexico \\ Melissa A. Jim \\ Centers for Disease Control and Prevention \\ See next page for additional authors
}

Follow this and additional works at: https://digitalcommons.unl.edu/publichealthresources

Part of the Public Health Commons

Espey, David K.; Wu, Xiao-Cheng; Swan, Judith; Wiggins, Charles; Jim, Melissa A.; Ward, Elizabeth; Wingo, Phyllis A.; Howe, Holly L.; Ries, Lynn A. G.; Miller, Barry A.; Jemal, Ahmedin; Ahmed, Faruque; Cobb, Nathaniel; Kaur, Judith S.; and Edwards, Brenda K., "Annual Report to the Nation on the Status of Cancer, 1975-2004, Featuring Cancer in American Indians and Alaska Natives" (2007). Public Health Resources. 247.

https://digitalcommons.unl.edu/publichealthresources/247

This Article is brought to you for free and open access by the Public Health Resources at DigitalCommons@University of Nebraska - Lincoln. It has been accepted for inclusion in Public Health Resources by an authorized administrator of DigitalCommons@University of Nebraska - Lincoln. 


\section{Authors}

David K. Espey, Xiao-Cheng Wu, Judith Swan, Charles Wiggins, Melissa A. Jim, Elizabeth Ward, Phyllis A. Wingo, Holly L. Howe, Lynn A. G. Ries, Barry A. Miller, Ahmedin Jemal, Faruque Ahmed, Nathaniel Cobb, Judith S. Kaur, and Brenda K. Edwards 


\section{O M M E N T A R Y}

We thank Andrew Lake, Rick Firth, Danielle Melbert, and Martin Krapcho of Information Management Services, Inc. for assisting in statistical analyses.

We also thank Tom Richards and Mary White, Division of Cancer Prevention and Control, Centers for Disease Control and Prevention, Atlanta, Georgia for assistance with graphics and their helpful comments on the article.

Phyllis A. Wingo was under contract with the Indian Health Service for a portion of her work on this manuscript.

This article was originally published online on October 15, 2007, and it is presented here with the following modifications: Dr. Wu's degree appears correctly above, and some data was realigned in the tables to improve the readability of the data being presented. The changes do not affect the core data or the conclusions of the article in any way. The publisher apologizes for this oversight and any confusion that may have ensued.

Address for reprints: David K. Espey, MD, Division of Cancer Prevention and Control, Centers for Disease Prevention and Control and Division of Epidemiology and Disease Prevention, Indian Health Service, 5300 Homestead NE, Albuquerque, NM 87110; Fax: (505) 248-4393; E-mail: david.espey@ihs.gov

Received August 13, 2007; revision received August 20, 2007; accepted August 21, 2007.

*This article is a U.S. government work and, as such, is in the public domain in the United States of America.

\section{Annual Report to the Nation on the Status of Cancer, 1975-2004, Featuring Cancer in American Indians and Alaska Natives}

\author{
David K. Espey, MD ${ }^{1}$ \\ Xiao-Cheng $\mathrm{Wu}, \mathrm{MD}, \mathrm{MPH}^{2,3}$ \\ Judith Swan, MSH $^{4}$ \\ Charles Wiggins, MPH, PhD ${ }^{5}$ \\ Melissa A. Jim, MPH ${ }^{1}$ \\ Elizabeth Ward, $\mathrm{PhD}^{6}$ \\ Phyllis A. Wingo, PhD ${ }^{1}$ \\ Holly L. Howe, PhD ${ }^{2}$ \\ Lynn A. G. Ries, $\mathrm{ms}^{4}$ \\ Barry A. Miller, DrPH ${ }^{4}$ \\ Ahmedin Jemal, DVM, PhD ${ }^{6}$ \\ Faruque Ahmed, PhD ${ }^{1}$ \\ Nathaniel Cobb, MD $^{7}$ \\ Judith S. Kaur, ${ }^{8}{ }^{8}$ \\ Brenda K. Edwards, PhD ${ }^{4}$
}

${ }^{1}$ Division of Cancer Prevention and Control, National Center for Chronic Disease Prevention and Health Promotion, Centers for Disease Control and Prevention, Atlanta, Georgia.

${ }^{2}$ North American Association of Central Cancer Registries, Springfield, Illinois.

${ }^{3}$ Louisiana Tumor Registry, Epidemiology Program, School of Public Health, Louisiana State University Health Science Center, Louisiana State University, New Orleans, Louisiana.

${ }^{4}$ Division of Cancer Control and Population Sciences, National Cancer Institute, Bethesda, Maryland.

${ }^{5}$ New Mexico Tumor Registry, University of New Mexico, Albuquerque, New Mexico.

${ }^{6}$ Epidemiology and Surveillance Research Department, American Cancer Society, Atlanta, Georgia.

${ }^{7}$ Division of Epidemiology and Disease Prevention, Indian Health Service, Albuquerque, New Mexico.

${ }^{8}$ Department of Oncology, Mayo Clinic College of Medicine, Rochester, Minnesota.

BACKGROUND. The American Cancer Society, the Centers for Disease Control and Prevention, the National Cancer Institute, and the North American Association of Central Cancer Registries collaborate annually to provide updated information on cancer occurrence and trends in the U.S. The 2007 report features a comprehensive compilation of cancer information for American Indians and Alaska Natives (AI/AN). METHODS. Cancer incidence data were available for up to $82 \%$ of the U.S. population. Cancer deaths were available for the entire U.S. population. Long-term (1975 through 2004) and fixed-interval (1995 through 2004) incidence and mortality trends were evaluated by annual percent change using regression analyses (2-sided $P<.05)$. Cancer screening, risk factors, socioeconomic characteristics, incidence data, and stage were compiled for non-Hispanic whites (NHW) and AI/AN across 6 regions of the U.S. 
$\mathbf{T}$ he American Cancer Society (ACS), the Centers for Disease Control and Prevention (CDC), the National Cancer Institute (NCI), and the North American Association of Central Cancer Registries (NAACCR) collaborate annually to assess the cancer burden in the U.S. The 1998 report documented the first sustained decline in cancer death rates since the 1930s. ${ }^{1}$ Subsequent reports updated information on trends in incidence and death rates and featured timely, in-depth analyses of selected topics. ${ }^{2-9}$ The American Indian and Alaska Native (AI/AN) cancer experience has not been described well except for a few geographic areas. This 2007 report updates the cancer profile for the U.S. and describes regional patterns of cancer in AI/AN using methods that mitigate the effects of race misclassification.

\section{MATERIALS AND METHODS \\ Cancer Cases, Cancer Deaths, and Population Estimates}

Population-based cancer registries collect information on all reportable cancer cases. They participate in the CDC's National Program of Cancer Registries
(NPCR), in the NCI's Surveillance, Epidemiology, and End Results (SEER) Program, or both; and all are members of NAACCR. In this report, incidence data from these registries refer to invasive cancers, with the exception of in situ cancer of the urinary bladder (bladder). Primary cancer site and histology data were coded according to the International Classification of Diseases (ICD) for Oncology (ICD-O) edition in use at the time of diagnosis, converted to the Third Edition coding ${ }^{10}$ and categorized according to SEER site groups. ${ }^{11}$

U.S. cancer deaths, reported to state vital statistics offices and consolidated through CDC's National Vital Statistics System, ${ }^{12}$ were coded using the version of the ICD in use at the time of death. ${ }^{13-16}$ Underlying causes of cancer death were grouped according to the SEER cause of death recode for maximum comparability among ICD versions. ${ }^{11}$ Mortality data were provided by all 50 states and the District of Columbia; however, death rates for the Hispanic population did not include data from 5 states (Maine, Minnesota, New Hampshire, North Dakota, and Oklahoma) because of incomplete ethnicity information for at least one of the reporting years in the analyses. ${ }^{17}$ 
TABLE 1

U.S. Population Coverage for Data Sets Used in Cancer Incidence Analyses by Race/Ethnicity

\begin{tabular}{|c|c|c|c|c|c|c|}
\hline \multirow[b]{3}{*}{ Race/ethnicity } & \multicolumn{2}{|c|}{ Incidence trends } & \multicolumn{4}{|c|}{ Incidence rates } \\
\hline & \multirow{2}{*}{$\begin{array}{l}\text { Long-term trends } \\
1975-2004 \\
\text { SEER }^{\mathrm{a}} \\
\%^{\mathrm{d}}\end{array}$} & \multirow{2}{*}{$\begin{array}{l}\text { Fixed-interval trends } \\
1995-2004 \\
24 \text { States }^{\text {b }} \\
\%^{\text {d }}\end{array}$} & \multirow[b]{2}{*}{$\begin{array}{l}2000-2004 \\
39 \text { States }^{b} \\
\%^{d}\end{array}$} & \multirow{2}{*}{$\begin{array}{l}\frac{\mathrm{AI} / \mathrm{AN}}{1999-2004} \\
\begin{array}{l}41 \text { States } \\
\%^{\mathrm{d}, \mathrm{c}}\end{array}\end{array}$} & \multicolumn{2}{|c|}{ AI/AN (CHSDA Counties) } \\
\hline & & & & & $\begin{array}{l}1999-2004 \\
30 \text { States }^{\text {b,c }} \\
\%^{d}\end{array}$ & $\begin{array}{l}2001-2003 \\
30 \text { States }^{b, c} \\
\%^{d}\end{array}$ \\
\hline & (Table 2) & (Table 4) & (Table 4) & (Table 4) & (Tables 4,7,8) & (Table 9) \\
\hline \multirow{3}{*}{$\begin{array}{l}\text { All race/ethnic groups } \\
\text { White } \\
\text { Black }\end{array}$} & 9.4 & 59.3 & 81.8 & & & \\
\hline & & 58.8 & 82.1 & & & \\
\hline & & 56.0 & 77.9 & & & \\
\hline \multicolumn{2}{|l|}{ API } & 80.6 & 89.7 & & & \\
\hline \multicolumn{2}{|l|}{$\mathrm{AI} / \mathrm{AN}$} & 48.5 & & 87.7 & & \\
\hline \multicolumn{2}{|l|}{ AI/AN (CHSDA counties) } & $20.7^{\mathrm{e}}$ & & & 52.1 & 52.7 \\
\hline \multicolumn{2}{|l|}{ Hispanic } & 84.6 & 91.0 & & & \\
\hline \multicolumn{2}{|l|}{ Non-Hispanic } & 55.7 & 80.4 & & & \\
\hline \multicolumn{3}{|l|}{ Non-Hispanic white } & & & 19.8 & 20.2 \\
\hline \multirow{2}{*}{\multicolumn{7}{|c|}{ AI/AN indicates American Indian and Alaska Native; CHSDA, Indian Health Service Contract Health Service Delivery Area; SEER, Surveillance, Epidemiology, and End Results; NPCR, National Program of Cancer }} \\
\hline & & & & & & \\
\hline \multicolumn{7}{|c|}{$\begin{array}{l}\text { Registries; NAACCR, North American Association of Central Cancer Registries. } \\
\text { a SEER areas include Connecticut, Hawaii, Iowa, Utah, and New Mexico and the metropolitan areas of San Francisco, Detroit, Atlanta, and Seattle-Puget Sound (ie SEER 9). }\end{array}$} \\
\hline \multicolumn{7}{|c|}{ b NPCR and SEER areas with cancer registry data reported by the NAACR as meeting high-quality standards for the specified period. } \\
\hline \multicolumn{7}{|c|}{${ }^{\mathrm{c}}$ The Wisconsin and Arizona data for the specified period are used for AI/AN as well as AI/AN and non-Hispanic white in CHSDA counties only. } \\
\hline \multicolumn{7}{|c|}{${ }^{\mathrm{d}}$ Percentage of the U.S. population. } \\
\hline e Data from 17 states that me & standards for the s & & & & & \\
\hline
\end{tabular}

County level population estimates from the U.S. Bureau of the Census, modified by NCI, were used as denominators in the rate calculations. ${ }^{18}$ Because the 2000 census allowed respondents to identify themselves as multiracial, CDC's National Center for Health Statistics collaborated with the Census Bureau to develop bridging methods for single-race estimates to describe long-term trends in disease. ${ }^{19}$ The bridged, single-race annual population estimates were used for the years 1990 through 2004.

All analyses (long-term trends, fixed-interval trends, and average annual rates) were based on incidence data for various geographic areas. Incidence data were not available uniformly for all populations, time periods, and geographic areas. Long-term incidence trends (1975 through 2004) for all races/ethnicities combined by sex for all sites combined and the 15 most common cancers were based on SEER incidence data covering approximately $10 \%$ of the U.S. population, the only source for long-term incidence analyses. ${ }^{20}$ Fixed-interval trends (1995 through 2004) for all race/ethnic populations combined and for white, black, Asian/Pacific Islander (API), Hispanic, and non-Hispanic populations for all sites combined and for the 15 most common cancers were based on data from 24 cancer registries covering approxi- mately $59 \%$ of the U.S. population. Average-annual (2000 through 2004), sex-specific, and age-adjusted incidence rates for white, black, API, Hispanic, and non-Hispanic populations were based on incidence data from 39 cancer registries, covering approximately $82 \%$ of the U.S. population. For the AI/AN population, data for 2 geographic catchment areas are presented for fixed-interval trends and rates. The first includes AI/AN data from all counties in states that were included in the analytic dataset. The second includes only data from Indian Health Service (IHS) Contract Health Service Delivery Area (CHSDA) counties in the states that were included in the analytic dataset (see "Data for AI/AN" below, for an explanation of CHSDA) (Table 1). Because the AI/AN population is smaller proportionally than the other major race/ethnic populations, 6 years of data (1999 through 2004) were used for AI/AN incidence and death rates to increase the precision of the estimates. All registry data included in the analyses met NAACCR's standards for high-quality cancer incidence data. The percent of population coverage for each of the cancer incidence datasets used for the tables in this report are summarized in Table 1, including the percentage of the AI/AN population covered by each. 


\section{Classification of American Indian and Alaska Native Race}

Race generally is documented by cancer registries based on the patient's medical record; however, it has been determined that many AI/AN were misclassified as non-Native in some central cancer registries $^{21-26}$ and in state death records. ${ }^{27}$ Such misclassification leads to underestimation of the true burden of cancer in AI/AN populations.

To improve race classification for AI/AN cases, all records for cases diagnosed from 1995 through 2004 were linked with the IHS patient registration database to identify AI/AN cases that were misclassified as non-Native. The IHS provides medical services to $\mathrm{AI} / \mathrm{AN}$ persons who are members of federally recognized tribes. Membership criteria are determined by individual tribes and typically refer to a percentage of "blood quantum" or fraction of AI/AN ancestry, with some tribes requiring only proof of descent from an AI/AN ancestor, whereas others may require as much as one-half ancestry (one-half blood quantum). ${ }^{28}$ The patient registration database includes persons who have received services since 1985 provided either in an IHS and/or tribal facility or by a non-IHS or nontribal program and paid by IHS Contract Health Services funds. A small number of non-AI/AN persons are eligible for IHS services through marriage or other basis; these records were removed before linkage with the registries. Linkages were conducted using LinkPlus, a probabilistic linkage software program that was developed by CDC that was applied to key patient identifiers (Social Security number, first name, last name, middle initial, date of birth, and date of death). ${ }^{29}$ Possible matches, requiring manual review, were examined independently by 2 reviewers and, when necessary, were adjudicated by a third reviewer.

The cancer incidence rates in this report use information from the IHS linkage in combination with information from the race variables that are reported routinely by the central cancer registries. Beginning with cancer cases diagnosed on January 1, 2000 and later, registries report data in multiple race fields for multiracial individuals if that information is available from medical records. ${ }^{30}$ Coding rules specify that, for persons of multiple races, a nonwhite race takes priority over white race for analytic purposes. ${ }^{31}$ For this report, all cases classified as AI/AN in the first race field were retained in that category. In addition, when the first race field was classified as white or unknown and there was a positive IHS link, then the case also was reclassified as AI/AN for this report. If the first race field was coded as API, black, or other race and there was a positive IHS link, then the value for first race was retained.

\section{Data for American Indians and Alaska Natives}

For the AI/AN population in this report, emphasis is placed on data from IHS CHSDA counties, which, in general, contain federally recognized tribal lands or are adjacent to tribal lands (Fig. 1). Unpublished data indicate less race misclassification for AI/AN in these counties than in non-CHSDA counties. Also, the proportions of $\mathrm{AI} / \mathrm{AN}$ in relation to total population are higher in CHSDA counties than in non-CHSDA counties; $57 \%$ of the U.S. AI/AN population resides in the 624 counties designated as CHSDA (Table 1 Supplement A, which shows the AI/AN population by region and residence in CHSDA county, is available at URL: www.seer.cancer.gov/report_to_nation/). Analyses restricted to CHSDA counties are presented for cancer incidence and death rates and stage distribution in this report to improve accuracy in interpreting cancer statistics for AI/AN persons (for distribution of CHSDA counties, see Fig. 1). All results described in the text for $\mathrm{AI} / \mathrm{AN}$ refer to $\mathrm{AI} / \mathrm{AN}$ persons who reside in CHSDA counties unless noted otherwise.

The analysis of AI/AN data by IHS region (Alaska, Pacific Coast, Northern Plains, Southern Plains, Southwest, and East) (Fig. 1) was consistent with known regional trends for specific health outcomes and risk factors for AI/AN. Regional analyses have been presented in several publications focusing on $\mathrm{AI} / \mathrm{AN},{ }^{32-35}$ and this approach was preferable to the use of smaller jurisdictions, such as the Administrative Areas defined by IHS, ${ }^{36}$ which yielded less stable estimates. Supplemental information regarding population coverage and other measures of the burden of cancer in the AI/AN by IHS region is contained in a Table on the NCI web site (available at URL: www.seer.cancer.gov/report_to_nation/). Additional data regarding cancer incidence and mortality are available from the following sites: www.cancer.gov (NCI), www.cancer.org (ACS), www.cdc.gov/cancer/npcr/index.htm and www.cdc.gov/nchs/about/ major/dvs/mortdata.htm (CDC), and www.naaccr. org/CINAP?index.htm (NAACCR).

\section{Socioeconomic Status, Healthcare Access, Risk Factors, Screening, and Stage}

Data regarding socioeconomic status, healthcare access, behavioral risk factors, and cancer screening by race/ethnicity and geographic region were obtained from the U.S. Census Bureau and the CDC's Behavioral Risk Factor Surveillance System (BRFSS) and were categorized according to Healthy People 2010 objectives. ${ }^{37}$ Questions concerning cigarette smoking, physical activity, alcohol consumption, and Papanicolaou (Pap) tests (women only) were asked of 


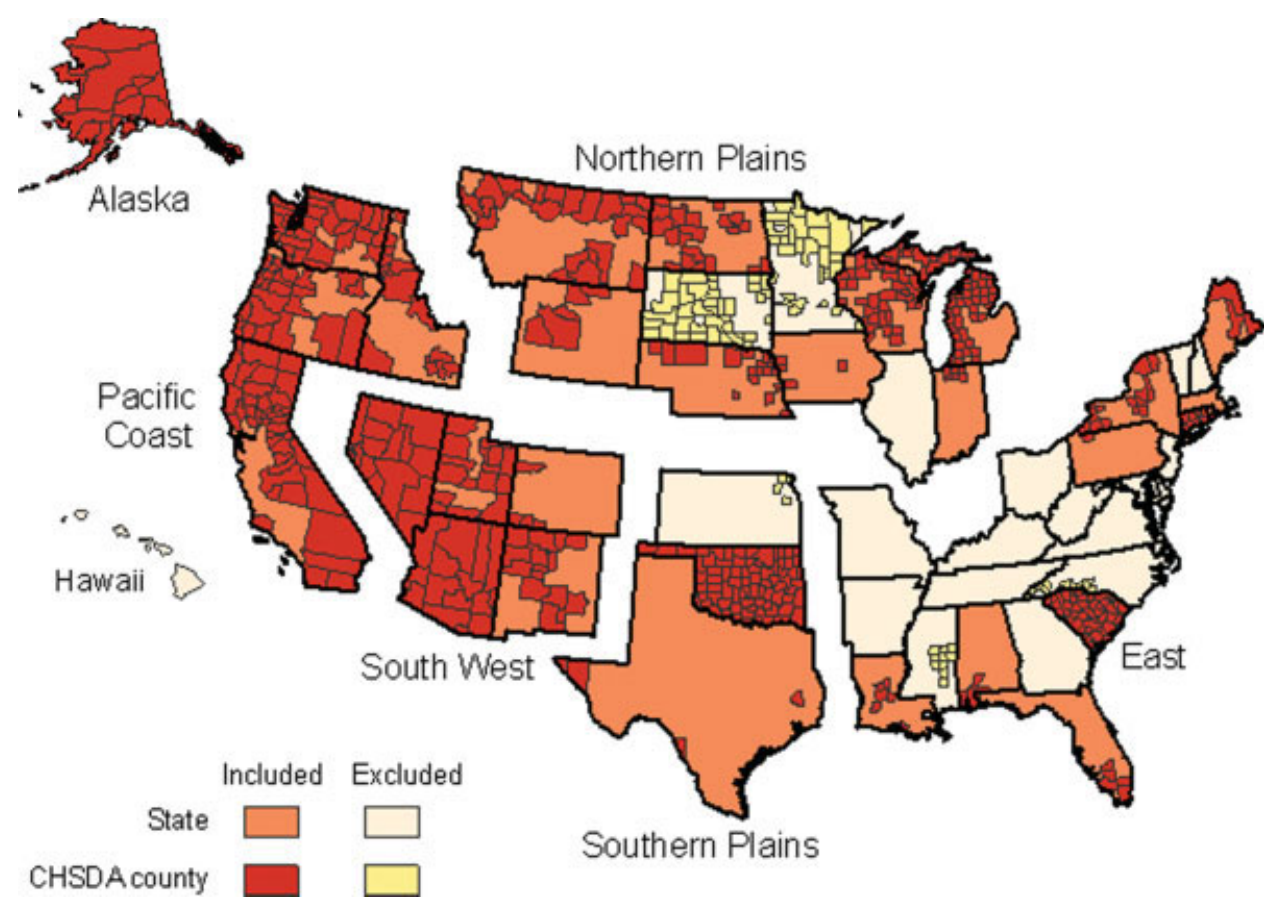

FIGURE 1. States and Contract Health Service Delivery Area (CHSDA) counties used in cancer incidence analyses for the American Indian/Alaska Native population, by Indian Health Service region.

adults aged $\geq 18$ years. Questions also were asked regarding participation in mammography screening among women aged $\geq 40$ years, colorectal cancer screening among persons aged $\geq 50$ years, and prostate-specific antigen (PSA) testing among men aged $\geq 50$ years who reported no history of prostate cancer. Adults aged $\geq 20$ years were asked about selfreported obesity prevalence.

The distribution of stage of disease at diagnosis for cancers of the breast, prostate, colon and rectum, and cervix uteri (cervix) was examined for non-Hispanic white (NHW) and AI/AN populations regionally and in all regions combined. Cancer incident cases were staged using the 2000 SEER Summary Stage. To eliminate the effect of different staging systems both before 2001 and after 2003, only individuals who were diagnosed from 2001 through 2003 were included for cancer stage statistics. ${ }^{38}$

\section{Statistical Analysis}

For all populations, cancer incidence and death rates were expressed per 100,000 persons and were ageadjusted by 19 age groups (aged $<1$ year, ages $1-4$ years, ages 5-9 years, ..., ages $80-84$ years, aged $\geq 85$ years) to the 2000 U.S. standard population. Age adjustment summarizes age-specific rates and eliminates the effect of differences in age composition among the populations being compared. ${ }^{39}$ The AI/
AN population is younger on average than the NHW population. ${ }^{40}$ Rates, standard errors, and 95\% confidence intervals $(95 \%$ CIs) were generated using SEER*Stat software, version 6.3 (available at URL: http://www.seer.cancer.gov/seerstat/). ${ }^{20}$ All incidence and death rates that were calculated with $<16$ observations were suppressed. Similarly, the annual percent change (APC) statistic was suppressed if it was based on $<10$ cases for at least 1 year within the time interval.

Long-term cancer incidence and death trends (1975 through 2004) were described using joinpoint analysis, including the APC for each interval, for all races/ethnicities combined. ${ }^{41}$ Statistical significance was set at $P<.05$. The observed incidence trends and those adjusted for reporting delay (mostly affecting recent years) were presented using models based on long-term reporting patterns in SEER. ${ }^{42}$ Nondelay-adjusted and delay-adjusted APCs are presented; however, only delay-adjusted results are referred to in the text. APC analysis was used to describe fixed interval trends (1995 through 2004); the incidence data for the fixed interval APCs were not adjusted for reporting delay. For both methods of trend analysis, the terms "increase" or "decrease" were used when the slope of the trend was statistically significant $(P<.05)$; otherwise, the terms "stable" or "level" were used. 
Prevalence estimates for screening and risk factors were calculated using data from the BRFSS aggregated over the 6-year period 1999 through 2005. Not all years were available for each BRFSS-derived risk factor, because some questions were not asked every year. Prevalence estimates from BRFSS were age-adjusted to the 2000 U.S. standard population and sample-weighted using SUDAAN software to account for the complex BRFSS sampling design. ${ }^{43}$ Prevalence estimates for cancer risk factors and screening were suppressed if they were based on $<50$ observations. Prevalence estimates of socioeconomic characteristics from U.S. Census were not age-adjusted. Confidence intervals are provided for all prevalence estimates; however, they do not provide a basis for significance testing of regional differences. $^{44}$

Regional, site-specific comparisons of incidence rates between AI/AN and NHW populations are shown by rate ratios (RR) with $95 \%$ CIs. In describing rate comparisons for AI/AN and NHW populations, the terms "higher" or "lower" were used when the RRs differed significantly from $1.0(P<.05)$. Thus, when the $\mathrm{RR}$ was $<1.0$, the rate among $\mathrm{AI} / \mathrm{AN}$ was lower than that among NHW; when the RR was $>1.0$, the rate among AI/AN was higher than that among NHW. Otherwise, the RRs were described as comparable. Relative percents $(\mathrm{R} \%)$ were calculated to facilitate comparisons of distributions of age-adjusted, stage-specific incidence rates between NHW and AI/AN populations across IHS regions.

\section{RESULTS}

\section{Update on Long-term Incidence Trends, 1975-2004}

For all populations, both sexes, and all cancer sites combined, incidence rates increased from 1975 through 1992 and then decreased $(-0.3 \%$ per year) from 1992 through 2004 (Table 2). For men, the rates increased from 1975 through 1992, decreased from 1992 through 1995, and subsequently stabilized from 1995 through 2004. For women, rates increased from 1979 through 1986, increased more slowly from 1986 through 1999, and stabilized from 1999 through 2004.

Among men, prostate cancer incidence rates stabilized from 1995 through 2004 after the steep increase reported from 1988 through 1992 and the subsequent decline from 1992 through 1995. Increases in cancer incidence were noted from 1975 through 2004 for myeloma and for cancers of the kidney and renal pelvis (kidney), liver and intrahepatic bile ducts (liver), and esophagus. Declining trends in incidence were noted for the most recent joinpoint segments for cancers of the lung and bronchus (lung), colon and rectum, oral cavity and pharynx (oral cavity), and stomach. Rates were stable for the most recent joinpoint segments for the remaining top 15 cancers in men.

Among women, breast cancer incidence rates decreased for the period 2001 through 2004 by 3.5\% per year, reversing a long-term increase that began in the early 1980s. Lung cancer rates increased from 1975 through 1998 and stabilized from 1998 through 2004. Colorectal cancer rates decreased from 1998 through 2004. Rates also declined for cancers of the cervix and stomach from 1975 through 2004 and for cancers of the corpus uteri and uterus not otherwise specified (uterus), ovary, and oral cavity in the most recent joinpoint segments. Increasing trends were noted from 1975 through 2004 for melanoma, nonHodgkin lymphoma (NHL), leukemia, and cancers of the bladder and kidney. Increasing rates of thyroid cancer were noted from 1980 through 1995, with the rate of increase nearly tripling from 1995 through 2004. Pancreatic cancer incidence rates stabilized for the most recent joinpoint segment.

\section{Update on Long-term Mortality Trends, 1975-2004}

Cancer death rates for all races/ethnicities and both sexes combined decreased by $2.1 \%$ per year from 2002 to 2004 compared with $1.1 \%$ per year from 1993 to 2002 (Table 3). The decreases involved both men and women, but they were greater in men than in women from 2002 through 2004 (2.6\% per year in men and $1.8 \%$ per year in women). Accelerated declines in cancer mortality rates largely reflect more rapid decreases in the death rates from leading causes of cancer mortality: lung and prostate cancer in men, breast cancer in women, and colon and rectum cancer in both men and women.

During the last joinpoint segment, rates were declining for 12 of the 15 most common causes of cancer death in men (lung, prostate, colon and rectum, pancreas, leukemia, NHL, bladder, kidney, stomach, brain, myeloma, and oral cavity) (Table 4). Melanoma rates remained stable from 1990 through 2004. The rates for only 2 sites-cancer of the liver and esophagus-increased ( $1.8 \%$ and $0.4 \%$ per year, respectively).

Similarly, rates declined for 10 of the 15 most common causes of cancer death in women (breast, colon and rectum, NHL, leukemia, brain, myeloma, stomach, kidney, cervix, and bladder). Death rates for the most recent joinpoint segments were stable in women for cancers of the pancreas, ovary, and 
TABLE 2

Surveillance, Epidemiology, and End Results Cancer Incidence Rate Trends With Joinpoint Analyses for 1975-2004 for the Top 15 Cancers, by Sex, for All Races

\begin{tabular}{|c|c|c|c|c|c|c|c|c|}
\hline \multirow[b]{3}{*}{ Sex/cancer site or type } & \multicolumn{8}{|c|}{ Joinpoint analyses (1975-2004) ${ }^{\mathrm{a}}$} \\
\hline & \multicolumn{2}{|c|}{ Trend 1} & \multicolumn{2}{|c|}{ Trend 2} & \multicolumn{2}{|c|}{ Trend 3} & \multicolumn{2}{|c|}{ Trend 4} \\
\hline & Years & $A P C^{d}$ & Years & $\mathrm{APC}^{\mathrm{d}}$ & Years & $\mathrm{APC}^{\mathrm{d}}$ & Years & $A P C^{d}$ \\
\hline \multicolumn{9}{|l|}{ All sites ${ }^{\mathrm{b}}$} \\
\hline $\begin{array}{l}\text { Both sexes } \\
\quad \text { (Delay-adjusted) }\end{array}$ & $\begin{array}{l}1975-1992 \\
1975-1992\end{array}$ & $\begin{array}{l}1.4^{\mathrm{e}} \\
1.4^{\mathrm{e}}\end{array}$ & $\begin{array}{l}1992-1995 \\
1992-2004\end{array}$ & $\begin{array}{l}-1.3 \\
-0.3^{\mathrm{e}}\end{array}$ & 1995-2001 & 0.3 & 2001-2004 & $-2.1^{\mathrm{e}}$ \\
\hline $\begin{array}{l}\text { Males } \\
\text { (Delay-adiusted) }\end{array}$ & $\begin{array}{l}1975-1989 \\
1975-1989\end{array}$ & $1.3^{\mathrm{e}}$ & $\begin{array}{l}1989-1992 \\
1989-1992\end{array}$ & $5.0^{\mathrm{e}}$ & $\begin{array}{l}1992-1995 \\
1992-1995\end{array}$ & $\begin{array}{l}-4.1^{\mathrm{e}} \\
-4.3^{\mathrm{e}}\end{array}$ & $\begin{array}{l}1995-2004 \\
1995-2004\end{array}$ & $\begin{array}{l}-0.5^{\mathrm{e}} \\
-0.2\end{array}$ \\
\hline $\begin{array}{l}\text { Females } \\
\text { (Delav-adiusted) }\end{array}$ & $\begin{array}{l}1975-1979 \\
1975-1979\end{array}$ & $\begin{array}{l}-0.2 \\
-0.3\end{array}$ & $\begin{array}{l}1979-1987 \\
1979-1986\end{array}$ & $1.5^{\mathrm{e}}$ & $\begin{array}{l}1987-2001 \\
1986-1999\end{array}$ & $0.3^{\mathrm{e}}$ & $\begin{array}{l}2001-2004 \\
1999-2004\end{array}$ & $\begin{array}{l}-1.7^{\mathrm{e}} \\
-0.5\end{array}$ \\
\hline \multicolumn{9}{|l|}{ Top 15 cancers for males ${ }^{\mathrm{c}}$} \\
\hline $\begin{array}{l}\text { Prostate } \\
\text { (Delay-adjusted) }\end{array}$ & $\begin{array}{l}1975-1988 \\
1975-1988\end{array}$ & $\begin{array}{l}2.6^{\mathrm{e}} \\
2.6^{\mathrm{e}}\end{array}$ & $\begin{array}{l}1988-1992 \\
1988-1992\end{array}$ & $\begin{array}{l}16.2^{\mathrm{e}} \\
16.2^{\mathrm{e}}\end{array}$ & $\begin{array}{l}1992-1995 \\
1992-1995\end{array}$ & $\begin{array}{l}-10.1^{\mathrm{e}} \\
-10.2^{\mathrm{e}}\end{array}$ & $\begin{array}{l}1995-2004 \\
1995-2004\end{array}$ & $\begin{array}{l}0.1 \\
0.4\end{array}$ \\
\hline $\begin{array}{l}\text { Lung and bronchus } \\
\text { (Delay-adjusted) }\end{array}$ & $\begin{array}{l}1975-1982 \\
1975-1982\end{array}$ & $\begin{array}{l}1.4^{\mathrm{e}} \\
1.5^{\mathrm{e}}\end{array}$ & $\begin{array}{l}1982-1991 \\
1982-1991\end{array}$ & $\begin{array}{l}-0.4 \\
-0.5\end{array}$ & $\begin{array}{l}1991-2004 \\
1991-2004\end{array}$ & $\begin{array}{l}-1.9^{\mathrm{e}} \\
-1.8^{\mathrm{e}}\end{array}$ & & \\
\hline $\begin{array}{l}\text { Colon and rectum } \\
\text { (Delay-adjusted) }\end{array}$ & $\begin{array}{l}1975-1986 \\
1975-1986\end{array}$ & $1.1^{\mathrm{e}}$ & $\begin{array}{l}1986-1995 \\
1986-1995\end{array}$ & $\begin{array}{l}-2.1^{\mathrm{e}} \\
-2.1^{\mathrm{e}}\end{array}$ & $\begin{array}{l}1995-1998 \\
1995-1998\end{array}$ & $\begin{array}{l}1.1 \\
1.1\end{array}$ & $\begin{array}{l}1998-2004 \\
1998-2004\end{array}$ & $\begin{array}{l}-2.8^{\mathrm{e}} \\
-2.6^{\mathrm{e}}\end{array}$ \\
\hline Urinary bladder & $1975-1987$ & $1.0^{\mathrm{e}}$ & $1987-1995$ & -0.6 & $1995-2000$ & 1.1 & $2000-2004$ & $-1.6^{\mathrm{e}}$ \\
\hline (Delay-adjusted) & 1975-1987 & $1.0^{\mathrm{e}}$ & 1987-1996 & -0.5 & 1996-1999 & 2.0 & 1999-2004 & -0.9 \\
\hline $\begin{array}{l}\text { Non-Hodgkin lymphoma } \\
\text { (Delay-adjusted) }\end{array}$ & $\begin{array}{l}1975-1991 \\
1975-1991\end{array}$ & $\begin{array}{l}4.3^{\mathrm{e}} \\
4.2^{\mathrm{e}}\end{array}$ & $\begin{array}{l}1991-2004 \\
1991-2004\end{array}$ & $\begin{array}{l}0.1 \\
0.3\end{array}$ & & & & \\
\hline $\begin{array}{l}\text { Melanoma of the skin } \\
\text { (Delay-adjusted) }\end{array}$ & $\begin{array}{l}1975-1985 \\
1975-1985\end{array}$ & $\begin{array}{l}5.4^{\mathrm{e}} \\
5.4^{\mathrm{e}}\end{array}$ & $\begin{array}{l}1985-2000 \\
1985-2000\end{array}$ & $\begin{array}{l}3.3^{\mathrm{e}} \\
3.4^{\mathrm{e}}\end{array}$ & $\begin{array}{l}2000-2004 \\
2000-2004\end{array}$ & $\begin{array}{l}0.0 \\
0.5\end{array}$ & & \\
\hline $\begin{array}{l}\text { Kidney and renal pelvis } \\
\text { (Delay-adjusted) }\end{array}$ & $\begin{array}{l}1975-2004 \\
1975-2004\end{array}$ & $\begin{array}{l}1.7^{\mathrm{e}} \\
1.8^{\mathrm{e}}\end{array}$ & & & & & & \\
\hline $\begin{array}{l}\text { Leukemia } \\
\text { (Delay-adjusted) }\end{array}$ & $\begin{array}{l}1975-2001 \\
1975-2004\end{array}$ & $\begin{array}{r}-0.1 \\
0.1\end{array}$ & 2001-2004 & -3.2 & & & & \\
\hline $\begin{array}{l}\text { Oral cavity and pharynx } \\
\text { (Delay-adjusted) }\end{array}$ & $\begin{array}{l}1975-1983 \\
1975-1983\end{array}$ & $\begin{array}{l}-0.1 \\
-0.2\end{array}$ & $\begin{array}{l}1983-2004 \\
1983-2004\end{array}$ & $\begin{array}{l}-1.5^{\mathrm{e}} \\
-1.4^{\mathrm{e}}\end{array}$ & & & & \\
\hline $\begin{array}{l}\text { Pancreas } \\
\text { (Delay-adjusted) }\end{array}$ & $\begin{array}{l}1975-1993 \\
1975-1993\end{array}$ & $\begin{array}{l}-0.8^{\mathrm{e}} \\
-0.9^{\mathrm{e}}\end{array}$ & $\begin{array}{l}1993-2004 \\
1993-2004\end{array}$ & $\begin{array}{l}0.1 \\
0.3\end{array}$ & & & & \\
\hline $\begin{array}{l}\text { Stomach } \\
\text { (Delay-adjusted) }\end{array}$ & $\begin{array}{l}1975-1988 \\
1975-1988\end{array}$ & $\begin{array}{l}-1.2^{\mathrm{e}} \\
-1.2^{\mathrm{e}}\end{array}$ & $\begin{array}{l}1988-2004 \\
1988-2004\end{array}$ & $\begin{array}{l}-2.1^{\mathrm{e}} \\
-2.0^{\mathrm{e}}\end{array}$ & & & & \\
\hline $\begin{array}{l}\text { Liver and intrahepatic bile duct } \\
\text { (Delav-adiusted) }\end{array}$ & $\begin{array}{l}1975-1986 \\
1975-1986\end{array}$ & $2.1^{\mathrm{e}}$ & $\begin{array}{l}1986-1996 \\
1986-1996\end{array}$ & $5.0^{\mathrm{e}}$ & $\begin{array}{l}1996-2004 \\
1996-2004\end{array}$ & $\begin{array}{l}2.1^{\mathrm{e}} \\
2.5^{\mathrm{e}}\end{array}$ & & \\
\hline $\begin{array}{l}\text { Brain and other nervous system } \\
\text { (Delay-adjusted) }\end{array}$ & $\begin{array}{l}1975-1991 \\
1975-1991\end{array}$ & $\begin{array}{l}1.1^{\mathrm{e}} \\
1.0^{\mathrm{e}}\end{array}$ & $\begin{array}{l}1991-2004 \\
1991-2004\end{array}$ & $\begin{array}{l}-0.7^{\mathrm{e}} \\
-0.6\end{array}$ & & & & \\
\hline $\begin{array}{l}\text { Esophagus } \\
\text { (Delay-adjusted) }\end{array}$ & $\begin{array}{l}1975-2004 \\
1975-2004\end{array}$ & $\begin{array}{l}0.8^{\mathrm{e}} \\
0.8^{\mathrm{e}}\end{array}$ & & & & & & \\
\hline $\begin{array}{l}\text { Myeloma } \\
\text { (Delay-adjusted) }\end{array}$ & $\begin{array}{l}1975-1991 \\
1975-2004\end{array}$ & $\begin{array}{l}1.3^{\mathrm{e}} \\
0.8^{\mathrm{e}}\end{array}$ & 1991-2004 & -0.1 & & & & \\
\hline Top 15 cancers for females $^{\mathrm{c}}$ & & & & & & & & \\
\hline $\begin{array}{l}\text { Breast } \\
\text { (Delav-adjusted) }\end{array}$ & $\begin{array}{l}1975-1980 \\
1975-1980\end{array}$ & $\begin{array}{l}-0.4 \\
-0.4\end{array}$ & $\begin{array}{l}1980-1987 \\
1980-1987\end{array}$ & $\begin{array}{l}3.7^{\mathrm{e}} \\
3.7^{\mathrm{e}}\end{array}$ & $\begin{array}{l}1987-2001 \\
1987-2001\end{array}$ & $\begin{array}{l}0.4^{\mathrm{e}} \\
0.5^{\mathrm{e}}\end{array}$ & $\begin{array}{l}2001-2004 \\
2001-2004\end{array}$ & $\begin{array}{l}-3.9^{\mathrm{e}} \\
-3.5^{\mathrm{e}}\end{array}$ \\
\hline Lung and bronchus & 1975-1982 & $5.5^{\mathrm{e}}$ & 1982-1990 & $3.5^{\mathrm{e}}$ & 1990-1998 & $1.0^{\mathrm{e}}$ & 1998-2004 & -0.5 \\
\hline (Delay-adjusted) & 1975-1982 & $5.5^{\mathrm{e}}$ & 1982-1990 & $3.5^{\mathrm{e}}$ & 1990-1998 & $1.0^{\mathrm{e}}$ & 1998-2004 & -0.1 \\
\hline $\begin{array}{l}\text { Colon and rectum } \\
\text { (Delay-adjusted) }\end{array}$ & $\begin{array}{l}1975-1985 \\
1975-1985\end{array}$ & $\begin{array}{l}0.3 \\
0.3\end{array}$ & $\begin{array}{l}1985-1995 \\
1985-1995\end{array}$ & $\begin{array}{l}-1.9^{\mathrm{e}} \\
-1.8^{\mathrm{e}}\end{array}$ & $\begin{array}{l}1995-1998 \\
1995-1998\end{array}$ & $\begin{array}{l}1.9 \\
1.8\end{array}$ & $\begin{array}{l}1998-2004 \\
1998-2004\end{array}$ & $\begin{array}{l}-2.4^{\mathrm{e}} \\
-2.2^{\mathrm{e}}\end{array}$ \\
\hline Corpus and uterus, NOS & $\begin{array}{l}1975-1979 \\
1975-1979\end{array}$ & $-6.0^{\mathrm{e}}$ & $\begin{array}{l}1979-1988 \\
1979-1988\end{array}$ & $\begin{array}{l}-1.7^{\mathrm{e}} \\
-17^{\mathrm{e}}\end{array}$ & $\begin{array}{l}1988-1998 \\
1988-1998\end{array}$ & $0.6^{\mathrm{e}}$ & $\begin{array}{l}1998-2004 \\
1998-2004\end{array}$ & $\begin{array}{l}-1.0^{\mathrm{e}} \\
-0.8^{\mathrm{e}}\end{array}$ \\
\hline Non-Hodgkin lymphoma & $1975-1990$ & $2.9^{\mathrm{e}}$ & $1990-2004$ & $1.1^{\mathrm{e}}$ & & & & \\
\hline (Delay-adjusted) & 1975-1988 & $3.0^{\mathrm{e}}$ & 1988-2004 & $1.4^{\mathrm{e}}$ & & & & \\
\hline Melanoma of the skin & $1975-1981$ & $5.2^{\mathrm{e}}$ & $1981-2004$ & $2.2^{\mathrm{e}}$ & & & & \\
\hline (Delay-adjusted) & 1975-1981 & $5.1^{\mathrm{e}}$ & 1981-2004 & $2.3^{\mathrm{e}}$ & & & & \\
\hline Ovary ${ }^{b}$ & $1975-1985$ & 0.1 & $1985-2001$ & $-0.7^{\mathrm{e}}$ & 2001-2004 & $-3.5^{\mathrm{e}}$ & & \\
\hline (Delay-adjusted) $^{\text {b }}$ & $1975-1987$ & 0.1 & $1987-2004$ & $-0.9^{\mathrm{e}}$ & & & & \\
\hline
\end{tabular}


TABLE 2

(continued)

\begin{tabular}{|c|c|c|c|c|c|c|c|c|}
\hline \multirow[b]{3}{*}{ Sex/cancer site or type } & \multicolumn{8}{|c|}{ Joinpoint analyses $(1975-2004)^{\mathrm{a}}$} \\
\hline & \multicolumn{2}{|c|}{ Trend 1} & \multicolumn{2}{|c|}{ Trend 2} & \multicolumn{2}{|c|}{ Trend 3} & \multicolumn{2}{|c|}{ Trend 4} \\
\hline & Years & $A P C^{d}$ & Years & $A P C^{d}$ & Years & $A P C^{d}$ & Years & $\mathrm{APC}^{\mathrm{d}}$ \\
\hline \multirow{2}{*}{$\begin{array}{l}\text { Thyroid } \\
\text { (Delay-adjusted) }\end{array}$} & $1975-1977$ & 6.5 & 1977-1980 & -5.3 & 1980-1995 & $2.3^{\mathrm{e}}$ & 1995-2004 & $5.9^{\mathrm{e}}$ \\
\hline & 1975-1977 & 6.5 & 1977-1980 & -5.3 & 1980-1995 & $2.3^{\mathrm{e}}$ & 1995-2004 & $6.1^{\mathrm{e}}$ \\
\hline \multirow{2}{*}{$\begin{array}{l}\text { Pancreas } \\
\text { (Delay-adjusted) }\end{array}$} & $1975-1983$ & $1.4^{\mathrm{e}}$ & 1983-2004 & -0.2 & & & & \\
\hline & $1975-1983$ & $1.3^{\mathrm{e}}$ & $1983-2004$ & -0.1 & & & & \\
\hline \multirow{2}{*}{$\begin{array}{l}\text { Leukemia } \\
\quad \text { (Delay-adjusted) }\end{array}$} & $1975-2004$ & -0.1 & & & & & & \\
\hline & $1975-2004$ & $0.2^{\mathrm{e}}$ & & & & & & \\
\hline \multirow{2}{*}{$\begin{array}{l}\text { Urinary bladder } \\
\text { (Delay-adjusted) }\end{array}$} & $1975-2004$ & $0.1^{\mathrm{e}}$ & & & & & & \\
\hline & $1975-2004$ & $0.2^{\mathrm{e}}$ & & & & & & \\
\hline \multirow{2}{*}{$\begin{array}{l}\text { Cervix uteri } \\
\text { (Delay-adjusted) }\end{array}$} & $1975-1981$ & $-4.6^{\mathrm{e}}$ & 1981-1996 & $-1.1^{\mathrm{e}}$ & 1996-2004 & $-3.9^{\mathrm{e}}$ & & \\
\hline & $1975-1981$ & $-4.6^{\mathrm{e}}$ & 1981-1996 & $-1.1^{\mathrm{e}}$ & $1996-2004$ & $-3.7^{\mathrm{e}}$ & & \\
\hline \multirow{2}{*}{$\begin{array}{l}\text { Kidney and renal pelvis } \\
\text { (Delay-adjusted) }\end{array}$} & $1975-2004$ & $2.2^{\mathrm{e}}$ & & & & & & \\
\hline & $1975-2004$ & $2.3^{\mathrm{e}}$ & & & & & & \\
\hline \multirow{2}{*}{$\begin{array}{l}\text { Oral cavity and pharynx } \\
\text { (Delay-adjusted) }\end{array}$} & $1975-1980$ & $2.7^{\mathrm{e}}$ & 1980-2004 & $-1.0^{\mathrm{e}}$ & & & & \\
\hline & $1975-1980$ & $2.6^{\mathrm{e}}$ & 1980-2004 & $-1.0^{\mathrm{e}}$ & & & & \\
\hline \multirow{2}{*}{$\begin{array}{l}\text { Stomach } \\
\text { (Delay-adjusted) }\end{array}$} & $1975-2004$ & $-1.6^{\mathrm{e}}$ & & & & & & \\
\hline & $1975-2004$ & $-1.6^{\mathrm{e}}$ & & & & & & \\
\hline
\end{tabular}

Source: Surveillance, Epidemiology, and End Results (SEER) 9 areas covering about 10\% of the U.S. population (Connecticut, Hawaii, Iowa, Utah, and New Mexico and the metropolitan areas of San Francisco, Detroit, Atlanta, and Seattle-Puget Sound).

APC indicates annual percent change; NOS, not otherwise specified.

a Joinpoint analyses with up to 3 joinpoints are based on rates per 100,000 persons and were age-adjusted to the 2000 U.S. standard population (19 age groups, Census p25-1130; Jointpoint [JP] Regression Program, Version 3.0; National Cancer Institute, April, 2005).

${ }^{\mathrm{b}}$ All sites excludes myelodysplastic syndromes and borderline tumors; ovary excludes borderline tumors.

c The top 15 cancers were selected based on the sex-specific, age-adjusted incidence rates for 2000-2004 for all races combined and are listed in rank order.

${ }^{\mathrm{d}}$ APC is based on rates that were age-adjusted to the 2000 U.S. standard population (19 age groups; Census, p25-1130).

${ }^{\mathrm{e}} \mathrm{APC}$ is statistically significantly different from zero (2-sided $\left.P<.05\right)$.

uterus. Lung cancer death rates have increased since 1975. However, the rate of increase has slowed over time to $0.2 \%$ annually from 1995 to 2004 . Finally, from 2001 through 2004, liver cancer rates increased $2.6 \%$ annually in women.

\section{Cancer Incidence Rates, 2000-2004 and Fixed Interval Trends, 1995-2004}

Table 4 presents cancer incidence for the 15 most common cancers for each sex, for all races/ethnicities combined, and for the 6 major race/ethnic populations. In men, the 3 leading incident cancers were prostate, lung, and colon and rectum in all race/ethnic populations, although colorectal cancer ranked second and lung cancer ranked third among Hispanic men. For most men, bladder cancer and NHL were the fourth and fifth leading incident cancers. However, cancers of the kidney and bladder ranked fourth and fifth for black and AI/AN men, and liver and stomach ranked fourth and fifth for API men.

Cancer incidence trends for men in all race/ethnic groups combined decreased from 1995 through
2004. Among men, incidence rates of cancers of the lung, larynx, and stomach decreased in each race/ ethnic population for which the APC was presented. Prostate cancer rates decreased for black and AI/AN men but were stable for white, API, Hispanic, and non-Hispanic men. Colorectal cancer incidence rates decreased for white, API, and non-Hispanic men and remained stable for black, AI/AN, and Hispanic men. Increases were noted for kidney and liver cancer in men except API and AI/AN men, in whom the rates remained stable. Thyroid cancer showed the largest annual increases in populations for which the APC was presented. Melanoma rates increased in white and non-Hispanic men, were stable in API and Hispanic men, and decreased in black men.

Among women, the 4 leading incident cancers from 2000 through 2004 were breast, lung, colon and rectum, and uterus across all race/ethnic populations (Table 4). NHL was ranked fifth for all populations except black, API, and AI/AN women. Cancer of the pancreas ranked fifth for black women, thyroid cancer ranked fifth for API women, and kidney 
TABLE 3

U.S. Death Rate Trends With Joinpoint Analyses for 1975-2004 for the Top 15 Cancers, by Sex, for All Races

\begin{tabular}{|c|c|c|c|c|c|c|c|c|}
\hline \multirow[b]{3}{*}{ Sex/cancer site or type } & \multicolumn{8}{|c|}{ Joinpoint analyses (1975-2004) ${ }^{\mathrm{a}}$} \\
\hline & \multicolumn{2}{|c|}{ Trend 1} & \multicolumn{2}{|c|}{ Trend 2} & \multicolumn{2}{|c|}{ Trend 3} & \multicolumn{2}{|c|}{ Trend 4} \\
\hline & Years & $\mathrm{APC}^{\mathrm{c}}$ & Years & $\mathrm{APC}^{\mathrm{c}}$ & Years & $\mathrm{APC}^{\mathrm{c}}$ & Years & $\mathrm{APC}^{\mathrm{c}}$ \\
\hline \multicolumn{9}{|l|}{ All sites } \\
\hline Both sexes & 1975-1990 & $0.5^{\mathrm{d}}$ & 1990-1993 & -0.3 & 1993-2002 & $-1.1^{\mathrm{d}}$ & 2002-2004 & $-2.1^{\mathrm{d}}$ \\
\hline Males & 1975-1980 & $0.9^{\mathrm{d}}$ & 1980-1992 & $0.3^{\mathrm{d}}$ & 1992-2002 & $-1.5^{\mathrm{d}}$ & $2002-2004$ & $-2.6^{\mathrm{d}}$ \\
\hline Females & 1975-1990 & $0.6^{\mathrm{d}}$ & 1990-1994 & -0.2 & 1994-2002 & $-0.8^{\mathrm{d}}$ & $2002-2004$ & $-1.8^{\mathrm{d}}$ \\
\hline \multicolumn{9}{|l|}{ Top 15 cancers for males ${ }^{b}$} \\
\hline Lung and bronchus & 1975-1982 & $1.7^{\mathrm{d}}$ & 1982-1990 & $0.5^{\mathrm{d}}$ & 1990-1994 & $-1.3^{\mathrm{d}}$ & $1994-2004$ & $-2.0^{\mathrm{d}}$ \\
\hline Prostate & $1975-1987$ & $0.9^{\mathrm{d}}$ & $1987-1991$ & $3.0^{\mathrm{d}}$ & 1991-1994 & -0.5 & $1994-2004$ & $-4.1^{\mathrm{d}}$ \\
\hline Colon and rectum & $1975-1979$ & 0.6 & 1979-1987 & $-0.6^{\mathrm{d}}$ & $1987-2002$ & $-1.9^{\mathrm{d}}$ & 2002-2004 & $-4.9^{\mathrm{d}}$ \\
\hline Pancreas & $1975-1986$ & $-0.9^{\mathrm{d}}$ & $1986-2004$ & $-0.2^{\mathrm{d}}$ & & & & \\
\hline Leukemia & 1975-1995 & $-0.2^{\mathrm{d}}$ & $1995-2004$ & $-0.8^{\mathrm{d}}$ & & & & \\
\hline Non-Hodgkin lymphoma & $1975-1981$ & $1.8^{\mathrm{d}}$ & 1981-1990 & $3.0^{\mathrm{d}}$ & 1990-1997 & $1.6^{\mathrm{d}}$ & $1997-2004$ & $-3.0^{\mathrm{d}}$ \\
\hline Esophagus & $1975-1985$ & $0.7^{\mathrm{d}}$ & 1985-1994 & $1.2^{\mathrm{d}}$ & 1994-2004 & $0.4^{\mathrm{d}}$ & & \\
\hline Urinary bladder & $1975-1983$ & $-1.4^{\mathrm{d}}$ & 1983-1987 & $-2.7^{\mathrm{d}}$ & $1987-1993$ & 0.1 & 1993-2004 & $-0.6^{\mathrm{d}}$ \\
\hline Liver and intrahepatic bile duct & $1975-1985$ & $1.5^{\mathrm{d}}$ & $1985-1995$ & $3.8^{\mathrm{d}}$ & 1995-2004 & $1.8^{\mathrm{d}}$ & & \\
\hline Kidney and renal pelvis & $1975-1992$ & $1.1^{\mathrm{d}}$ & $1992-2004$ & $-0.3^{\mathrm{d}}$ & & & & \\
\hline Stomach & $1975-1987$ & $-2.3^{\mathrm{d}}$ & $1987-1991$ & -0.9 & 1991-2004 & $-3.5^{\mathrm{d}}$ & & \\
\hline Brain and other nervous system & 1975-1977 & 4.4 & 1977-1982 & -0.3 & 1982-1991 & $1.3^{\mathrm{d}}$ & $1991-2004$ & $-0.9^{\mathrm{d}}$ \\
\hline Myeloma & 1975-1994 & $1.5^{\mathrm{d}}$ & $1994-2004$ & $-1.1^{\mathrm{d}}$ & & & & \\
\hline Oral cavity and pharynx & $1975-1980$ & -0.8 & $1980-2004$ & $-2.2^{\mathrm{d}}$ & & & & \\
\hline Melanoma of the skin & $1975-1990$ & $2.2^{\mathrm{d}}$ & $1990-2004$ & 0.0 & & & & \\
\hline \multicolumn{9}{|l|}{ Top 15 cancers for females ${ }^{\mathrm{b}}$} \\
\hline Lung and bronchus & 1975-1982 & $6.0^{\mathrm{d}}$ & 1982-1990 & $4.2^{\mathrm{d}}$ & 1990-1995 & $1.7^{\mathrm{d}}$ & 1995-2004 & $0.2^{\mathrm{d}}$ \\
\hline Breast & $1975-1990$ & $0.4^{\mathrm{d}}$ & $1990-2004$ & $-2.2^{\mathrm{d}}$ & & & & \\
\hline Colon and rectum & $1975-1984$ & $-1.0^{\mathrm{d}}$ & $1984-2002$ & $-1.8^{\mathrm{d}}$ & 2002-2004 & $-4.5^{\mathrm{d}}$ & & \\
\hline Pancreas & 1975-1984 & $0.8^{\mathrm{d}}$ & $1984-2004$ & 0.1 & & & & \\
\hline Ovary & $1975-1982$ & $-1.2^{\mathrm{d}}$ & 1982-1992 & 0.3 & 1992-1998 & $-1.1^{\mathrm{d}}$ & 1998-2004 & 0.2 \\
\hline Non-Hodgkin lymphoma & $1975-1995$ & $2.2^{\mathrm{d}}$ & $1995-1998$ & -0.3 & 1998-2004 & $-3.8^{\mathrm{d}}$ & & \\
\hline Leukemia & $1975-1980$ & 0.8 & $1980-2001$ & $-0.4^{\mathrm{d}}$ & 2001-2004 & $-2.4^{\mathrm{d}}$ & & \\
\hline Corpus and uterus, NOS & 1975-1992 & $-1.5^{\mathrm{d}}$ & $1992-2004$ & 0.0 & & & & \\
\hline Brain and other nervous system & $1975-1992$ & $0.9^{\mathrm{d}}$ & $1992-2004$ & $-1.0^{\mathrm{d}}$ & & & & \\
\hline Myeloma & $1975-1993$ & $1.5^{\mathrm{d}}$ & $1993-2001$ & -0.4 & $2001-2004$ & $-2.4^{\mathrm{d}}$ & & \\
\hline Liver and intrahepatic bile duct & $1975-1987$ & $0.8^{\mathrm{d}}$ & 1987-1995 & $3.8^{\mathrm{d}}$ & $1995-2001$ & 0.3 & 2001-2004 & $2.6^{\mathrm{d}}$ \\
\hline Stomach & $1975-1987$ & $-2.8^{\mathrm{d}}$ & $1987-1990$ & -0.5 & $1990-2004$ & $-2.6^{\mathrm{d}}$ & & \\
\hline Kidney and renal pelvis & $1975-1992$ & $1.3^{\mathrm{d}}$ & $1992-2004$ & $-0.5^{\mathrm{d}}$ & & & & \\
\hline Cervix uteri & $1975-1982$ & $-4.3^{\mathrm{d}}$ & $1982-1996$ & $-1.6^{\mathrm{d}}$ & 1996-2004 & $-3.7^{\mathrm{d}}$ & & \\
\hline Urinary bladder & $1975-1986$ & $-1.7^{\mathrm{d}}$ & $1986-2004$ & $-0.4^{\mathrm{d}}$ & & & & \\
\hline
\end{tabular}

Source: National Center for Health Statistics public-use data file for the total U.S.

APC indicates annual percent change; NOS, not otherwise specified.

a Joinpoint analyses with up to 3 joinpoints are based on rates per 100,000 persons and were age-adjusted to the 2000 U.S. standard population (19 age groups, Census p25-1130; Jointpoint [JP] Regression Program, Version 3.0; National Cancer Institute, April, 2005).

${ }^{\mathrm{b}}$ The top 15 cancers were selected based on the sex-specific, age-adjusted incidence rates for 2000-2004 for all races combined and are listed in rank order.

${ }^{\mathrm{c}} \mathrm{APC}$ is based on rates that were age-adjusted to the 2000 U.S. standard population (19 age groups; Census, p25-1130).

${ }^{\mathrm{d}} \mathrm{APC}$ is statistically significantly different from zero (2-sided $\left.P<.05\right)$.

cancer ranked fifth for AI/AN women. The ranking of cancers beyond the top 5 varied by race/ethnicity.

Cancer incidence trends for women for all race/ ethnicities combined were stable from 1995 through 2004. Although breast cancer rates for all races combined from 1995 through 2004 appeared stable, the use of joinpoint methods revealed that the trend did change in 2001, with a statistically significant decline of $3.4 \%$ per year from 2001 through 2004 (data not shown), comparable to the long-term trend results based on SEER data. Hispanic women experienced a decrease in breast cancer incidence rates from 1995 through 2004, and rates for AI/AN women were 


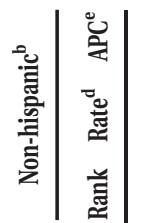

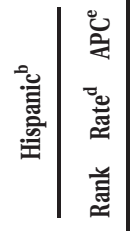

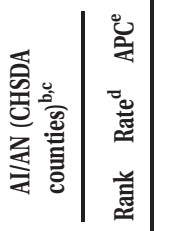

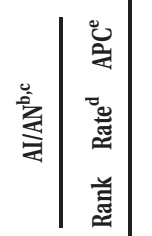

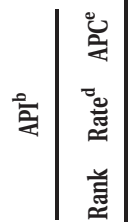

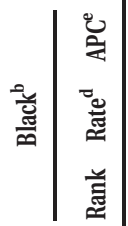

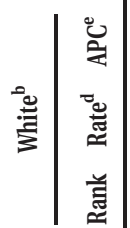

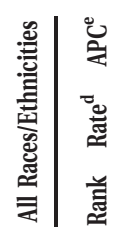

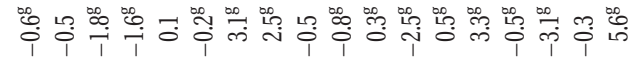

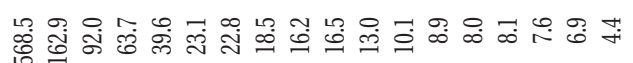

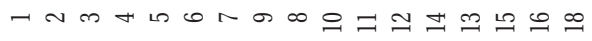

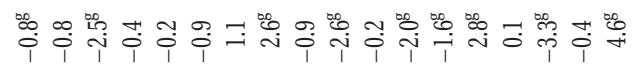

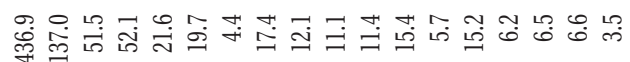

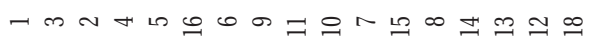

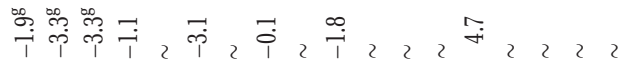

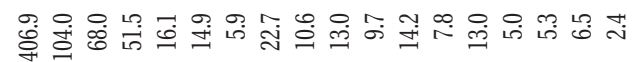

$\neg$ กั

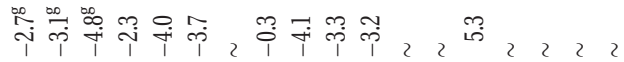

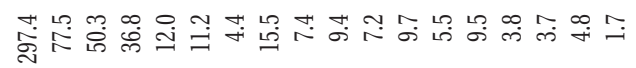

ー

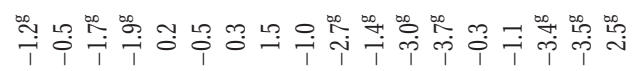

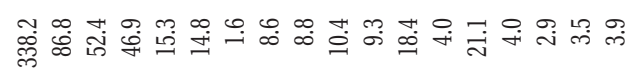

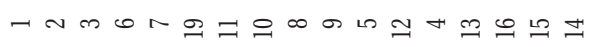

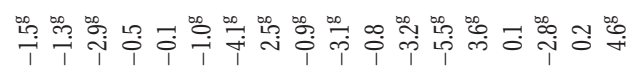

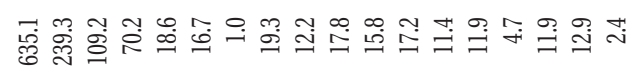

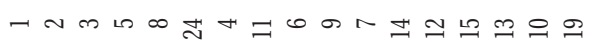

兽

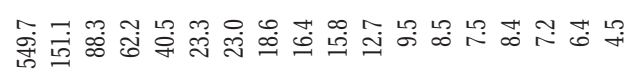

$\neg$ ก

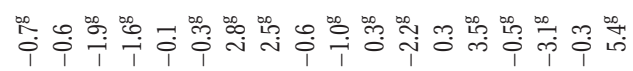

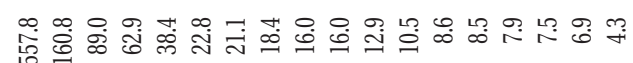

$\neg$ เ

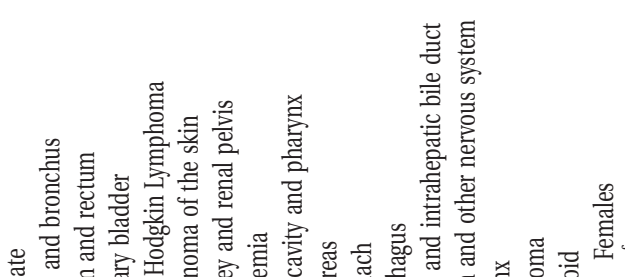

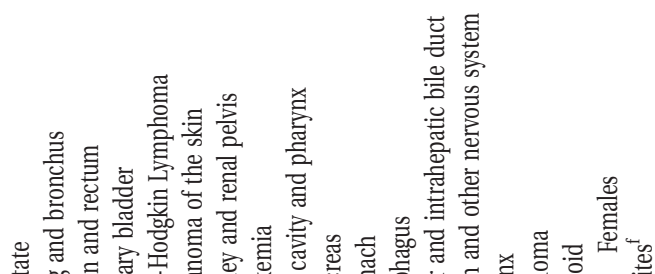

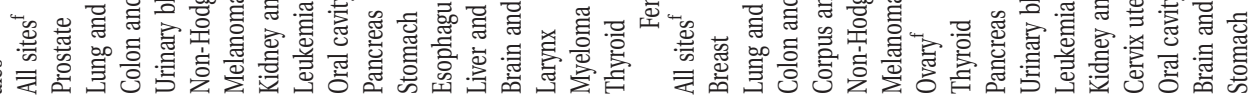

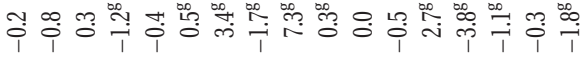

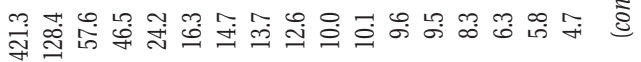

-

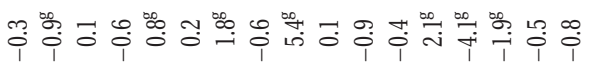

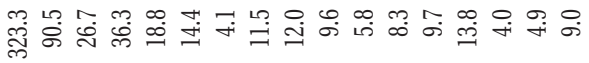
$\neg$ ๓

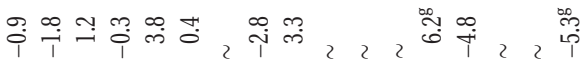

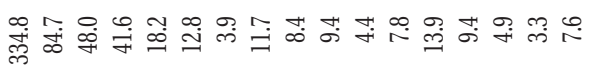
-

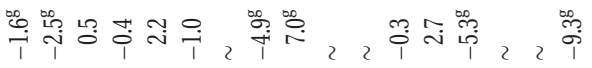

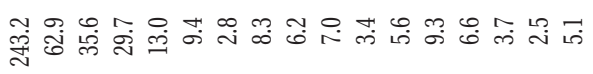
-

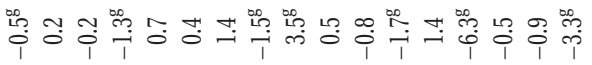

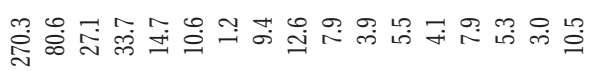

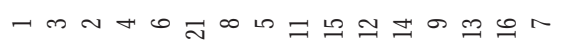

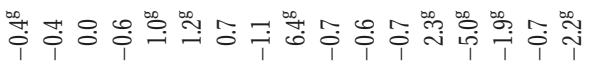

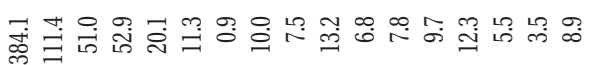

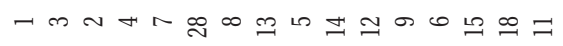

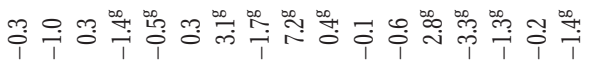

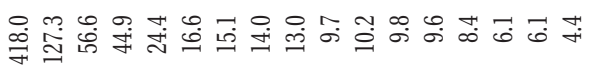
ーn

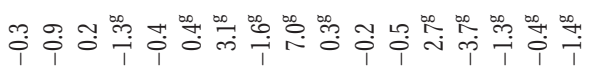

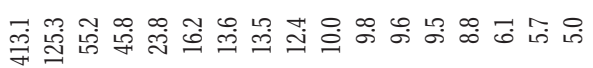
ー
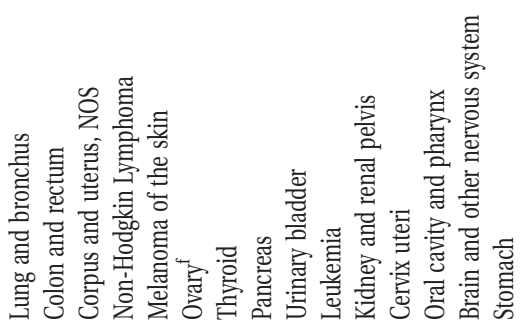


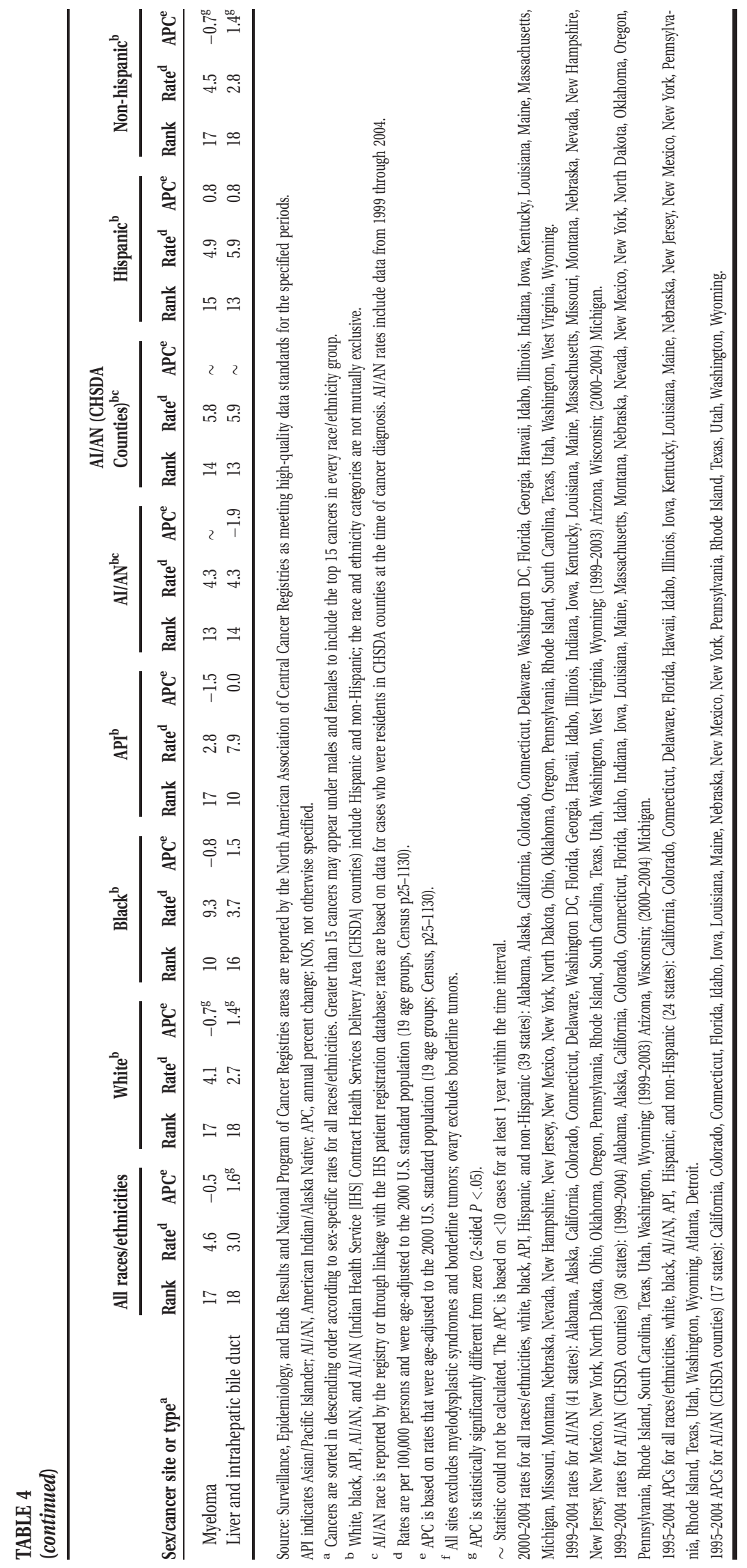


stable. White, API, and non-Hispanic women experienced a decrease in cancer of the colon and rectum, whereas the rates for black, AI/AN, and Hispanic women remained stable. Uterine cancer decreased among white women, increased among black and Hispanic women, and was stable for API and AI/AN women. Cervical cancer declined for all race/ethnic populations except AI/AN women, in whom it was stable, as did stomach cancer for all except Hispanic women, in whom rates were stable. Ovarian cancer decreased in white, API, and non-Hispanic women and remained stable in black, AI/AN, and Hispanic women. The use of joinpoint methods for the period from 1995 through 2004 revealed a $1.0 \%$ decline per year in ovarian cancer incidence from 1995 through 2001 and an increased rate of decline of $3.3 \%$ per year from 2001 through 2004 for all races combined (data not shown); this increased rate of decline was confined to white women. Similar patterns were observed for uterine cancer (data not shown). Thyroid cancer rates had the largest annual increase (7.0\% per year).

\section{Update on Cancer Death Rates, 2000-2004 and Fixed Interval Trends, 1995-2004}

Among men, overall cancer death rates from 2000 through 2004 were highest for black men and lowest for API men (Table 5). Cancers of the lung, prostate, and colon and rectum were the leading causes of cancer death from 2000 through 2004 among men for all race/ethnic populations except API men, in whom cancer of the liver ranked second. Beyond the top 3 sites, race-specific rankings varied.

For men of most race/ethnic populations, trends of all cancers combined and trends of the 3 leading causes of cancer death declined from 1995 through 2004. For AI/AN men, trends in death rates were level for all cancers combined, prostate cancer, and colorectal cancer and declined for lung cancer.

Among women, overall cancer death rates from 2000 through 2004 were highest for black women and lowest for API and Hispanic women (Table 5). Among all race/ethnic populations, cancer of the lung ranked first in cause of death, breast cancer ranked second, and colorectal cancer ranked third with the exception of Hispanic women, for whom breast cancer ranked first and lung cancer ranked second. Similar to men, among women, race-specific rankings of less common cancers varied. From 1995 through 2004, women experienced a smaller decrease than men in death rates for all cancers combined ( $1.0 \%$ per year vs $1.7 \%$ per year, respectively). Similarly, the slight increase in lung cancer mortality in women $(0.2 \%$ per year $)$ contrasted with the substantial decrease in men $(2.0 \%$ per year). A comparison of death rates from 2000 through 2004 for all cancer sites combined showed that API women had the largest annual decline ( $1.4 \%$ per year), and AI/AN women had a stable death rate.

\section{SPECIAL SECTION: CANCER AMONG AMERICAN INDIANS AND ALASKA NATIVES, 1999-2004 General Characteristics}

The 2004 intercensal population estimates of 3.3 million AI/AN persons represented $1.1 \%$ of the total U.S. population. ${ }^{18}$ These persons are members of-or related to -1 or more of $>550$ federally recognized or $>200$ nonfederally recognized tribes with diverse languages, cultures, and histories. The median age of the U.S. AI/AN population was 29 years in 2000, which was younger than the nationwide median age of 35 years. ${ }^{40}$ Approximately $75 \%$ of the AI/AN population reside west of the Mississippi River and is concentrated in Alaska, Oklahoma, and other selected regions - the Southwest, Northern Plains, and Pacific Northwest (Fig. 2). Approximately one-third of AI/AN reside on tribal reservations, trust lands, or other tribal-affiliated areas, and others live primarily in urban areas. ${ }^{40,45}$

\section{Socioeconomic Characteristics, Cancer Risk Factors, and Use of Cancer Screening}

Poverty among the AI/AN population was 3 times that of the NHW population, with the Southwest AI/ AN population having the highest regional prevalence of poverty (Table 6). AI/AN adults were less likely to graduate from high school and were more likely to have less than a ninth grade education than NHW adults, with Alaska and Southwest AI/AN populations having the lowest formal education attained. The percentage of AI/AN persons age $<65$ years with no health coverage was twice that of NHW adults. The proportion of persons ages 18 to 64 years with no usual source of care was higher among the AI/AN population overall and in all regions. For NHW and AI/AN populations in all regions, men were more likely than women to have no usual source of medical care. It is noteworthy that AI/AN persons in Alaska aged $\geq 65$ years reported the highest prevalence of no healthcare coverage; a 10 -fold higher prevalence than NHW persons aged $>65$ years. Additional information regarding cancer incidence and county poverty level among AI/AN and NHW populations for selected cancer sites is available in Table Supplement-Poverty (available at URL: www.seer.cancer.gov/report_to_nation/). 


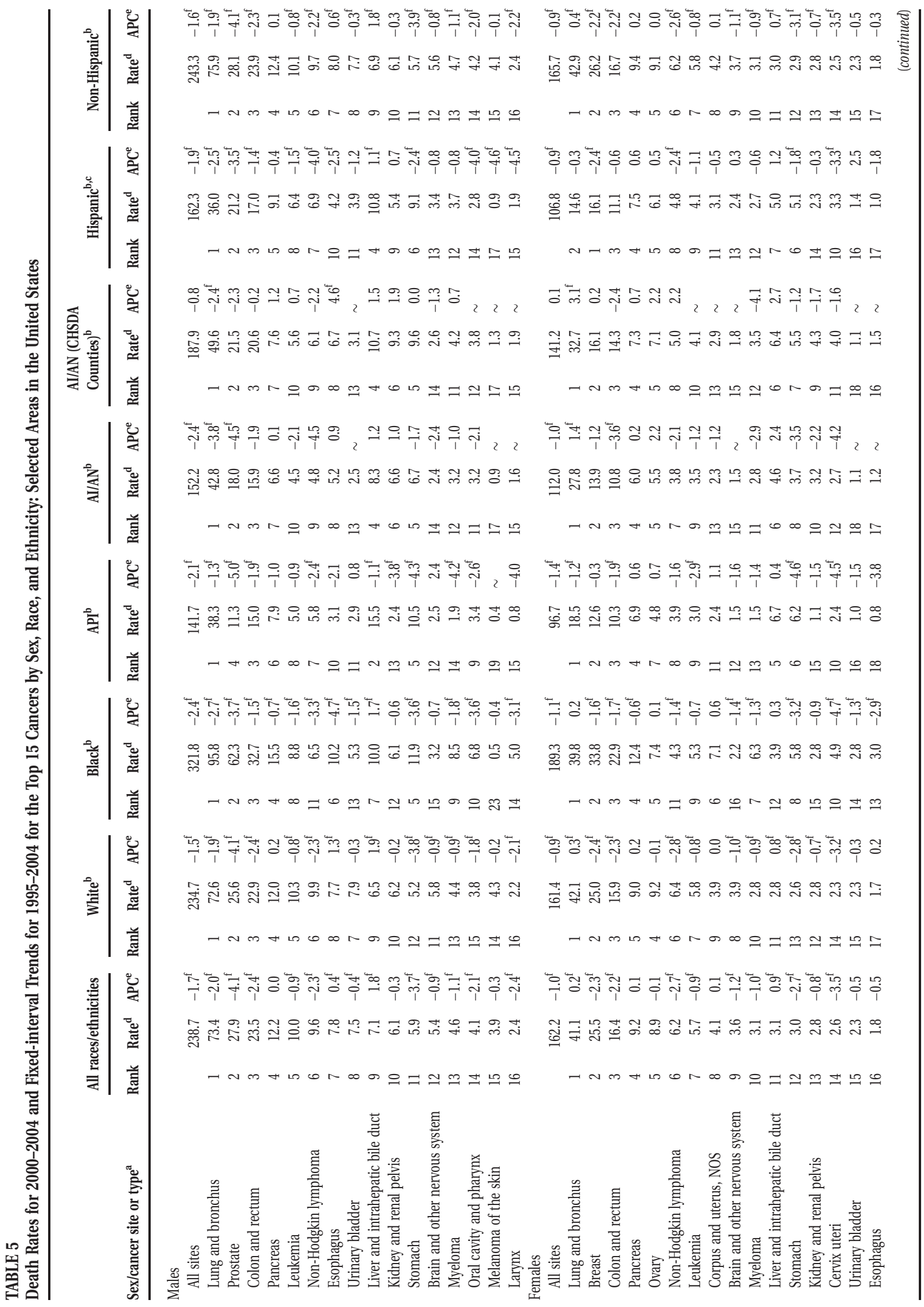




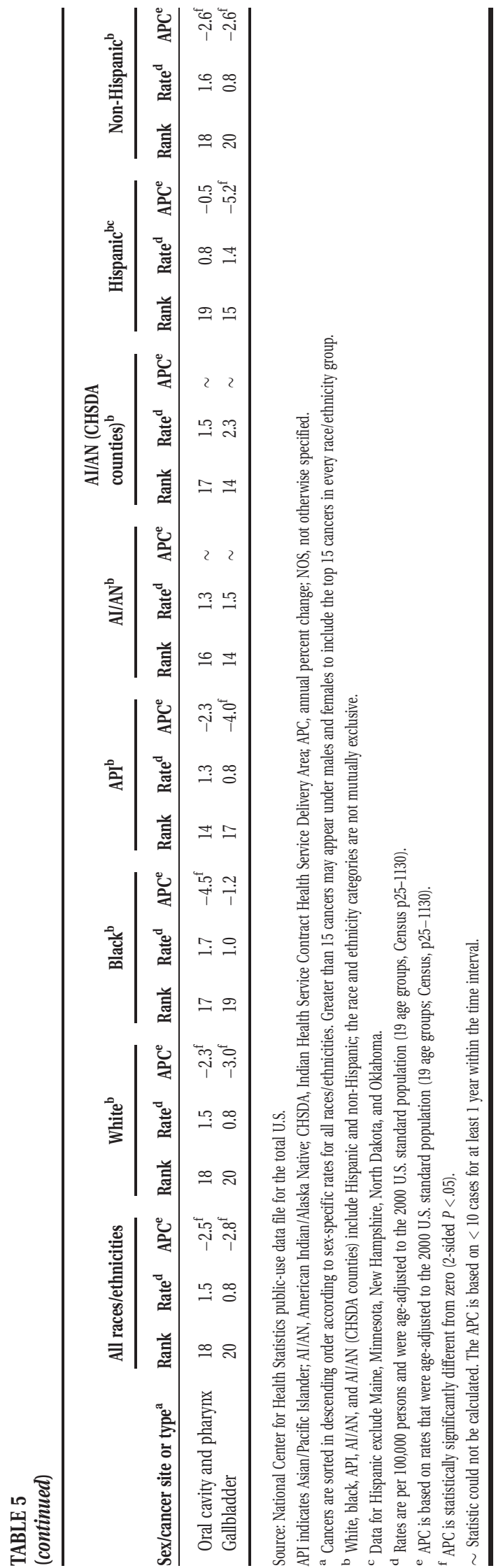

Current smoking prevalence among persons aged $\geq 18$ years was higher among AI/AN persons overall than among NHW persons, with the highest prevalence among AI/AN populations in Alaska and the Northern Plains (Table 6). Smoking prevalence among AI/AN was the lowest in the Southwest and did not differ greatly from that among NHW. In all regions, more AI/AN than NHW men and women aged $\geq 20$ years reported being obese; and, correspondingly, more AI/AN than NHW persons aged $\geq 18$ years reported no leisure time physical activity. Whereas heavy drinking was more common among men than among women in both populations, the percentage of AI/AN persons aged $\geq 18$ years who consumed $\geq 5$ drinks on 1 occasion was higher overall than that of NHW adults. The estimates for AI/AN in the individual regions were less stable; however, in Alaska and in the Northern Plains, both AI/AN men and AI/AN women had a higher prevalence of heavy drinking than NHW. In the Southwest, this was true for AI/AN men only.

The prevalence of cancer screening was lower among AI/AN than NHW persons and varied widely across IHS regions (Table 6). Mammography screening was lower among AI/AN women than among NHW women, with the lowest AI/AN prevalence estimates in the Pacific Coast and Southwest. Similarly, among AI/AN men and women aged $\geq 50$ years, fecal occult blood testing (FOBT) and endoscopy within the past 5 years were lower than that among NHW men and women. The prevalence of endoscopy for the AI/AN population in the Southwest was half the prevalence for the NHW population. Pap testing prevalence was lowest for AI/AN women in the Southern Plains and the East and was higher for Alaskan AI/AN women than for NHW women. Similarly, the prevalence of PSA testing was lower for AI/ AN men than for NHW men.

\section{Cancer Incidence}

Cancer incidence rates in AI/AN persons for all cancers combined were lower than for NHW persons for all regions combined (Tables 7 and 8). However, incidence rates varied by geographic region and cancer site. Among AI/AN men, cancer incidence rates for all sites combined ranged from 262 per 100,000 men in the Southwest to 611 per 100,000 men in the Northern Plains compared with the rates in NHW men, which ranged from 513 per 100,000 men in the Southwest to 578 per 100,000 men in the East. Among AI/AN women, the cancer incidence rates ranged from 219 per 100,000 women in the Southwest to 511 per 100,000 women in Alaska compared with a range from 404 per 100,000 women in the 


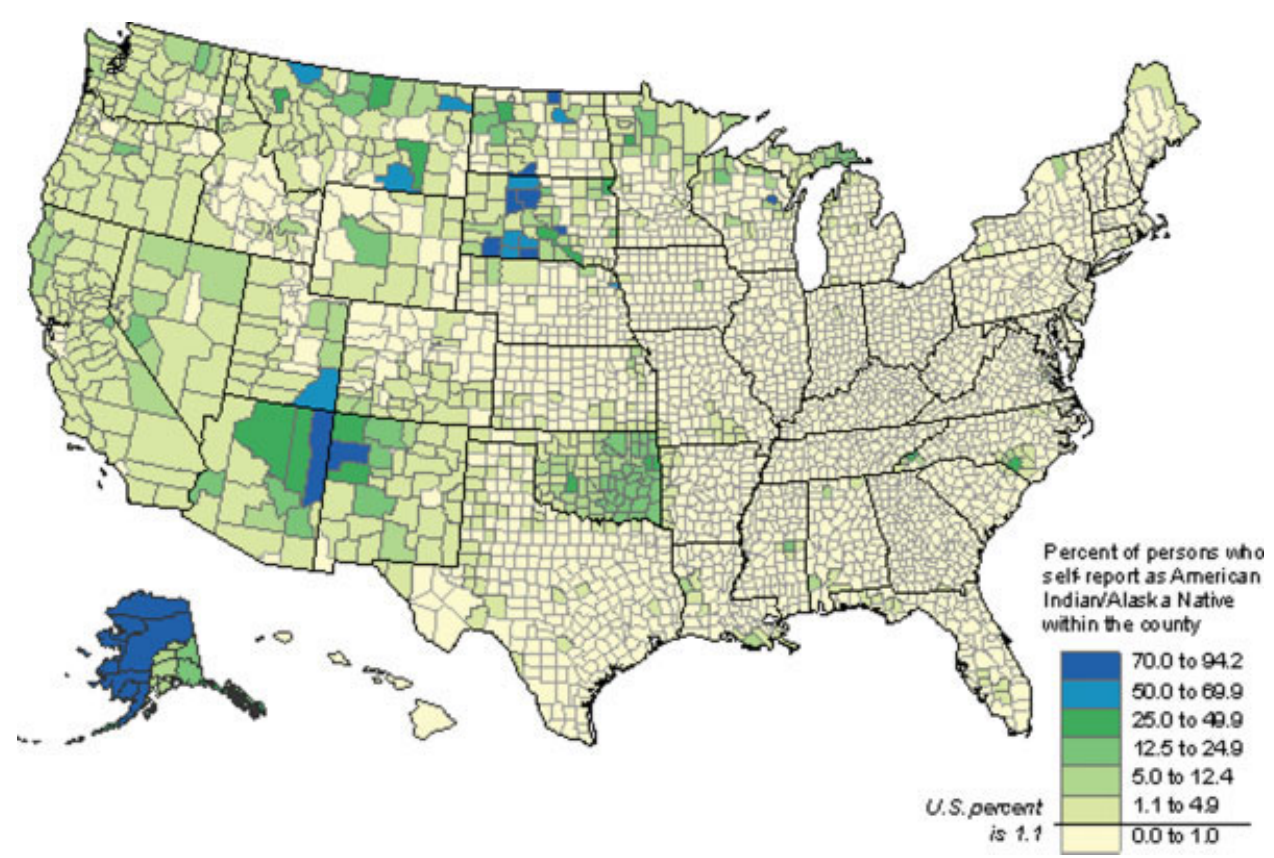

FIGURE 2. Percentage of the county population that is American Indian/Alaska Native, 2004. Source: 2004 Intercensal bridged single-race population estimates, U.S. Census Bureau/National Cancer Institute. Available at URL: http://seer.cancer.gov/popdata/.

Southern Plains to 438 per 100,000 women in the Pacific Coast among NHW women. In general, these regional variations persisted for most cancer sites among $\mathrm{AI} / \mathrm{AN}$ populations, and incidence rates were significantly higher among AI/AN populations in Alaska and the Northern and Southern Plains than among AI/AN populations in the Southwest (95\% CIs for AI/AN incidence rates for all regions combined and individual regions are available online at URL: www.seer.cancer.gov/report_to_nation/).

Among AI/AN men, the top 3 incident cancers were prostate, lung, and colon and rectum for all regions except the Southwest, where the leading cancers were prostate, colon and rectum, and kidney (Table 7). Prostate cancer rates for AI/AN men were highest in the Northern and Southern Plains and were similar to the prostate cancer rates for NHW men in those regions. Lung and colorectal cancer rates were highest in the Northern Plains and Alaska and were elevated significantly compared with NHW men. The Southwest had the lowest rates for the top 3 sites in AI/AN men for all regions combined. Rates of kidney cancer in AI/AN men were higher than those in NHW men in Alaska, the Northern Plains, the Southern Plains, and the Southwest. Stomach cancer in $\mathrm{AI} / \mathrm{AN}$ men was more than 4 times as common as in NHW men in Alaska and was twice as common in AI/AN men in the Southwest and Northern Plains compared with NHW men. Cancer of the liver was greater in AI/AN men than in NHW men in 5 regions and was highest for AI/AN men in the Northern Plains. Gallbladder cancer in AI/AN men was 3.7 times that of NHW men for all regions combined and was 6 times greater in the Southwest, the only individual region for which data are shown. The incidence rates for leukemia, melanoma, and cancers of the bladder, brain, and testis generally were lower in $\mathrm{AI} / \mathrm{AN}$ men than in NHW men.

Among AI/AN women, the 3 top cancer sites were breast, lung, and colon and rectum in all regions except the Southwest, where the rate for uterine cancer ranked third (Table 8). In Alaska, the breast cancer rate among AI/AN women was similar to the rate among NHW women; however, in all other regions, breast cancer was significantly lower among AI/AN women. In the Northern Plains, the rate of lung cancer among AI/AN women was nearly double that among NHW women; whereas, in the Southwest, AI/AN women had one-fifth the lung cancer rate of NHW women. The colorectal cancer rate was highest among AI/AN women in Alaska (2.6 times the rate in NHW women); whereas $\mathrm{AI} / \mathrm{AN}$ women in the Southwest had less than half the colorectal cancer rate of NHW women. Kidney cancer incidence for AI/AN women exceeded that for NHW women in the Northern and Southern Plains and in the Southwest. Stomach cancer, which was elevated for AI/AN women overall, was nearly 6 times the rate 


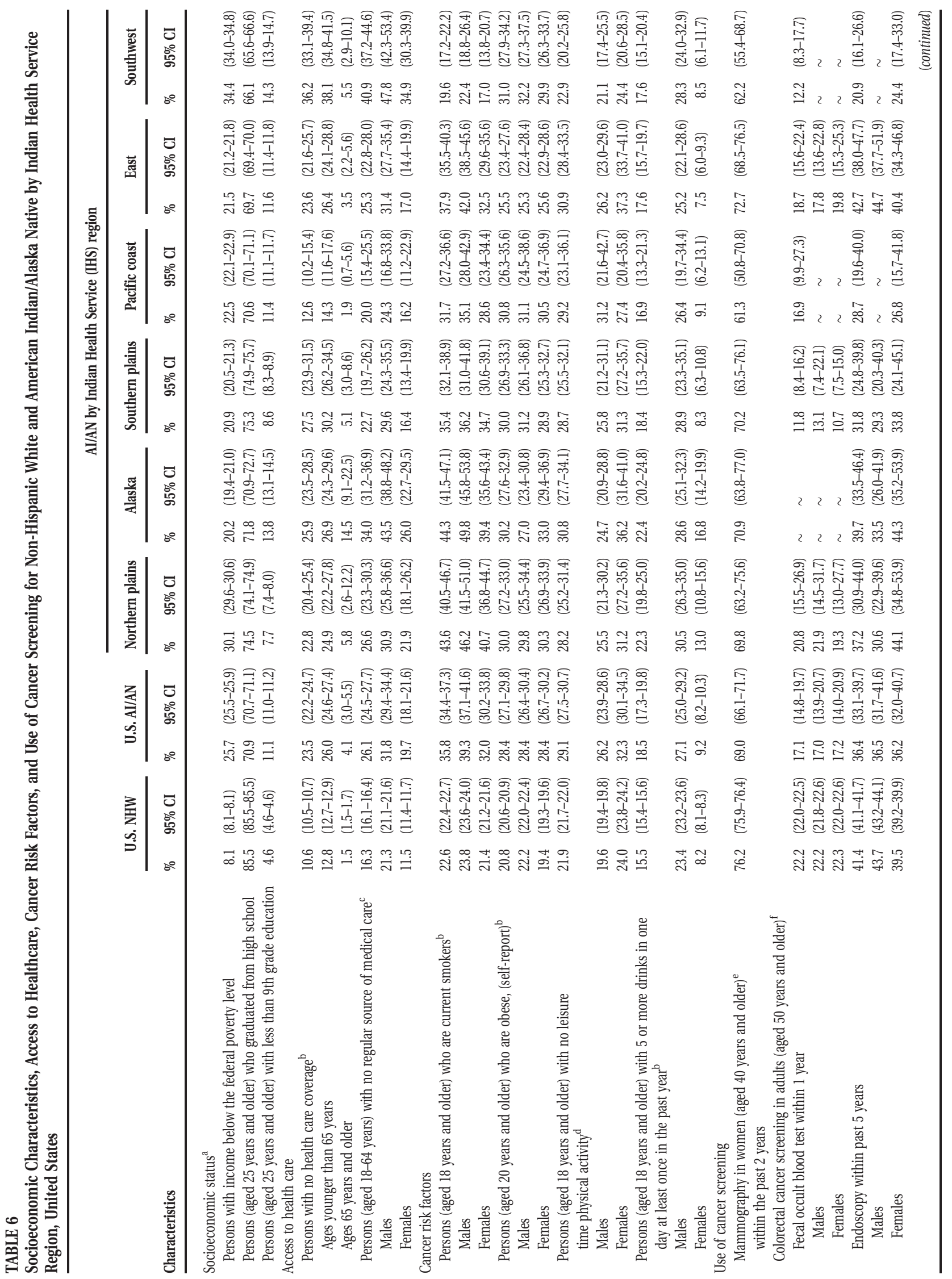




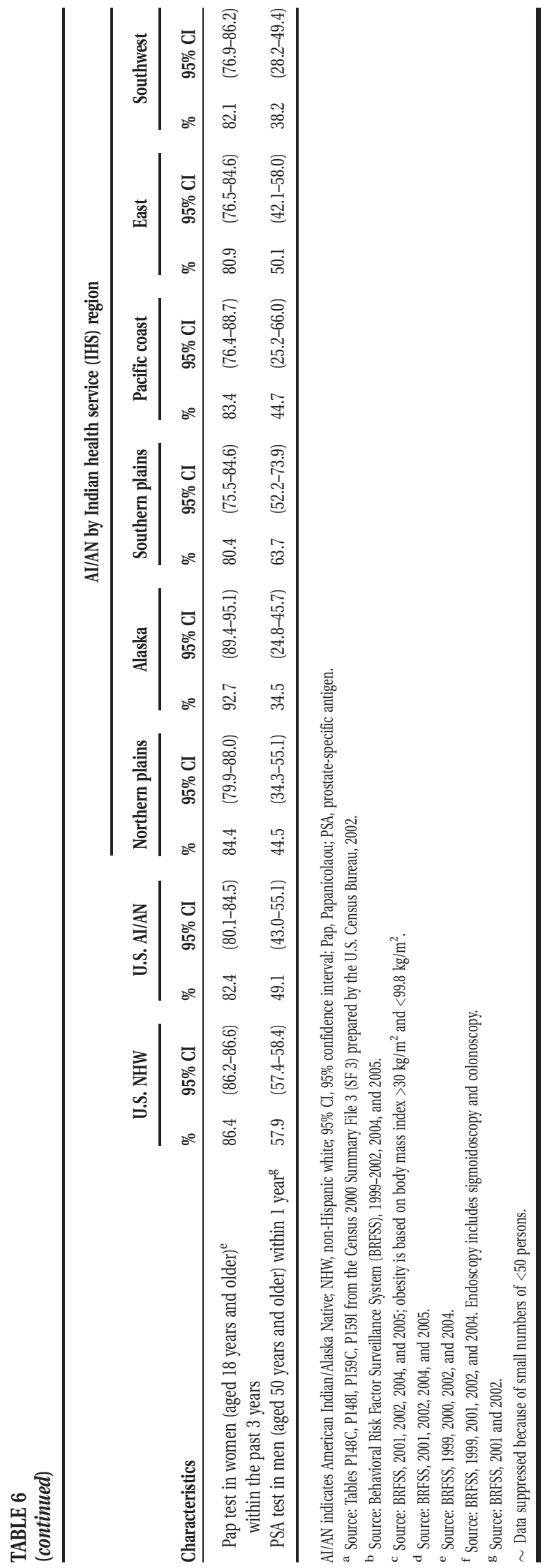

for NHW women in Alaska, 3 times greater than for NHW women in the Southwest, and 2 times greater than for NHW women in the Northern and Southern Plains. The rate of liver cancer among AI/AN women ranged from 1.9 times the rate among NHW women in the Southern Plains to 3.4 times greater in the Northern Plains. The rate of cancer of the cervix was elevated in AI/AN women in the Northern and Southern Plains. The incidence rate of gallbladder cancer was elevated in AI/AN women in the Southern Plains and the Southwest, whereas it was 2.7 and 7.1 times the rate of NHW women, respectively. The incidence rates of NHL, melanoma, and bladder cancer generally were lower in AI/AN women than in NHW women.

\section{Cancer Stage}

Overall, AI/AN persons were less likely than NHW persons to be diagnosed with early stages of colorectal cancer, although this pattern varied by region; the difference between AI/AN and NHW persons was larger in the Southwest, Northern Plains, and Southern Plains than in other regions (Table 9). Approximately three-fourths of prostate cancer cases were diagnosed with localized stage among NHW men overall and among AI/AN men in Alaska and the Southern Plains regions. AI/AN women in all regions were less likely than NHW women to be diagnosed with localized breast cancer. Similarly, AI/AN women in all regions combined were less likely than NHW women to be diagnosed with localized cervical cancer.

\section{DISCUSSION}

Overall Cancer Incidence and Mortality Trends in the U.S.

The overall decline in cancer death rates, which was noted first in the 1990s, has accelerated in recent years. Declines in colorectal cancer mortality in men and women, especially recent declines from 2002 through 2004, together with the continuation of long-term declines in mortality from lung and prostate cancer in men and from breast cancer in women, strongly contribute to the overall declining cancer death rates.

Noteworthy in this year's report are the decline in the incidence of colorectal cancer in men and women, the decline in breast cancer incidence in women from 2001 through 2004, and a leveling of lung cancer incidence in women after long-term increases. Lung cancer incidence rates in men continue to decline, and the prostate cancer trend was level. 
TABLE 7

Incidence Rates and Rate Ratios of the Top 15 Cancers for American Indian/Alaska Native Males Compared With Non-Hispanic White Males by Indian Health Service Region, Contract Health Service Delivery Area Counties in Selected Areas in the United States, 1999-2004

\begin{tabular}{|c|c|c|c|c|c|c|c|c|c|c|c|c|c|c|c|}
\hline \multirow[b]{3}{*}{ Cancer site or type $^{\mathrm{a}}$} & \multicolumn{5}{|c|}{ U.S. (CHSDA counties) } & \multicolumn{5}{|c|}{ Northern plains } & \multicolumn{5}{|c|}{ Alaska } \\
\hline & \multicolumn{2}{|c|}{ AI/AN } & \multirow[b]{2}{*}{ NHW rate ${ }^{c}$} & \multicolumn{2}{|c|}{ AI/AN:NHW } & \multicolumn{2}{|c|}{ AI/AN } & \multirow[b]{2}{*}{ NHW rate ${ }^{c}$} & \multicolumn{2}{|c|}{ AI/AN:NHW } & \multicolumn{2}{|c|}{ AI/AN } & \multirow[b]{2}{*}{ NHW rate ${ }^{c}$} & \multicolumn{2}{|c|}{ AI/AN:NHW } \\
\hline & Rank & Rate $^{c}$ & & RR & $95 \% \mathrm{CI}$ & Rank & $\operatorname{Rate}^{\mathrm{c}}$ & & RR & $95 \% \mathrm{CI}$ & Rank & Rate $^{c}$ & & RR & $95 \% \mathrm{CI}$ \\
\hline All sites ${ }^{b}$ & & 406.9 & 553.5 & $0.74^{\mathrm{d}}$ & $0.72-0.75$ & & 611.4 & 542.5 & $1.13^{\mathrm{d}}$ & $1.06-1.20$ & & 543.3 & 569.0 & 0.95 & $0.88-1.03$ \\
\hline Prostate & 1 & 104.0 & 154.7 & $0.67^{\mathrm{d}}$ & $0.64-0.70$ & 1 & 164.6 & 160.0 & 1.03 & $0.91-1.16$ & 3 & 82.1 & 179.9 & $0.46^{\mathrm{d}}$ & $0.37-0.56$ \\
\hline Lung and bronchus & 2 & 68.0 & 87.6 & $0.78^{\mathrm{d}}$ & $0.73-0.82$ & 2 & 115.5 & 86.7 & $1.33^{\mathrm{d}}$ & $1.15-1.54$ & 1 & 116.5 & 84.8 & $1.37^{\mathrm{d}}$ & $1.14-1.64$ \\
\hline Colon and rectum & 3 & 51.5 & 60.4 & $0.85^{\mathrm{d}}$ & $0.80-0.91$ & 3 & 79.8 & 62.0 & $1.29^{\mathrm{d}}$ & $1.08-1.52$ & 2 & 98.5 & 61.4 & $1.60^{\mathrm{d}}$ & $1.31-1.95$ \\
\hline Kidney and renal pelvis & 4 & 22.7 & 17.4 & $1.31^{\mathrm{d}}$ & $1.20-1.43$ & 4 & 29.7 & 17.4 & $1.71^{\mathrm{d}}$ & $1.33-2.15$ & 5 & 28.6 & 18.7 & $1.53^{\mathrm{d}}$ & $1.06-2.16$ \\
\hline Urinary bladder & 5 & 16.1 & 41.5 & $0.39^{\mathrm{d}}$ & $0.34-0.43$ & 5 & 27.6 & 39.4 & $0.70^{\mathrm{d}}$ & $0.49-0.95$ & 6 & 23.0 & 47.3 & $0.49^{\mathrm{d}}$ & $0.31-0.71$ \\
\hline Non-Hodgkin lymphoma & 6 & 14.9 & 23.2 & $0.64^{\mathrm{d}}$ & $0.57-0.72$ & 8 & 20.2 & 22.8 & 0.89 & $0.61-1.24$ & 11 & 13.2 & 26.3 & $0.50^{\mathrm{d}}$ & $0.32-0.76$ \\
\hline Stomach & 7 & 14.2 & 8.5 & $1.67^{\mathrm{d}}$ & $1.48-1.88$ & 9 & 16.7 & 8.4 & $1.98^{\mathrm{d}}$ & $1.33-2.80$ & 4 & 34.6 & 7.7 & $4.46^{\mathrm{d}}$ & $2.89-6.84$ \\
\hline Oral cavity and pharynx & 8 & 13.0 & 16.6 & $0.78^{\mathrm{d}}$ & $0.70-0.88$ & 6 & 21.5 & 15.3 & 1.40 & $0.98-1.92$ & 8 & 20.9 & 15.3 & 1.36 & $0.92-1.97$ \\
\hline Liver and IBD & 9 & 13.0 & 6.4 & $2.02^{\mathrm{d}}$ & $1.79-2.27$ & 7 & 21.0 & 5.4 & $3.89^{\mathrm{d}}$ & $2.71-5.37$ & 9 & 17.2 & 8.2 & $2.09^{\mathrm{d}}$ & $1.19-3.46$ \\
\hline Leukemia & 10 & 10.6 & 16.4 & $0.65^{\mathrm{d}}$ & $0.57-0.73$ & 11 & 13.7 & 16.4 & 0.84 & $0.58-1.17$ & 12 & 8.4 & 15.2 & $0.55^{\mathrm{d}}$ & $0.31-0.95$ \\
\hline Pancreas & 11 & 9.7 & 12.6 & $0.77^{\mathrm{d}}$ & $0.66-0.88$ & 13 & 9.9 & 12.0 & 0.82 & $0.50-1.26$ & 7 & 21.4 & 9.6 & $2.22^{\mathrm{d}}$ & $1.37-3.47$ \\
\hline Esophagus & 12 & 7.8 & 8.7 & 0.90 & $0.76-1.05$ & 10 & 14.1 & 9.3 & 1.52 & $0.95-2.28$ & 10 & 13.2 & 9.3 & 1.43 & $0.80-2.39$ \\
\hline Myeloma & 13 & 6.5 & 6.3 & 1.03 & $0.86-1.22$ & 14 & 7.1 & 6.5 & 1.10 & $0.60-1.82$ & $\sim$ & $\sim$ & 6.1 & $\sim$ & $\sim$ \\
\hline Melanoma of the skin & 14 & 5.9 & 27.4 & $0.21^{\mathrm{d}}$ & $0.18-0.25$ & $\sim$ & $\sim$ & 19.0 & $\sim$ & $\sim$ & $\sim$ & $\sim$ & 16.4 & $\sim$ & $\sim$ \\
\hline Larynx & 15 & 5.3 & 6.7 & $0.78^{\mathrm{d}}$ & $0.64-0.94$ & 12 & 10.3 & 6.5 & 1.58 & $0.88-2.56$ & $\sim$ & $\sim$ & 5.2 & $\sim$ & $\sim$ \\
\hline Brain and ONS & 16 & 5.0 & 8.7 & $0.57^{\mathrm{d}}$ & $0.48-0.67$ & 15 & 5.6 & 8.4 & 0.66 & $0.37-1.11$ & $\sim$ & $\sim$ & 8.1 & $\sim$ & $\sim$ \\
\hline Testis & 17 & 4.0 & 6.6 & $0.61^{\mathrm{d}}$ & $0.52-0.71$ & 17 & 5.1 & 6.5 & 0.79 & $0.51-1.24$ & 13 & 6.1 & 7.1 & 0.86 & $0.50-1.48$ \\
\hline \multirow[t]{3}{*}{ Gallbladder } & 18 & 2.5 & 0.7 & $3.70^{\mathrm{d}}$ & $2.65-4.99$ & $\sim$ & $\sim$ & 0.6 & $\sim$ & $\sim$ & $\sim$ & $\sim$ & $\sim$ & $\sim$ & $\sim$ \\
\hline & & & Southern pla & & & & & Pacific coas & & & & & East & & \\
\hline & $\mathrm{AI}$ & AN & & & AN:NHW & $\overline{\mathrm{AI} /}$ & AN & & $\mathrm{AI} / \mathrm{A}$ & AN:NHW & $\mathrm{AI} /$ & AN & & & AN:NHW \\
\hline Cancer site or type $\mathrm{a}^{\mathrm{a}}$ & Rank & Rate $^{c}$ & NHW rate ${ }^{c}$ & $\overline{\mathrm{RR}}$ & $95 \% \mathrm{CI}$ & $\overline{\text { Rank }}$ & $\operatorname{Rate}^{\mathrm{c}}$ & NHW rate ${ }^{c}$ & $\overline{\mathrm{RR}}$ & $95 \% \mathrm{CI}$ & $\overline{\text { Rank }}$ & Rate $^{\mathrm{c}}$ & NHW rate ${ }^{c}$ & $\overline{\mathrm{RR}}$ & $95 \% \mathrm{CI}$ \\
\hline All sites ${ }^{\mathrm{b}}$ & & 568.2 & 549.3 & 1.03 & $1.00-1.07$ & & 333.0 & 556.8 & $0.60^{\mathrm{d}}$ & $0.57-0.63$ & & 286.3 & 578.4 & $0.50^{\mathrm{d}}$ & $0.44-0.55$ \\
\hline Prostate & 1 & 156.9 & 146.6 & 1.07 & $0.99-1.15$ & 1 & 83.1 & 160.4 & $0.52^{\mathrm{d}}$ & $0.47-0.57$ & 1 & 82.9 & 156.3 & $0.53^{\mathrm{d}}$ & $0.43-0.65$ \\
\hline Lung and bronchus & 2 & 108.7 & 109.1 & 1.00 & $0.91-1.09$ & 2 & 56.5 & 82.4 & $0.69^{\mathrm{d}}$ & $0.60-0.78$ & 2 & 45.4 & 94.5 & $0.48^{\mathrm{d}}$ & $0.36-0.63$ \\
\hline Colon and rectum & 3 & 68.9 & 63.5 & 1.08 & $0.97-1.21$ & 3 & 44.0 & 56.4 & $0.78^{\mathrm{d}}$ & $0.67-0.90$ & 3 & 35.5 & 65.9 & $0.54^{\mathrm{d}}$ & $0.38-0.73$ \\
\hline Kidney and renal pelvis & 4 & 25.2 & 17.8 & $1.41^{\mathrm{d}}$ & $1.19-1.67$ & 4 & 14.8 & 16.8 & 0.88 & $0.70-1.10$ & 5 & 15.1 & 18.7 & 0.81 & $0.48-1.27$ \\
\hline Urinary bladder & 5 & 24.8 & 34.9 & $0.71^{\mathrm{d}}$ & $0.58-0.85$ & 5 & 13.3 & 41.9 & $0.32^{\mathrm{d}}$ & $0.24-0.41$ & 4 & 20.4 & 43.9 & $0.46^{\mathrm{d}}$ & $0.28-0.70$ \\
\hline Non-Hodgkin lymphoma & 6 & 23.5 & 22.1 & 1.06 & $0.87-1.28$ & 8 & 12.6 & 24.1 & $0.52^{\mathrm{d}}$ & $0.40-0.67$ & $\sim$ & $\sim$ & 23.9 & $\sim$ & $\sim$ \\
\hline Stomach & 12 & 10.2 & 7.3 & $1.40^{\mathrm{d}}$ & $1.05-1.83$ & 9 & 11.8 & 8.2 & $1.43^{\mathrm{d}}$ & $1.05-1.90$ & $\sim$ & $\sim$ & 9.9 & $\sim$ & $\sim$ \\
\hline Oral cavity and pharynx & 7 & 18.5 & 18.3 & 1.01 & $0.82-1.23$ & 7 & 12.6 & 17.1 & $0.74^{\mathrm{d}}$ & $0.58-0.93$ & 6 & 9.8 & 16.8 & $0.58^{\mathrm{d}}$ & $0.33-0.96$ \\
\hline Liver and IBD & 11 & 11.1 & 6.1 & $1.81^{\mathrm{d}}$ & $1.37-2.34$ & 6 & 12.7 & 6.5 & $1.94^{\mathrm{d}}$ & $1.50-2.46$ & $\sim$ & $\sim$ & 6.9 & $\sim$ & $\sim$ \\
\hline Leukemia & 8 & 17.2 & 16.3 & 1.06 & $0.85-1.30$ & 10 & 9.3 & 16.6 & $0.56^{\mathrm{d}}$ & $0.41-0.74$ & $\sim$ & $\sim$ & 17.1 & $\sim$ & $\sim$ \\
\hline Pancreas & 9 & 12.3 & 13.0 & 0.95 & $0.72-1.22$ & 12 & 6.6 & 12.8 & $0.52^{\mathrm{d}}$ & $0.35-0.73$ & $\sim$ & $\sim$ & 13.3 & $\sim$ & $\sim$ \\
\hline Esophagus & 14 & 8.5 & 7.8 & 1.10 & $0.78-1.49$ & 11 & 7.5 & 8.7 & 0.86 & $0.60-1.18$ & $\sim$ & $\sim$ & 8.8 & $\sim$ & $\sim$ \\
\hline Myeloma & 15 & 8.3 & 5.8 & $1.41^{\mathrm{d}}$ & $1.01-1.92$ & 14 & 4.6 & 6.4 & 0.72 & $0.45-1.08$ & $\sim$ & $\sim$ & 6.5 & $\sim$ & $\sim$ \\
\hline Melanoma of the skin & 10 & 11.6 & 20.4 & $0.57^{\mathrm{d}}$ & $0.44-0.73$ & 13 & 5.6 & 31.9 & $0.18^{\mathrm{d}}$ & $0.12-0.26$ & $\sim$ & $\sim$ & 27.2 & $\sim$ & $\sim$ \\
\hline Larynx & 13 & 9.1 & 7.8 & 1.17 & $0.86-1.55$ & 17 & 3.2 & 5.8 & $0.56^{\mathrm{d}}$ & $0.33-0.88$ & $\sim$ & $\sim$ & 8.2 & $\sim$ & $\sim$ \\
\hline Brain and ONS & 16 & 8.1 & 8.8 & 0.92 & $0.68-1.21$ & 16 & 3.7 & 9.2 & $0.40^{\mathrm{d}}$ & $0.26-0.60$ & $\sim$ & $\sim$ & 8.6 & $\sim$ & $\sim$ \\
\hline Testis & 17 & 3.5 & 5.6 & $0.63^{\mathrm{d}}$ & $0.43-0.91$ & 15 & 3.8 & 7.2 & $0.53^{\mathrm{d}}$ & $0.38-0.72$ & $\sim$ & $\sim$ & 6.2 & $\sim$ & $\sim$ \\
\hline Gallbladder & $\sim$ & $\sim$ & 0.7 & $\sim$ & $\sim$ & $\sim$ & $\sim$ & 0.6 & $\sim$ & $\sim$ & $\sim$ & $\sim$ & 0.8 & $\sim$ & $\sim$ \\
\hline & & & Southwest & & & & & & & & & & & & \\
\hline & & & & & AN:NHW & & & & & & & & & & \\
\hline Cancer site or type $^{\mathrm{a}}$ & Rank & Rate $^{\mathrm{c}}$ & NHW rate ${ }^{\mathrm{c}}$ & RR & $95 \% \mathrm{CI}$ & & & & & & & & & & \\
\hline All sites ${ }^{b}$ & & 261.5 & 513.1 & $0.51^{\mathrm{d}}$ & $0.49-0.54$ & & & & & & & & & & \\
\hline Prostate & 1 & 67.0 & 136.7 & $0.49^{\mathrm{d}}$ & $0.44-0.54$ & & & & & & & & & & \\
\hline Lung and bronchus & 4 & 22.1 & 78.1 & $0.28^{\mathrm{d}}$ & $0.24-0.34$ & & & & & & & & & & \\
\hline Colon and rectum & 2 & 26.7 & 56.1 & $0.48^{\mathrm{d}}$ & $0.41-0.55$ & & & & & & & & & & \\
\hline Kidney and renal pelvis & 3 & 25.1 & 15.8 & $1.59^{\mathrm{d}}$ & $1.35-1.85$ & & & & & & & & & & \\
\hline Urinary bladder & 11 & 5.5 & 41.1 & $0.13^{\mathrm{d}}$ & $0.09-0.19$ & & & & & & & & & & \\
\hline Non-Hodgkin lymphoma & 7 & 10.4 & 20.5 & $0.51^{\mathrm{d}}$ & $0.40-0.64$ & & & & & & & & & & \\
\hline
\end{tabular}


TABLE 7

(continued)

\begin{tabular}{|c|c|c|c|c|c|}
\hline \multirow[b]{3}{*}{ Cancer site or type $^{\mathrm{a}}$} & \multicolumn{5}{|c|}{ Southwest } \\
\hline & \multicolumn{2}{|c|}{ AI/AN } & \multirow[b]{2}{*}{ NHW rate ${ }^{c}$} & \multicolumn{2}{|c|}{ AI/AN:NHW } \\
\hline & Rank & Rate $^{\mathrm{c}}$ & & $\overline{\mathrm{RR}}$ & $95 \% \mathrm{CI}$ \\
\hline Stomach & 5 & 16.0 & 7.2 & $2.23^{\mathrm{d}}$ & $1.79-2.74$ \\
\hline Oral cavity and pharynx & 12 & 4.8 & 15.5 & $0.31^{\mathrm{d}}$ & $0.21-0.43$ \\
\hline Liver and IBD & 6 & 12.6 & 6.2 & $2.05^{\mathrm{d}}$ & $1.62-2.56$ \\
\hline Leukemia & 10 & 6.7 & 14.8 & $0.45^{\mathrm{d}}$ & $0.34-0.59$ \\
\hline Pancreas & 8 & 7.6 & 11.5 & $0.66^{\mathrm{d}}$ & $0.48-0.87$ \\
\hline Esophagus & 13 & 4.4 & 8.0 & $0.55^{\mathrm{d}}$ & $0.36-0.79$ \\
\hline Myeloma & 9 & 7.4 & 5.4 & 1.37 & $0.98-1.84$ \\
\hline Melanoma of the skin & 17 & 3.6 & 29.5 & $0.12^{\mathrm{d}}$ & $0.08-0.18$ \\
\hline Larynx & $\sim$ & $\sim$ & 6.1 & $\sim$ & $\sim$ \\
\hline Brain and ONS & 16 & 3.8 & 8.0 & $0.48^{\mathrm{d}}$ & $0.32-0.68$ \\
\hline Testis & 14 & 4.2 & 6.3 & $0.67^{\mathrm{d}}$ & $0.50-0.89$ \\
\hline Gallbladder & 15 & 4.1 & 0.7 & $6.33^{\mathrm{d}}$ & $3.87-9.81$ \\
\hline
\end{tabular}

Source: Surveillance, Epidemiology, and Ends Results and National Program of Cancer Registries areas are reported by the North American Association of Central Cancer Registries as meeting high-quality data standards from 1999 through 2004

CHSDA indicates Indian Health Service (IHS) Contract Health Service Delivery Area; AI/AN, American Indian/Alaska Native; NHW, non-Hispanic white; RR, rate ratio; 95\% CI, 95\% confidence interval; IBD, intrahepatic bile duct; ONS, other nervous system.

a Cancers are sorted in descending order according to sex-specific rates for AI/AN. Greater than 15 cancers may appear to include the top 15 cancers in every IHS region.

$\mathrm{b}$ All sites excludes myelodysplastic syndromes and borderline tumors.

${ }^{\mathrm{c}}$ Rates are per 100,000 persons and were age-adjusted to the 2000 U.S. standard population (19 age groups, Census p25-1130).

d The RR was statistically significant $(P<.05)$.

$\sim$ Statistic could not be calculated when $<16$ cases were reported.

Years of data and registries used (30 states). 1999-2004: Alabama, Alaska, California, Colorado, Connecticut, Florida, Idaho, Indiana, Iowa, Louisiana, Maine, Massachusetts, Montana, Nebraska, Nevada, New Mexico, New York, North Dakota, Oklahoma, Oregon, Pennsylvania, Rhode Island, South Carolina, Texas, Utah, Washington, Wyoming; 1993-2003: Arizona, Wisconsin; 2000-2004: Michigan.

Percent regional coverage of AI/AN CHSDA data to all AI/AN in region: Alaska, 100\%; East, 12.2\%; North Plains, 38.1\%; Pacific Coast, 55.1\%; South Plains, 65\%; Southwest, 86.1\%.

After steadily decreasing for many years, the decline in colorectal cancer death rates has accelerated. The concurrent declines in colorectal cancer mortality and incidence are likely associated with preventing colorectal cancer through screening and removal of precancerous polyps, improving cancer outcomes by earlier stage diagnosis, reducing exposure to risk factors, and improving cancer treatment. ${ }^{46-52}$

Lung cancer incidence trends have stabilized for women and have continued declining for men. Both joinpoint and fixed-interval trends for lung cancer death rates in women demonstrated a considerably slower rate of increase (APC, 0.2\%) from 1995 through 2004 than in earlier periods; lung cancer incidence rates remained essentially unchanged from 1998 through 2004. The data suggest that the epidemic of tobacco-related lung cancer in women has reached a plateau and likely will begin to decline, similar to what is occurring in men, although some fluctuations still may occur as trends stabilize. , $^{8,9,53,54}$

Prostate cancer incidence rates remained stable over the past decade. However, substantial declines in prostate cancer death rates occurred in all racial/ ethnic populations, a phenomenon previously observed in the U.S. ${ }^{55}$ and in other western coun- tries. ${ }^{56,57}$ The reasons for the decline in prostate cancer mortality are unclear. PSA has been used widely for prostate cancer screening, ${ }^{58}$ although to our knowledge its efficacy in reducing prostate cancer mortality has not been established, ${ }^{59}$ and its contribution to declining mortality is uncertain. ${ }^{60,61}$ Other factors possibly related to declining prostate cancer mortality rates include more effective treatment ${ }^{62-65}$ and serendipitous effects of noncancer-directed therapies. ${ }^{66}$

The decrease in breast cancer incidence rates from 2001 through 2004 is a change from increasing rates during the previous 20 years. Although many factors influence breast cancer incidence rates, recent reports highlight changes in hormone-replacement therapy (HRT) and screening mammography use. ${ }^{67-71}$ Between the years 1987 and 2000, the percentage of women aged $\geq 40$ years reporting a mammogram within the past 2 years increased from $29.1 \%$ to $70.1 \%{ }^{72}$ Recently, however, the direction of the trend with the percentage of women who had a mammogram in the past 2 years reversed and declined nearly 4 percentage points to $66.4 \%$. Reductions in mammography use were observed in populations that previously reported higher rates: women ages 50 to 64 years, NHW women, and women with 
TABLE 8

Incidence Rates and Rate Ratios of the Top 15 Cancers for American Indian/Alaska Native Females Compared With Non-Hispanic White Females by Indian Health Service Region, Contract Health Service Delivery Area Counties in Selected Areas in the United States, 1999-2004

\begin{tabular}{|c|c|c|c|c|c|c|c|c|c|c|c|c|c|c|c|}
\hline \multirow[b]{3}{*}{ Cancer site or type ${ }^{a}$} & \multicolumn{5}{|c|}{ U.S. (CHSDA counties) } & \multicolumn{5}{|c|}{ Northern plains } & \multicolumn{5}{|c|}{ Alaska } \\
\hline & \multicolumn{2}{|c|}{ AI/AN } & \multirow[b]{2}{*}{ NHW rate ${ }^{c}$} & \multicolumn{2}{|c|}{ AI/AN:NHW } & \multicolumn{2}{|c|}{ AI/AN } & \multirow[b]{2}{*}{ NHW rate ${ }^{c}$} & \multicolumn{2}{|c|}{ AI/AN:NHW } & \multicolumn{2}{|c|}{ AI/AN } & \multirow[b]{2}{*}{ NHW rate ${ }^{c}$} & \multicolumn{2}{|c|}{ AI/AN:NHW } \\
\hline & Rank & Rate $^{c}$ & & RR & $95 \% \mathrm{CI}$ & Rank & Rate $^{\text {c }}$ & & RR & $95 \% \mathrm{CI}$ & Rank & Rate $^{c}$ & & RR & $95 \% \mathrm{CI}$ \\
\hline All sites ${ }^{b}$ & & 334.8 & 425.8 & $0.79^{\mathrm{d}}$ & $0.77-0.80$ & & 468.1 & 413.3 & $1.13^{\mathrm{d}}$ & $1.07-1.20$ & & 511.0 & 415.3 & $1.23^{\mathrm{d}}$ & $1.15-1.32$ \\
\hline Breast & 1 & 84.7 & 134.8 & $0.63^{\mathrm{d}}$ & $0.60-0.65$ & 1 & 112.2 & 130.5 & $0.86^{\mathrm{d}}$ & $0.77-0.96$ & 1 & 139.5 & 135.6 & 1.03 & $0.91-1.17$ \\
\hline Lung and bronchus & 2 & 48.0 & 59.2 & $0.81^{\mathrm{d}}$ & $0.77-0.86$ & 2 & 97.4 & 52.0 & $1.87^{\mathrm{d}}$ & $1.64-2.12$ & 3 & 78.9 & 59.9 & $1.32^{\mathrm{d}}$ & $1.08-1.59$ \\
\hline Colon and rectum & 3 & 41.6 & 43.8 & 0.95 & $0.90-1.01$ & 3 & 60.4 & 45.3 & $1.33^{\mathrm{d}}$ & $1.13-1.57$ & 2 & 106.2 & 40.6 & $2.62^{\mathrm{d}}$ & $2.18-3.14$ \\
\hline Corpus and uterus, NOS & 4 & 18.2 & 23.4 & $0.78^{\mathrm{d}}$ & $0.71-0.84$ & 4 & 21.3 & 26.7 & 0.80 & $0.60-1.03$ & 5 & 14.0 & 22.9 & $0.61^{\mathrm{d}}$ & $0.41-0.90$ \\
\hline Kidney and renal pelvis & 5 & 13.9 & 8.7 & $1.59^{\mathrm{d}}$ & $1.44-1.75$ & 5 & 18.8 & 9.3 & $2.03^{\mathrm{d}}$ & $1.51-2.67$ & 8 & 12.0 & 8.6 & 1.39 & $0.85-2.21$ \\
\hline Non-Hodgkin lymphoma & 6 & 12.8 & 16.4 & $0.78^{\mathrm{d}}$ & $0.70-0.87$ & 6 & 16.2 & 16.7 & 0.97 & $0.69-1.31$ & 10 & 9.9 & 17.8 & $0.55^{\mathrm{d}}$ & $0.33-0.88$ \\
\hline Ovary ${ }^{\mathrm{b}}$ & 7 & 11.7 & 14.4 & $0.81^{\mathrm{d}}$ & $0.73-0.90$ & 7 & 12.6 & 14.0 & 0.90 & $0.63-1.25$ & 12 & 7.6 & 13.5 & $0.56^{\mathrm{d}}$ & $0.31-0.95$ \\
\hline Pancreas & 8 & 9.4 & 9.5 & 1.00 & $0.88-1.13$ & 11 & 9.9 & 9.0 & 1.09 & $0.70-1.61$ & 9 & 11.9 & 10.7 & 1.12 & $0.67-1.78$ \\
\hline Cervix uteri & 9 & 9.4 & 7.5 & $1.25^{\mathrm{d}}$ & $1.11-1.39$ & 9 & 11.3 & 7.5 & $1.50^{\mathrm{d}}$ & $1.07-2.06$ & 11 & 9.2 & 6.0 & 1.52 & $0.88-2.51$ \\
\hline Thyroid & 10 & 8.4 & 12.0 & $0.70^{\mathrm{d}}$ & $0.63-0.79$ & 10 & 10.2 & 11.9 & 0.86 & $0.60-1.19$ & 6 & 12.6 & 12.3 & 1.03 & $0.69-1.50$ \\
\hline Leukemia & 11 & 7.8 & 9.7 & $0.80^{\mathrm{d}}$ & $0.70-0.91$ & 8 & 11.5 & 10.1 & 1.14 & $0.75-1.66$ & 14 & 5.7 & 10.9 & $0.52^{\mathrm{d}}$ & $0.27-0.92$ \\
\hline Stomach & 12 & 7.6 & 3.7 & $2.05^{\mathrm{d}}$ & $1.77-2.35$ & 14 & 7.4 & 3.5 & $2.12^{\mathrm{d}}$ & $1.28-3.28$ & 4 & 17.7 & 3.0 & $5.90^{\mathrm{d}}$ & $3.41-10.38$ \\
\hline Liver and IBD & 13 & 5.9 & 2.5 & $2.39^{\mathrm{d}}$ & $2.02-2.80$ & 13 & 7.7 & 2.3 & $3.39^{\mathrm{d}}$ & $1.97-5.35$ & $\sim$ & $\sim$ & 2.7 & $\sim$ & $\sim$ \\
\hline Myeloma & 14 & 5.8 & 3.8 & $1.53^{\mathrm{d}}$ & $1.30-1.79$ & 15 & 5.6 & 4.0 & 1.41 & $0.80-2.28$ & 13 & 7.5 & 4.0 & 1.88 & $0.95-3.55$ \\
\hline Oral cavity and pharynx & 15 & 4.9 & 6.4 & $0.77^{\mathrm{d}}$ & $0.65-0.91$ & 12 & 9.6 & 6.1 & $1.56^{\mathrm{d}}$ & $1.03-2.26$ & 7 & 12.3 & 5.8 & $2.12^{\mathrm{d}}$ & $1.23-3.55$ \\
\hline Urinary bladder & 16 & 4.4 & 10.4 & $0.42^{\mathrm{d}}$ & $0.35-0.50$ & $\sim$ & $\sim$ & 10.5 & $\sim$ & $\sim$ & $\sim$ & $\sim$ & 8.6 & $\sim$ & $\sim$ \\
\hline Melanoma of the skin & 17 & 3.9 & 18.5 & $0.21^{\mathrm{d}}$ & $0.18-0.25$ & $\sim$ & $\sim$ & 13.7 & $\sim$ & $\sim$ & $\sim$ & $\sim$ & 12.7 & $\sim$ & $\sim$ \\
\hline \multirow{3}{*}{ Gallbladder } & 18 & 3.8 & 1.1 & $3.36^{\mathrm{d}}$ & $2.72-4.11$ & $\sim$ & $\sim$ & 1.4 & $\sim$ & $\sim$ & $\sim$ & $\sim$ & $\sim$ & $\sim$ & $\sim$ \\
\hline & & & Southern pla & & & & & Pacific coa & & & & & East & & \\
\hline & & AN & & $\mathrm{AI} /$ & $\mathrm{AN}: \mathrm{NHW}$ & $\overline{\mathrm{AI}}$ & & & $\mathrm{AI} / \mathrm{t}$ & $\mathrm{N}: \mathrm{NHW}$ & $\mathrm{AI} /$ & $\overline{\mathrm{AN}}$ & & & AN:NHW \\
\hline Cancer site or type $^{a}$ & Rank & Rate $^{\mathrm{c}}$ & NHW rate ${ }^{c}$ & $\overline{\mathrm{RR}}$ & $95 \% \mathrm{CI}$ & Rank & Rate $^{\mathrm{c}}$ & NHW rate ${ }^{c}$ & $\overline{\mathrm{RR}}$ & $95 \% \mathrm{CI}$ & Rank & Rate $^{c}$ & NHW rate ${ }^{c}$ & $\overline{\mathbf{R R}}$ & $95 \% \mathrm{CI}$ \\
\hline All sites ${ }^{b}$ & & 439.2 & 403.7 & $1.09^{\mathrm{d}}$ & $1.05-1.13$ & & 292.7 & 437.5 & $0.67^{\mathrm{d}}$ & $0.64-0.70$ & & 258.3 & 435.1 & $0.59^{\mathrm{d}}$ & $0.54-0.65$ \\
\hline Breast & 1 & 115.2 & 130.0 & $0.89^{\mathrm{d}}$ & $0.83-0.95$ & 1 & 74.5 & 142.5 & $0.52^{\mathrm{d}}$ & $0.48-0.57$ & 1 & 69.1 & 132.8 & $0.52^{\mathrm{d}}$ & $0.43-0.62$ \\
\hline Lung and bronchus & 2 & 68.8 & 62.9 & $\begin{array}{l}0.03 \\
1.09\end{array}$ & $1.00-1.20$ & 2 & 47.0 & 60.9 & $0.77^{\mathrm{d}}$ & $0.68-0.87$ & 2 & 45.2 & 61.3 & $0.74^{\mathrm{d}}$ & $0.57-0.93$ \\
\hline Colon and rectum & 3 & 54.4 & 43.4 & $1.25^{\mathrm{d}}$ & $1.13-1.39$ & 3 & 34.8 & 42.0 & $0.83^{\mathrm{d}}$ & $0.72-0.95$ & 3 & 34.6 & 46.9 & $0.74^{\mathrm{d}}$ & $0.56-0.96$ \\
\hline Corpus and uterus, NOS & 4 & 22.5 & 19.4 & 1.16 & $0.98-1.35$ & 4 & 16.8 & 23.7 & $0.71^{\mathrm{d}}$ & $0.59-0.85$ & 4 & 13.1 & 24.4 & $0.54^{\mathrm{d}}$ & $0.33-0.81$ \\
\hline Kidney and renal pelvis & 6 & 17.9 & 9.1 & $1.96^{\mathrm{d}}$ & $1.62-2.36$ & 7 & 10.4 & 8.3 & 1.26 & $0.98-1.59$ & 5 & 11.5 & 9.2 & 1.25 & $0.77-1.91$ \\
\hline Non-Hodgkin lymphoma & 5 & 18.4 & 15.6 & 1.17 & $0.97-1.40$ & 5 & 12.4 & 16.7 & $0.74^{\mathrm{d}}$ & $0.58-0.93$ & $\sim$ & $\sim$ & 16.8 & $\sim$ & $\sim$ \\
\hline Ovary ${ }^{b}$ & 7 & 14.4 & 14.0 & 1.03 & $0.84-1.25$ & 8 & 9.9 & 14.9 & $0.66^{\mathrm{d}}$ & $0.51-0.84$ & $\sim$ & $\sim$ & 14.6 & $\sim$ & $\sim$ \\
\hline Pancreas & 9 & 9.9 & 8.7 & 1.13 & $0.87-1.44$ & 6 & 10.8 & 9.7 & 1.12 & $0.85-1.43$ & $\sim$ & $\sim$ & 10.0 & $\sim$ & $\sim$ \\
\hline Cervix uteri & 8 & 14.1 & 9.2 & $1.53^{\mathrm{d}}$ & $1.25-1.86$ & 10 & 6.9 & 7.0 & 0.98 & $0.74-1.27$ & 6 & 8.2 & 7.7 & 1.07 & $0.62-1.71$ \\
\hline Thyroid & 11 & 9.3 & 8.1 & 1.14 & $0.89-1.44$ & 11 & 6.3 & 11.0 & $0.57^{\mathrm{d}}$ & $0.43-0.75$ & 7 & 7.9 & 13.1 & $0.60^{\mathrm{d}}$ & $0.34-0.98$ \\
\hline Leukemia & 10 & 9.7 & 9.7 & 1.00 & $0.78-1.26$ & 9 & 7.5 & 9.7 & 0.77 & $0.57-1.02$ & $\sim$ & $\sim$ & 9.8 & $\sim$ & $\sim$ \\
\hline Stomach & 13 & 7.4 & 3.4 & $2.18^{\mathrm{d}}$ & $1.60-2.90$ & 13 & 4.4 & 3.5 & 1.25 & $0.81-1.83$ & $\sim$ & $\sim$ & 4.4 & $\sim$ & $\sim$ \\
\hline Liver and IBD & 17 & 5.3 & 2.8 & $1.88^{\mathrm{d}}$ & $1.30-2.64$ & 12 & 5.9 & 2.6 & $2.29^{\mathrm{d}}$ & $1.58-3.18$ & $\sim$ & $\sim$ & 2.4 & $\sim$ & $\sim$ \\
\hline Myeloma & 15 & 6.8 & 3.7 & $1.86^{\mathrm{d}}$ & $1.36-2.50$ & 15 & 4.1 & 3.8 & 1.09 & $0.70-1.60$ & $\sim$ & $\sim$ & 4.0 & $\sim$ & $\sim$ \\
\hline Oral cavity and pharynx & 16 & 5.9 & 6.0 & 0.98 & $0.70-1.32$ & 17 & 3.9 & 6.7 & $0.59^{\mathrm{d}}$ & $0.39-0.84$ & $\sim$ & $\sim$ & 6.5 & $\sim$ & $\sim$ \\
\hline Urinary bladder & 14 & 7.3 & 8.5 & 0.85 & $0.63-1.13$ & 14 & 4.3 & 10.1 & $0.42^{\mathrm{d}}$ & $0.27-0.62$ & $\sim$ & $\sim$ & 11.3 & $\sim$ & $\sim$ \\
\hline Melanoma of the skin & 12 & 7.7 & 12.5 & $0.62^{\mathrm{d}}$ & $0.47-0.80$ & 16 & 4.0 & 22.5 & $0.18^{\mathrm{d}}$ & $0.12-0.25$ & $\sim$ & $\sim$ & 17.8 & $\sim$ & $\sim$ \\
\hline Gallbladder & 20 & 2.6 & 1.0 & $2.65^{\mathrm{d}}$ & $1.53-4.31$ & $\sim$ & $\sim$ & 1.1 & $\sim$ & $\sim$ & & & 1.1 & & \\
\hline & & & Southwes & & & & & & & & & & & & \\
\hline & & AN & & $\mathrm{AI} / \mathrm{t}$ & $\mathrm{AN}: \mathrm{NHW}$ & & & & & & & & & & \\
\hline Cancer site or type $^{\mathrm{a}}$ & Rank & Rate $^{\mathrm{c}}$ & NHW rate ${ }^{c}$ & $\overline{\mathrm{RR}}$ & $95 \% \mathrm{CI}$ & & & & & & & & & & \\
\hline All sites ${ }^{\mathrm{b}}$ & & 219.3 & 404.3 & $0.54^{\mathrm{d}}$ & $0.52-0.57$ & & & & & & & & & & \\
\hline Breast & 1 & 50.4 & 127.2 & $0.40^{\mathrm{d}}$ & $0.36-0.43$ & & & & & & & & & & \\
\hline Lung and bronchus & 6 & 10.3 & 56.9 & $0.18^{\mathrm{d}}$ & $0.14-0.22$ & & & & & & & & & & \\
\hline Colon and rectum & 2 & 17.6 & 40.3 & $0.44^{\mathrm{d}}$ & $0.37-0.51$ & & & & & & & & & & \\
\hline Corpus and uterus, NOS & 3 & 16.8 & 19.7 & $0.85^{\mathrm{d}}$ & $0.73-0.99$ & & & & & & & & & & \\
\hline Kidney and renal pelvis & 5 & 12.6 & 8.2 & $1.54^{\mathrm{d}}$ & $1.26-1.85$ & & & & & & & & & & \\
\hline Non-Hodgkin lymphoma & 7 & 9.0 & $\begin{array}{r}0.2 \\
14.9\end{array}$ & $0.60^{\mathrm{d}}$ & $0.47-0.75$ & & & & & & & & & & \\
\hline
\end{tabular}


TABLE 8

(continued)

\begin{tabular}{|c|c|c|c|c|c|}
\hline \multirow[b]{3}{*}{ Cancer site or type $^{\mathrm{a}}$} & \multicolumn{5}{|c|}{ Southwest } \\
\hline & \multicolumn{2}{|c|}{ AI/AN } & \multirow[b]{2}{*}{ NHW rate ${ }^{c}$} & \multicolumn{2}{|c|}{ AI/AN:NHW } \\
\hline & Rank & Rate $^{c}$ & & RR & $95 \% \mathrm{CI}$ \\
\hline Ovary ${ }^{b}$ & 4 & 13.1 & 13.7 & 0.95 & $0.79-1.14$ \\
\hline Pancreas & 11 & 7.9 & 8.5 & 0.92 & $0.70-1.18$ \\
\hline Cervix uteri & 10 & 7.9 & 7.5 & 1.06 & $0.83-1.33$ \\
\hline Thyroid & 9 & 8.4 & 14.5 & $0.58^{\mathrm{d}}$ & $0.47-0.71$ \\
\hline Leukemia & 14 & 6.1 & 9.4 & $0.65^{\mathrm{d}}$ & $0.50-0.84$ \\
\hline Stomach & 8 & 8.8 & 3.1 & $2.84^{\mathrm{d}}$ & $2.18-3.64$ \\
\hline Liver and IBD & 15 & 6.0 & 2.3 & $2.61^{\mathrm{d}}$ & $1.89-3.51$ \\
\hline Myeloma & 13 & 6.1 & 3.0 & $2.01^{\mathrm{d}}$ & $1.48-2.66$ \\
\hline Oral cavity and pharynx & 18 & 2.1 & 5.9 & $0.35^{\mathrm{d}}$ & $0.21-0.54$ \\
\hline Urinary bladder & $\sim$ & $\sim$ & 10.1 & $\sim$ & $\sim$ \\
\hline Melannoma of the skin & 20 & 1.8 & 18.5 & $0.10^{\mathrm{d}}$ & $0.06-0.15$ \\
\hline Gallbladder & 12 & 6.6 & 0.9 & $7.10^{\mathrm{d}}$ & $5.08-9.68$ \\
\hline
\end{tabular}

Source: Surveillance, Epidemiology, and Ends Results and National Program of Cancer Registries areas are reported by the North American Association of Central Cancer Registries as meeting high-quality data standards from 1999 through 2004.

CHSDA indicates Indian Health Service (IHS) Contract Health Service Delivery Area; AI/AN, American Indian/Alaska Native; NHW, non-Hispanic white; RR, rate ratio; 95\% CI, 95\% confidence interval; NOS, not otherwise specified; IBD, intrahepatic bile duct.

${ }^{\text {a }}$ Cancers are sorted in descending order according to sex-specific rates for AI/AN. Greater than 15 cancers may appear to include the top 15 cancers in every IHS region.

b All sites excludes myelodysplastic syndromes and borderline tumors.

${ }^{\mathrm{c}}$ Rates are per 100,000 persons and were age-adjusted to the 2000 U.S. standard population (19 age groups, Census p25-1130).

d The RR was statistically significant $(P<.05)$.

$\sim$ Statistic could not be calculated when $<16$ cases were reported.

Years of data and registries used (30 states), 1999-2004: Alabama, Alaska, California, Colorado, Connecticut, Florida, Idaho, Indiana, Iowa, Louisiana, Maine, Massachusetts, Montana, Nebraska, Nevada, New Mexico, New York, North Dakota, Oklahoma, Oregon, Pennsylvania, Rhode Island, South Carolina, Texas, Utah, Washington, Wyoming; 1999-2003: Arizona, Wisconsin; 2000-2004: Michigan.

Percent regional coverage of AI/AN CHSDA data to all AI/AN in region: Alaska, 100\%; East, 12.2\%; North Plains, 38.1\%; Pacific Coast, 55.1\%; South Plains, 65\%; Southwest, 86.1\%.

high incomes and education levels. ${ }^{70}$ The drop in incidence rates over the last several years may be associated in part with the small but significant decline in mammography use. ${ }^{68,70} \mathrm{~A}$ decrease in breast cancer incidence attributable to lower mammography use would represent an artifact of underdiagnosis or delayed diagnosis and not a true decrease in the rate of invasive breast cancer. Treatment of ductal and lobular carcinomas in situ, most of which are identified by screening mammography, also may have contributed to the observed decrease in breast cancer incidence. ${ }^{73}$

Recent reports also highlight the contribution from the dramatic decrease in HRT among postmenopausal women for the decrease in breast cancer incidence rates, primarily in those ages 50 to 69 years, and among women with estrogen receptor-positive tumors, which are dependent on hormones for their growth. ${ }^{69}$ Follow-up of women in the Women's Health Initiative may provide valuable answers to the impact of HRT cessation on breast cancer risk or timing and whether the impact can be sustained over time or throughout a woman's life. Whether the decline in inci- dence will accelerate the existing mortality decline also needs to be determined.

Because HRT is also a risk factor for ovarian cancer, ${ }^{74}$ the decline in breast cancer incidence rates prompted further examination of recent trends in ovarian cancer. Ovarian cancer incidence rates have been declining since the mid-1980s. However, in this study, the rate of decline among white women changed from $-1.0 \%$ per year during 1995 through 2001 to $-3.3 \%$ per year during 2001 through 2004 . The earlier declines in ovarian cancer incidence rates have been attributed in part to oral contraceptive use, ${ }^{75,76}$ whereas the most recent downturn, such as that observed in breast cancer, may be related to the abrupt reversal in HRT use.

The incidence of kidney cancer has been rising among men and women since 1975, but death rates have been declining since 1992. Similar incidence patterns are observed in fixed-interval trends for 1995 through 2004 for most racial/ethnic populations. Much of the increase in incidence has been attributed to small tumors ${ }^{77}$ or tumors diagnosed unexpectedly in patients who undergo diagnostic 
TABLE 9

Stage-specific Incidence Counts and Rates for Selected Cancer Sites and Age Groups for American Indian/Alaska Native and Non-Hispanic White Populations by Indian Health Service Region, Contract Health Service Delivery Area Counties in Selected Areas in the United States, 2001-2004; Males and Females Combined

\begin{tabular}{|c|c|c|c|c|c|c|c|c|c|c|c|c|}
\hline \multirow[b]{2}{*}{ Cancer site $^{\mathrm{a}} /$ stage $^{\mathrm{b}}$} & \multicolumn{4}{|c|}{ U.S. (CHSDA counties) NHW } & \multicolumn{4}{|c|}{ U.S. (CHSDA counties) AI/AN } & \multicolumn{4}{|c|}{ Northern plains AI/AN } \\
\hline & Count & Rate $^{\mathrm{c}}$ & $(95 \% \mathrm{CI})$ & $\mathrm{R} \%$ & Count & Rate $^{\mathrm{c}}$ & $(95 \% \mathrm{CI})$ & $\mathrm{R} \%$ & Count & Rate $^{\mathrm{c}}$ & $(95 \% \mathrm{CI})$ & $\mathrm{R} \%$ \\
\hline \multicolumn{13}{|c|}{ Colon and rectum (aged 50 years and older) } \\
\hline All stages & 67,699 & 167.8 & $(166.6-169.1)$ & 100.0 & 1,058 & 144.4 & $(135.5-153.7)$ & 100.0 & 163 & 227.4 & $(191.7-267.8)$ & 100.0 \\
\hline Local & 25,037 & 62.2 & $(61.4-63.0)$ & 37.0 & 340 & 46.9 & $(41.9-52.4)$ & 32.1 & 48 & 63.7 & $(45.9-86.2)$ & 29.4 \\
\hline Regional/distant & 36,272 & 90.1 & $(89.1-91.0)$ & 53.6 & 619 & 83.1 & $(76.5-90.2)$ & 58.5 & 98 & 136.5 & $(109.2-168.6)$ & 60.1 \\
\hline Unknown & 6,390 & 15.6 & $(15.2-16.0)$ & 9.4 & 99 & 14.3 & $(11.6-17.6)$ & 9.4 & 17 & 27.1 & $(15.3-44.3)$ & 10.4 \\
\hline \multicolumn{13}{|c|}{ Breast (female aged 40 years and older) } \\
\hline All stages & 95,866 & 294.5 & (292.7-296.4) & 100.0 & 1,370 & 184.5 & $(174.5-194.8)$ & 100.0 & 189 & 254.5 & (217.9-295.6) & 100.0 \\
\hline Local & 60,073 & 184.0 & (182.5-185.4) & 62.7 & 761 & 103.3 & $(95.9-111.1)$ & 55.5 & 102 & 141.2 & (114.1-172.9) & 54.0 \\
\hline Regional/distant & 30,524 & 95.4 & $(94.3-96.5)$ & 31.8 & 505 & 66.7 & $(60.8-73.0)$ & 36.9 & 75 & 95.8 & (74.4-121.6) & 39.7 \\
\hline Unknown & 5,269 & 15.2 & $(14.7-15.6)$ & 5.5 & 104 & 14.5 & $(11.7-17.7)$ & 7.6 & $\sim$ & $\sim$ & $\sim$ & $\sim$ \\
\hline \multicolumn{13}{|c|}{ Cervix uteri (aged 20 years and older) } \\
\hline All stages & 4,729 & 10.2 & $(9.9-10.5)$ & 100.0 & 175 & 12.1 & $(10.4-14.1)$ & 100.0 & 19 & 13.0 & $(7.6-20.9)$ & 100.0 \\
\hline Local & 2,485 & 5.6 & $(5.4-5.8)$ & 52.5 & 75 & 5.0 & $(3.9-6.3)$ & 42.9 & $\sim$ & $\sim$ & $\sim$ & $\sim$ \\
\hline Regional/distant & 1,802 & 3.7 & $(3.5-3.9)$ & 38.1 & 84 & 5.8 & $(4.6-7.2)$ & 48.0 & $\sim$ & $\sim$ & $\sim$ & $\sim$ \\
\hline Unknown & 442 & 0.9 & $(0.8-1.0)$ & 9.3 & 16 & 1.3 & $(0.7-2.2)$ & 9.1 & $\sim$ & $\sim$ & $\sim$ & $\sim$ \\
\hline \multicolumn{13}{|c|}{ Prostate (aged 50 years and older) } \\
\hline All stages & 98,770 & 552.7 & $(549.3-556.2)$ & 100.0 & 1,165 & 364.0 & $(342.1-387.1)$ & 100.0 & 155 & 520.9 & $(433.7-620.6)$ & 100.0 \\
\hline Local & 75,737 & 421.2 & $(418.2-424.2)$ & 76.7 & 811 & 243.5 & $(226.1-261.9)$ & 69.6 & 106 & 325.5 & $(261.5-401.1)$ & 68.4 \\
\hline Regional/distant & 13,357 & 74.0 & $(72.7-75.2)$ & 13.5 & 200 & 60.4 & $(51.8-70.1)$ & 17.2 & 29 & 94.9 & $(61.1-141.2)$ & 18.7 \\
\hline \multirow[t]{2}{*}{ Unknown } & 9,676 & 57.6 & $(56.4-58.7)$ & 9.8 & 154 & 60.1 & $(50.4-71.0)$ & 13.2 & 20 & 100.6 & $(58.0-159.6)$ & 12.9 \\
\hline & \multicolumn{4}{|c|}{ Alaska AI/AN } & \multicolumn{4}{|c|}{ Southern plains AI/AN } & \multicolumn{4}{|c|}{ Pacific coast AI/AN } \\
\hline Cancer site $^{\mathrm{a}} /$ stage $^{\mathrm{b}}$ & $\overline{\text { Count }}$ & Rate $^{\mathrm{c}}$ & $(95 \% \mathrm{CI})$ & $\mathrm{R} \%$ & Count & Rate $^{\mathrm{c}}$ & $(95 \% \mathrm{CI})$ & $\mathrm{R} \%$ & Count & Rate $^{\mathrm{c}}$ & $(95 \% \mathrm{CI})$ & $\mathrm{R} \%$ \\
\hline \multicolumn{13}{|c|}{ Colon and rectum (aged 50 years and older) } \\
\hline All stages & 153 & 321.5 & $(270.4-379.3)$ & 100.0 & 333 & 191.4 & $(171.0-213.6)$ & 100.0 & 211 & 129.7 & $(111.7-149.7)$ & 100.0 \\
\hline Local & 64 & 136.7 & $(104.0-176.3)$ & 41.8 & 100 & 57.9 & $(46.9-70.7)$ & 30.0 & 75 & 47.1 & $(36.4-59.9)$ & 35.5 \\
\hline Regional/distant & 82 & 172.0 & $(135.1-215.6)$ & 53.6 & 194 & 109.4 & $(94.2-126.2)$ & 58.3 & 123 & 74.5 & $(61.1-89.9)$ & 58.3 \\
\hline Unknown & $\sim$ & $\sim$ & $\sim$ & $\sim$ & 39 & 24.2 & $(17.0-33.2)$ & 11.7 & $\sim$ & $\sim$ & $\sim$ & $\sim$ \\
\hline \multicolumn{13}{|c|}{ Breast (female aged 40 years and older) } \\
\hline All stages & 157 & 319.0 & $(269.6-375.1)$ & 100.0 & 435 & 257.8 & $(233.9-283.4)$ & 100.0 & 290 & 171.9 & $(151.5-194.3)$ & 100.0 \\
\hline Local & 89 & 188.2 & (149.8-233.5) & 56.7 & 247 & 145.3 & $(127.6-164.8)$ & 56.8 & 164 & 99.3 & $(83.8-116.8)$ & 56.6 \\
\hline Regional/distant & 40 & 74.6 & $(52.9-102.9)$ & 25.5 & 154 & 91.2 & $(77.3-107.0)$ & 35.4 & 117 & 56.5 & $(54.3-80.7)$ & 40.3 \\
\hline Unknown & 28 & 56.2 & $(37.0-82.2)$ & 17.8 & 34 & 21.3 & $(14.7-29.8)$ & 7.8 & $\sim$ & $\sim$ & $\sim$ & $\sim$ \\
\hline \multicolumn{13}{|c|}{ Cervix uteri (aged 20 years and older) } \\
\hline All stages & $\sim$ & $\sim$ & $\sim$ & $\sim$ & 66 & 21.7 & $(16.7-27.6)$ & 100.0 & 27 & 7.7 & $(5.0-11.5)$ & 100.0 \\
\hline Local & $\sim$ & $\sim$ & $\sim$ & $\sim$ & 33 & 10.7 & $(7.3-15.0)$ & 50.0 & $\sim$ & $\sim$ & $\sim$ & $\sim$ \\
\hline Regional/distant & $\sim$ & $\sim$ & $\sim$ & $\sim$ & 29 & 9.7 & $(6.5-13.9)$ & 43.9 & 17 & 4.8 & $(2.7-8.0)$ & 63.0 \\
\hline Unknown & $\sim$ & $\sim$ & $\sim$ & $\sim$ & $\sim$ & $\sim$ & $\sim$ & $\sim$ & $\sim$ & $\sim$ & $\sim$ & $\sim$ \\
\hline Prostate (aged 50 yea & and older & & & & & & & & & & & \\
\hline All stages & 72 & 331.5 & $(249.8-431.0)$ & 100.0 & 434 & 563.0 & $(508.5-621.7)$ & 100.0 & 221 & 303.7 & (261.6-350.7) & 100.0 \\
\hline Local & 53 & 235.6 & (169.9-318.7) & 73.6 & 318 & 399.7 & (354.9-448.6) & 73.3 & 156 & 210.9 & (176.6-249.9) & 70.6 \\
\hline Regional/distant & $\sim$ & $\sim$ & $\sim$ & $\sim$ & 57 & 73.3 & $(54.7-96.3)$ & 13.1 & 46 & 57.3 & $(40.4-79.0)$ & 20.8 \\
\hline Unknown & $\sim$ & $\sim$ & $\sim$ & $\sim$ & 59 & 90.0 & $(67.2-117.7)$ & 13.6 & 19 & 35.5 & $(20.5-56.5)$ & 8.6 \\
\hline & & & AI/AN & & & Sou & Nest AI/AN & & & & & \\
\hline Cancer site $^{\mathrm{a}} /$ stage $^{\mathrm{b}}$ & $\overline{\text { Count }}$ & Rate $^{\mathrm{C}}$ & $(95 \% \mathrm{CI})$ & $\mathrm{R} \%$ & $\overline{\text { Count }}$ & Rate $^{\mathrm{c}}$ & $(95 \% \mathrm{CI})$ & $\mathrm{R} \%$ & & & & \\
\hline Colon and rectum (a & d 50 years & nd older) & & & & & & & & & & \\
\hline All stages & 45 & 116.6 & (84.1-157.4) & 100.0 & 153 & 62.4 & $(52.6-73.5)$ & 100.0 & & & & \\
\hline Local & $\sim$ & $\sim$ & $\sim$ & $\sim$ & 42 & 17.3 & $(12.3-23.6)$ & 27.5 & & & & \\
\hline Regional/distant & 26 & 68.4 & (44.1-101.0) & 57.8 & 96 & 38.3 & $(30.8-47.1)$ & 62.7 & & & & \\
\hline Unknown & $\sim$ & $\sim$ & $\sim$ & $\sim$ & $\sim$ & $\sim$ & $\sim$ & $\sim$ & & & & \\
\hline Breast (female aged 4 & years and & der) & & & & & & & & & & \\
\hline All stages & 61 & 154.8 & (117.1-200.6) & 100.0 & 238 & 97.7 & $(85.4-111.4)$ & 100.0 & & & & \\
\hline Local & 35 & 92.0 & $(63.2-129.2)$ & 57.4 & 124 & 50.9 & $(42.1-60.9)$ & 52.1 & & & & \\
\hline Regional/distant & 23 & 56.9 & $(35.3-86.7)$ & 37.7 & 96 & 39.8 & $(32.0-48.9)$ & 40.3 & & & & \\
\hline Unknown & $\sim$ & $\sim$ & $\sim$ & $\sim$ & 18 & 7.1 & $(4.1-11.4)$ & 7.6 & & & & \\
\hline
\end{tabular}


TABLE 9

(continued)

\begin{tabular}{|c|c|c|c|c|c|c|c|c|}
\hline \multirow[b]{2}{*}{ Cancer site $^{\mathrm{a}} /$ stage $^{\mathrm{b}}$} & \multicolumn{4}{|c|}{ East AI/AN } & \multicolumn{4}{|c|}{ Southwest AI/AN } \\
\hline & Count & $\operatorname{Rate}^{\mathrm{c}}$ & $(95 \% \mathrm{CI})$ & $\mathrm{R} \%$ & Count & Rate $^{c}$ & $(95 \% \mathrm{CI})$ & $\mathrm{R} \%$ \\
\hline \multicolumn{9}{|c|}{ Cervix uteri (aged 20 years and older) } \\
\hline All stages & $\sim$ & $\sim$ & $\sim$ & $\sim$ & 50 & 11.2 & $(8.2-15.0)$ & 100.0 \\
\hline Local & $\sim$ & $\sim$ & $\sim$ & $\sim$ & 22 & 4.6 & $(2.8-7.0)$ & 44.0 \\
\hline Regional/distant & $\sim$ & $\sim$ & $\sim$ & $\sim$ & 22 & 4.9 & $(3.1-7.5)$ & 44.0 \\
\hline Unknown & $\sim$ & $\sim$ & $\sim$ & $\sim$ & $\sim$ & $\sim$ & $\sim$ & $\sim$ \\
\hline \multicolumn{9}{|c|}{ Prostate (aged 50 years and older) } \\
\hline All stages & 50 & 270.2 & $(196.0-363.6)$ & 100.0 & 233 & 238.1 & $(207.2-272.3)$ & 100.0 \\
\hline Local & 34 & 172.5 & (116.4-247.3) & 68.0 & 144 & 141.8 & $(118.7-168.1)$ & 61.8 \\
\hline Regional/distant & $\sim$ & $\sim$ & $\sim$ & $\sim$ & 54 & 52.9 & $(39.1-69.9)$ & 23.2 \\
\hline Unknown & $\sim$ & $\sim$ & $\sim$ & $\sim$ & 35 & 43.4 & $(29.8-60.8)$ & 15.0 \\
\hline
\end{tabular}

Source: Surveillance, Epidemiology, and Ends Results (SEER) and National Program of Cancer Registries areas are reported by the North American Association of Central Cancer Registries as meeting high-quality data standards for the specified years.

CHSDA indicates Indian Health Service (IHS) Contract Health Service Delivery Area; AI/AN, American Indian/Alaska Native; NHW, non-Hispanic white; $95 \%$ CI, 95\% confidence interval; R\%, percent distribution of the stage-specific incidence rate.

${ }^{a}$ Cancers were chosen based on existing evidence base for early detection.

b 2000 SEER Summary Stage was used for stage of disease at diagnosis.

${ }^{\mathrm{c}}$ Rates are per 100,000 persons and are age-adjusted to the 2000 U.S. standard population (19 age groups, Census p25-1130).

$\sim$ Statistic could not be calculated when $<16$ cases were reported.

Years of data and registries used (30 states), 2001-2003: Alabama, Alaska, Arizona, California, Colorado, Connecticut, Florida, Idaho, Indiana, Iowa, Louisiana, Maine, Massachusetts, Michigan, Montana, Nebraska, Nevada, New Mexico, New York, North Dakota, Oklahoma, Oregon, Pennsylvania, Rhode Island, South Carolina, Texas, Utah, Washington, Wisconsin, and Wyoming.

evaluation for unrelated conditions. ${ }^{78}$ Trends from SEER from 1997 through 2004 show that increases over the past decade are confined to disease in a localized stage. ${ }^{20}$

Long-term increases in incidence rates of NHL continue in women but currently are stable in men, and death rates have declined in recent years for both men and women. Incidence trends for NHL vary by histologic subtype, sex, race/ethnicity, and age; long-term trends have been influenced, but are not fully explained, by trends in human immunodeficiency virus-related subtypes. ${ }^{79,80}$ Moreover, changes in coding and classification complicate the analysis of incidence trends by histologic subtype. ${ }^{81,82}$ Recent mortality trends may be influenced by improving survival; 5-year relative survival increased from $53.6 \%$ for cases diagnosed from 1993 through 1995 to $63.8 \%$ for cases diagnosed in 1996 through $2003 .{ }^{55}$

The rapid increase in thyroid cancer incidence rates described in the 2006 annual report continued between 2003 and 2004 across all populations. ${ }^{9}$ It is postulated that increases in the detection of small tumors related to increased use of ultrasound and fine-needle aspiration account for a large part of this increase. ${ }^{83}$

The increase in melanoma incidence trends has slowed over the years, especially among men, in whom the rates stabilized from 2000 through 2004. The increase in the fixed-interval trends (1995 through 2004) of approximately $3 \%$ per year among both men and women was also smaller than the 5\% increase per year during the mid-1970s to the mid1980s. Although long-term increases in melanoma incidence rates are influenced by early detection and improved reporting of cases diagnosed outside hospitals, increasing trends are not confined to early-stage tumors and also may be influenced by changes in sun exposure. ${ }^{84}$

Increases in liver cancer incidence and mortality in the U.S. population also have been noted previously. The risk of liver cancer is elevated in persons with cirrhosis and chronic liver disease, and in the U.S., the main preventable causes of these conditions are chronic infection with hepatitis B and C viruses, chronic alcohol abuse, and nonalcoholic fatty liver disease. ${ }^{85,86}$ In many developing countries in which hepatitis B is endemic, chronic hepatitis B virus infection is the major causal agent, ${ }^{87}$ and it is likely that elevated liver cancer rates for API and Hispanic men and women are related to high rates of chronic viral hepatitis infection acquired in the countries of origin of recent immigrants. ${ }^{88}$ Obesity and Type 2 diabetes mellitus (Type 2 diabetes) also are emerging as risk factors. ${ }^{86}$

\section{Cancer in American Indians and Alaska Natives}

The current report enhances AI/AN cancer surveillance by presenting U.S. regional cancer incidence rates and by addressing the significant race misclassification of this population in cancer statistics. Link- 
ing IHS and cancer registry data and restricting analyses to CHSDA counties reduces AI/AN misclassification and improves on the accuracy of cancer incidence data previously reported for AI/AN. The report also includes data from 30 state cancer registries and is more representative nationally of the AI/ AN population than previous reports.

Findings from this study, as well as prior reports from specific regions or registries ${ }^{26,89-92}$ or from mortality data, ${ }^{32,34}$ indicate that wide regional variation is characteristic of $\mathrm{AI} / \mathrm{AN}$ cancer surveillance and that region-specific data are essential to characterize the AI/AN cancer burden. In general, cancer rates among AI/AN persons were highest in Alaska and the Northern and Southern Plains and lowest in the Southwest. The wide regional variations in cancer rates may reflect in part geographic variations in screening and in risk factors, such as tobacco use (lung, kidney, and colorectal cancer), obesity (colorectal and breast cancer), low level of physical activity (breast and colorectal cancer), heavy alcohol consumption (breast and liver cancer), and dietary factors, including consumption of large amounts of red meat and inadequate intake of fruits and vegetables (colorectal cancer). Research designed to elucidate regional variations in risk factors may help identify appropriate prevention and control strategies.

The regional patterns of lung cancer rates mirror the regional smoking prevalence from BRFSS, as noted in this report and elsewhere. ${ }^{35}$ Although smoking prevalence in AI/AN respondents in the Southwest is similar to that of NHW respondents, AI/AN smokers in the Southwest tend to smoke fewer cigarettes per day compared with non-AI/AN smokers and AI/AN smokers in other regions. ${ }^{93,94}$ Predictably, lung cancer incidence rates for the AI/AN population in the Southwest were lower than the rates among for the NHW population during the period of this report, a pattern that was documented previously ${ }^{95,96}$ and that reflects the lower rate of cigarette consumption. ${ }^{93,97,98}$ Nonetheless, radon exposure during uranium mining caused a disproportionate number of lung cancer cases among AI/AN men in this region in the 1970s and $1980 \mathrm{~s}^{99,100}$; the proportion of lung cancer cases attributable to uranium-related exposure in the past decade currently is unknown but remains a concern in this region.

Smoking also has been associated with an increased risk of developing ${ }^{101}$ or dying ${ }^{102}$ from colorectal cancer and of being diagnosed at an earlier age. ${ }^{103}$ Furthermore, there is mounting evidence of an association between Type 2 diabetes and colorectal cancer, ${ }^{104,105}$ including a positive interaction of smoking on this risk. ${ }^{106}$ The prevalence of Type 2 di- abetes is generally higher in $\mathrm{AI} / \mathrm{AN}$ persons, is growing rapidly, ${ }^{107}$ and exhibits regional differences ${ }^{35,108}$; it is high in the Northern Plains and the Southwest and low in Alaska, where, although it is lower, the prevalence is increasing at a rapid rate. ${ }^{109}$ Finally, colorectal cancer screening prevalence is low in the NHW population and is lower still in the AI/AN population except for endoscopic screening prevalence in the East and Alaska, where rates for the AI/ AN populations are similar to those for the NHW populations. The parity in endoscopic screening between AI/AN and NHW persons in Alaska may reflect efforts in that state to increase screening for the AI/AN population ${ }^{110,111}$ and also may reflect concerns that use of FOBT may yield false-positive results in a population with high prevalence of Helicobacter pylori (H. pylori) infection. ${ }^{112}$ This finding also is consistent with the observation of a higher probability of early-stage diagnosis for colorectal cancer in that region from this report.

Breast cancer incidence rates in AI/AN women were lower than for NHW women overall. Although the rate for AI/AN women was similar to the rate for NHW women in Alaska, it was nearly 3 times the rate of AI/AN women in the Southwest. Similar variations have been reported previously and may be because of differences in reproductive or behavioral risk factors or variations in mammography rates. ${ }^{91}$ Data regarding variations in reproductive characteristics among AI/AN women by region are limited, however. One study reported no differences in age at first birth among women receiving mammograms in IHS or tribal clinics in Alaska, where incidence rates are relatively high, compared with similar women in Arizona, where incidence rates are is low. ${ }^{113}$ Although it has been postulated that the recent decline in breast cancer incidence in the general population is because of the decline in use of HRT, no data are available on HRT use in AI/AN women. Higher rates of mammography in Alaska may be associated with higher breast cancer incidence rates.

AI/AN persons have higher rates of cancers of the kidney and gallbladder than other populations. In this report, rates for kidney cancer were generally higher in AI/AN than NHW populations, especially in the Northern and Southern Plains and the Southwest. The recognized risk factors for kidney cancer-smoking and obesity-account for $20 \%$ to $30 \%$ of renal cell cancers in the U.S. ${ }^{114}$ Other potential risk factors include hypertension and end-stage renal disease, ${ }^{115}$ the prevalence of which is 3 times greater in $\mathrm{AI} / \mathrm{AN}$ than NHW populations. ${ }^{116}$

Gallbladder cancer is elevated in AI/AN men and women for all regions combined; however, the cur- 
rent report permits presentation of regional rates only for the Southern Plains for women and the Southwest for women and men. Elevated rates in the AI/AN population may be related to a high prevalence of cholelithiasis, ${ }^{117,118}$ a strong risk factor for gallbladder cancer, and obesity. ${ }^{119}$ Recent declines in gallbladder cancer incidence rates in AI/AN populations in the Southwest most likely are because of increasing use of laparoscopic cholecystectomy in this region. ${ }^{120}$

Previous reports have documented high incidence rates of stomach cancer among AI/AN populations in many areas ${ }^{96,121,122}$; and, in the current report, incidence rates for stomach cancer among AI/AN persons were consistently higher than those for NHW persons in Alaska, the Northern and Southern Plains, and the Southwest. In recent years, chronic infection with $H$. pylori has emerged as a key factor in the development of gastric cancer ${ }^{123}$ and several studies have documented high prevalence of H. pylori infection in Native communities. ${ }^{112,124}$ Tobacco smoking, alcohol abuse, and obesity—with a higher prevalence among AI/AN than NHW populations-also are associated with an elevated risk of stomach cancer, especially gastric cardia adenocarcinoma. ${ }^{125-127}$ Additional research is needed to characterize the combination of risk factors that place AI/ AN persons at higher risk of this disease.

Although liver cancer incidence is increasing in most race/ethnic populations in the U.S., it was elevated consistently in AI/AN men and women compared with NHW men and women for the period 1999 through 2004. Alcohol-related morbidity varies across AI/AN communities but remains a significant health concern for many tribal groups. ${ }^{35,128,129}$ Before the introduction of hepatitis $\mathrm{B}$ vaccination, chronic hepatitis B virus infection was endemic among AI/ AN persons in Alaska. ${ }^{130}$ Alcohol abuse and viral hepatitis have a synergistic, positive association with liver cancer and are likely contributors. Furthermore, in 2002, the proportion of deaths attributable to chronic liver disease, a significant risk factor for liver cancer, was 4 times greater in AI/AN populations compared with U.S. white populations. ${ }^{131}$

\section{Healthcare for American Indians and Alaska Natives}

This study reports less favorable socioeconomic status and healthcare access for AI/AN groups compared with NHW groups. Having a usual source of care is a key predictor of cancer screening and other preventive services ${ }^{46}$; and consistent with this, the cancer screening prevalence for AI/AN populations is lower compared with the prevalence for NHW populations.
Previous studies have documented that AI/AN populations have been diagnosed disproportionately with late-stage disease and have relatively poor 5-year survival compared with other populations. ${ }^{7,132-137}$ The findings in this report are consistent with previous studies, indicating that AI/AN populations may not have benefited from available screening technologies and generally have more late-stage diagnoses than NHW populations. These observations in AI/AN populations have led to the development of culturally appropriate screening programs in many regions. ${ }^{138-141}$ Although data are limited on factors that may be associated with later stage at diagnosis among AI/AN populations, studies in other racial groups suggest that stage differences among populations may be influenced by awareness of cancer symptoms, access to a regular healthcare provider, and adequacy of follow-up for abnormal screening results, including timeliness between the first abnormal test result and receiving a definitive diagnosis. ${ }^{142,143}$ Despite persistent disparities, remarkable progress has been made in cervical cancer control. $^{144}$

The IHS provides primary healthcare to approximately 1.8 million enrolled members of federally recognized tribes of the estimated 3.3 million AI/AN in the U.S. ${ }^{145}$ The 150 IHS hospitals and clinics are located primarily on reservation lands and in a few cities with relatively large AI/AN populations. Half of these healthcare facilities are managed by tribal governments under negotiated agreements with the federal government, and half are operated directly by the federal government. An additional 34 urban health centers receive some federal funding to provide healthcare to urban AI/AN. Eligible AI/AN people can receive free healthcare at any IHS facility, but a complex set of rules governs and restricts delivery of contract health services for specialty medical care, such as cancer treatment, which generally is not available in IHS facilities. AI/AN people who do not live within the CHSDA counties, who do not have access to an IHS facility, or who receive non-IHS health benefits may not receive any health benefits from IHS. Funding for IHS is by Congressional appropriation and currently is at the level of $\$ 2532$, compared with $\$ 5645$ per capita personal medical services for U.S. citizens. ${ }^{146}$ Lower funding for IHS, combined with remote rural residence, may contribute to the lack of primary care even in the CHSDA counties. Geographic, financial, and bureaucratic barriers to receiving appropriate cancer treatment as well as cultural beliefs also may contribute to poor survival rates among AI/AN persons. 


\section{Outreach and Community Programs for American Indians and Alaska Natives}

Cancer control only recently has become an important concern for many AI/AN communities as cancer surveillance has revealed substantial increases in cancers that once were quite rare in this population. ${ }^{147-150}$ Committed professionals, community leaders, survivors, and partnering agencies have initiated programs to promote comprehensive cancer control in AI/AN communities. Although much remains to be done, the CDC, NCI, ACS, and other agencies have collaborated with the IHS and tribal and state partners around the country to improve cancer control for AI/AN populations by funding screening and treatment services, supporting coalitions, building cancer control infrastructure, educating professionals and the public, and supporting surveillance and research.

Although the IHS-initiated cervical cancer screening in the 1960s and 1970s resulted in declining cervical cancer incidence and mortality rates in the 1980s and 1990s, ${ }^{90,144}$ little screening mammography was being provided to women served by the IHS before the establishment of the CDC's National Breast and Cervical Cancer Early Detection Program. Fourteen tribal programs, in addition to all 50 states, currently receive support from this program to build infrastructure and provide screening services (Arctic Slope Native Association Limited, Barrow, Ark; Cherokee Nation, Tahlequah, Okla; Cheyenne River Sioux Tribe, Eagle Butte, SD; Hopi Tribe, Kykotsmovi, Ariz; Kaw Nation of Oklahoma, Newkirk, Okla; Mississippi Band of Choctaw Indians, Choctaw, Miss; Native American Rehabilitation Association of the Northwest, Portland, Ore; Navajo Nation, Window Rock, Ariz; Poarch Band of Creek Indians, Atmore, Ala; South East Alaska Regional Health Consortium, Sitka, Alaska; South Puget Intertribal Planning Agency, Shelton, Wash; Southcentral Foundation, Anchorage, Alaska; and Yukon-Kuskokwim Health Corporation, Bethel, Ark). Annual training for primary care providers to perform colposcopy, part of standard diagnostic follow-up for abnormal Pap smear results, is provided by IHS and CDC to increase the number and distribution of providers trained in colposcopy and to reduce the time from abnormal screening results to definitive diagnosis. ${ }^{151,152}$ Continued diligence in education, training, and prevention services to further reduce the death rate from cervical cancer is essential.

The NCI Network for Cancer Control Research Among AI/AN Populations (the Network) is a forum for Native and non-Native researchers with a mission to reduce preventable cancer morbidity and mortal- ity to the lowest levels possible and to improve survival from cancer to the highest level possible in AI/ AN populations. ${ }^{153}$ Realizing the importance of AI/ AN community participation in research, the Network also provides curriculum development and instructors for an annual cancer control training course for Native researchers. ${ }^{154} \mathrm{NCI}$ is an important partner in promoting and funding community networks programs, such as the "Spirit of Eagles" based at the Mayo Clinic in Rochester, Minnesota. This program works with major cancer centers, nonprofit organizations, policy boards, professional societies, and educators through community-based cancer control grants. ${ }^{155} \mathrm{NCI}$ has funded 3 other regional or local community networks in the Pacific Northwest, the Southwest, and Oklahoma. The NCI Cancer Information Service collaborates with community networks to reach medically underserved audiences and partners with researchers to develop messages, channels, and strategies for communicating risk and early detection approaches for AI/AN populations. In addition, NCI has initiated the Patient Navigator Research Program to reduce the time from an abnormal screening, to a definitive diagnosis, and, finally, to treatment.

IHS, CDC, NCI, ACS, NAACCR, and others work to improve cancer data among AI/AN populations. NCI gives technical assistance and training to tribes and regional Indian Health Boards to establish and maintain tribally operated cancer registration systems. Current projects are the Cherokee Nation Cancer Registry (Oklahoma), the Northwest Portland Area Registry Project (Idaho, Oregon, and Washington), ${ }^{92,156}$ and the South Dakota Patterns of Care Project. In addition, the Alaska Native Tumor Registry is a part of the SEER Program. In most cases, the individual tribal projects collaborate with state-operated cancer registries through special agreements to exchange information, maintain confidentiality, and contribute to more complete and accurate information concerning cancer in AI/AN communities. Finally, the CDC provides epidemiologic support and funding to the IHS to conduct the linkages for population-based cancer registries and promotes other cancer control activities that target AI/AN populations.

In the mid-1990s, CDC, ACS, and others promoted the concept of comprehensive cancer control to improve coordination of cancer control activities in state and local health departments and tribal organizations. ${ }^{157}$ The CDC Comprehensive Cancer Control Program began in 1998 and, since then, it has funded 6 tribal organizations (Alaska Native Tribal Health Consortium, South Puget Intertribal Planning 
Agency, Northwest Portland Area Indian Health Board, Aberdeen Tribal Chairmen's Health Board, Fond Du Lac Reservation, and Cherokee Nation) and all 50 states, the District of Columbia, and several U.S. territories. The National Partnership for Comprehensive Cancer Control, a group of national organizations that includes NAACCR, the Intercultural Cancer Council, and C-Change, now promotes comprehensive cancer control at federal, state, local, tribal, and territorial levels; they also support Comprehensive Cancer Control Leadership Institutes to improve implementation of cancer plans in tribal communities. Nonprofit organizations such as ACS and the Lance Armstrong Foundation are providing new resources to $\mathrm{AI} / \mathrm{AN}$ cancer control efforts. The ACS program Circle of Life is designed to decrease the breast cancer incidence and death rates among American Indian women. The Lance Armstrong Foundation has developed a strategic plan for AI/AN survivors to help overcome the fatalism that often accompanies a diagnosis of cancer in the community setting. All these efforts and more are essential to reducing the burden of cancer in $\mathrm{AI} / \mathrm{AN}$ populations.

\section{Issues in Data Interpretation}

The cancer surveillance infrastructure in the U.S. now provides cancer incidence data for most of the population by site, sex, race, and Hispanic origin. However, several limitations in the data collection and analyses may influence the interpretation of results in this report.

First, the 2 methods that were used for trend analysis-joinpoint and fixed-interval trends-sometimes appear to yield different results. The joinpoint method is used for long-term trends but also has the flexibility to identify changes in magnitude and direction of the trend within shorter intervals. The fixed-interval method facilitates comparison between groups but lacks the flexibility to identify changes in the trend over the fixed interval. Although they were not presented, when joinpoint analyses were applied to the fixed-interval time period, the results were more comparable to the long-term trends despite the differences in the U.S. population coverage of $59 \%$ for the fixed-interval analyses and $10 \%$ for the longterm joinpoint analyses and despite the lack of delay adjustment in the fixed-interval approach.

Second, as discussed earlier, it was discovered that many $\mathrm{AI} / \mathrm{AN}$ persons were misclassified as another race in cancer registry data, and the extent of misclassification varied by registry, ranging from $36 \%$ in Minnesota to $57 \%$ in California in published studies. $^{21-24,158,159}$ Although linkage with the IHS patient registration database improves the race clas- sification for AI/AN cases, the issue is not resolved completely, because AI/AN persons who are not members of the federally recognized tribes and are not eligible for IHS services are under-represented in the IHS database. Because the denominators used in the rate calculations were derived from the U.S. Census estimates, which are based on self-identification of race (because it is preferred as the most accurate classification), the actual rates for $\mathrm{AI} / \mathrm{AN}$ persons may be higher than those reported in our study.

Third, the analyses presented here for AI/AN populations are based on residents of CHSDA counties and exclude many $\mathrm{AI} / \mathrm{AN}$ residents in urban areas that are not included in the CHSDA counties; therefore, the findings may not represent all AI/AN populations in the U.S. or in individual IHS regions (see Supplementary Table 1B; available at URL: www.seer.cancer.gov/report_to_nation/). In particular, the East region includes only $12.2 \%$ of the total $\mathrm{AI} / \mathrm{AN}$ population in that region.

Fourth, the current analysis revealed less variation for NHW populations than for AI/AN populations by IHS regions using data from CHSDA counties only. This approach may obscure variation in cancer rates for NHW populations by alternate state or county groupings.

Finally, the median BRFSS response rate is approximately $50 \%$, the response rates vary widely by state, and the surveys rely exclusively on telephone interviews. ${ }^{35}$ Telephone coverage also varies within the AI/AN population and is lower in this population compared with other racial/ethnic groups. ${ }^{35}$ Generally, the questions regarding cancer screening tests do not distinguish between tests conducted for screening and tests conducted for diagnostic purposes. Mixed-mode sampling approaches (ie, combining random digit dialing, computerized address databases, web surveys, etc) are being investigated to address concerns about nonresponse and the declining coverage of the population with traditional landline household phones. ${ }^{160}$

\section{Future Directions}

Each year, the annual report to the nation on cancer brings together key agencies and organizations engaged in cancer surveillance in the U.S. to describe the latest cancer incidence and mortality data for the general population and to focus on a topic that warrants special attention. This year's report represents the 10th anniversary of this collaboration and provides improved data for $\mathrm{AI} / \mathrm{AN}$, highlighting the regional burden of cancer and the distinctive patterns of specific cancers in this population. 
Cancer registrars rely on information available in medical and administrative records for race/ethnicity information; this information often is not available or is not collected and recorded in a systematic manner. Several recent reports have recommended that hospitals implement a uniform framework for the collection of data concerning race, ethnicity, and language, including a rationale for reporting these data, providing scripts and developing other tools to facilitate data collection. ${ }^{161}$ Another approach to improve race classification further for $\mathrm{AI} / \mathrm{AN}$ is the development and expansion of tribal rosters, such as the Northwest tribal roster, ${ }^{25}$ to complement the IHS patient registration database and thereby increase the usefulness of data linkages.

The high rate of misclassification of AI/AN race on death certificates has been documented in several studies. $^{27,162}$ Although the cancer mortality data presented in this report were not linked to the IHS patient registration database to address racial misclassification and likely are underestimates, the development of linkage protocols for death certificates is in progress for addressing this challenge in future reports.

Improved surveillance data advance cancer control and guide future research to address gaps in knowledge. The AI/AN population has high incidence rates of several cancers for which some risk factors are modifiable, such as cigarette smoking, alcohol consumption, obesity, infectious agents (H. pylori and several viruses-hepatitis B, hepatitis C, and human papillomavirus), and possibly diabetes. To reduce cancer burden in AI/AN populations, specific cancer prevention and control interventions should be targeted accordingly and tailored to their special needs. In addition, the generally lower cancer screening rates for $\mathrm{AI} / \mathrm{AN}$ provide a compelling case for enhanced cancer screening programs for AI/AN populations in all regions. Regional geographic variations for the AI/AN populations are important when developing cancer control policies for these populations. AI/AN often live in remote communities with limited access to prevention services and unfavorable socioeconomic conditions, factors that further complicate successful cancer control programs. Delivering cancer screening and other preventive services in these communities hinges on innovative and culturally appropriate interventions. National and local cancer control partners should work with tribes to develop such demonstration projects and to explore other research needs (eg, identifying causes of the disproportionately high rates of colorectal cancer in Alaska and the Northern Plains, examining the determinants of low breast cancer rates in AI/AN women in the Southwest, or evaluating the association of diabetes to patterns of colorectal and other cancers in AI/AN populations).

Cigarette smoking remains the single most important behavioral risk factor for cancer. This is especially true for the AI/AN population, in which the use of both cigarettes and smokeless tobacco are substantially higher than in any other racial or ethnic population in the U.S. ${ }^{163}$ Although American Indians have cultivated and used tobacco since pre-Columbian times, the recreational or habitual use of commercial tobacco products is a relatively recent phenomenon. Many AI/AN individuals still use tobacco as part of traditional ceremonial or healing practices, so tobacco cessation programs must adopt culturally appropriate approaches. There are some tobacco control activities under way, such as the tribal tobacco centers funded by the CDC Office on Smoking and Health and tobacco cessation clinics in a few IHS and tribal clinics. These activities have been rather limited, however; and, until this problem is addressed with substantial resources, further increases in the incidence of lung cancer and other tobacco-related cancers can be expected in the AI/ AN population.

AI/AN populations must have improvements in access to high-quality cancer treatment. Achieving this will require changes in the healthcare delivery system for AI/AN. Few IHS and tribal facilities have specialized cancer care capabilities. Many AI/AN patients must travel long distances at substantial expense for clinic appointments or for scheduled treatment. AI/AN patients who are unfamiliar with the healthcare system are bewildered by the complexity and confusion of specialty cancer care. Expansion of initiatives such as the patient navigator programs could greatly improve access of AI/AN patients to needed preventive and treatment services.

This report emphasizes the importance of analyzing regional cancer incidence data for the AI/AN population to interpret a national picture which, by conveying overall lower AI/AN cancer incidence rates, creates the impression that cancer is not a priority for the AI/AN population. In keeping with what was noted in last year's report regarding the Hispanic population, subgroup analysis is essential to understand those differences-by region in the case of the AI/AN population-and to develop appropriate interventions. Information on geographic variation in cancer rates for NHW, non-Hispanic black, and Hispanic populations is available widely through the dissemination of state incidence and death rates in such publications as the United States Cancer Statistics, Cancer in North American from the NAACCR, 
Cancer Facts and Figures from the ACS, and the Cancer Planet website. Consideration should be given to providing regional data for the AI/AN population when state-based data are provided for other populations. Key to long-range improvement in cancer incidence, morbidity, and mortality is building the infrastructure to support comprehensive cancer control at the community level. The data in this report will strengthen those efforts.

In conclusion, considerable progress has occurred in cancer surveillance in AI/AN populations to provide a more comprehensive and accurate picture of the cancer burden in this population than was available previously. This report describes disparities in cancer incidence and gaps in cancer risk factors and screening that provide a clear, albeit challenging, course of action for national and local cancer control partners. Sufficient diagnostic and treatment capacity must be made available as screening services expand to accommodate those persons with positive screening examinations or those who are diagnosed with cancer. The substantial strides made in cervical cancer control for AI/AN women over the last 20 years by expanding screening and diagnostic follow-up services should serve as a model for addressing other cancers and risk factors. Future progress in decreasing the cancer burden in AI/AN populations is necessary and achievable with implementation of comprehensive cancer control programs that provide direction and motivate and actively engage partners across the spectrum of cancer control advocates, healthcare providers, policymakers, tribal leaders, and funding agencies.

In summary, the collaboration among the major public health cancer surveillance organizations in the U.S. (including, for the first time this year, the IHS) to produce the annual report to the nation on the status of cancer enables a comprehensive review and analysis of the progress being made in diminishing the cancer burden, highlighting the challenges ahead, and focusing on timely issues such as health disparities, cancer care, and specific segments of the cancer continuum, from screening and risk behaviors in healthy persons to quality of life for patients who are dying from cancer. This year's report provides the most comprehensive description of cancer incidence in the AI/AN population available to date and highlights several areas of progress in the general population, notably the continued decline in cancer mortality rates and the recent decline in female breast cancer incidence rates after 20 years of increases. The commitment and leadership from the national organizations to the state cancer registries, vital statistics systems, and local hospitals and other medical facilities that support the infrastructure are critical components that provide information for cancer control, public policy, and identifying important avenues for future research.

\section{REFERENCES}

1. Wingo PA, Ries LA, Rosenberg HM, Miller DS, Edwards BK. Cancer incidence and mortality, 1973-1995: a report card for the U.S. Cancer. 1998;82:1197-1207.

2. Wingo PA, Ries LA, Giovino GA, et al. Annual report to the nation on the status of cancer, 1973-1996, with a special section on lung cancer and tobacco smoking. J Natl Cancer Inst. 1999;91:675-690.

3. Ries LA, Wingo PA, Miller DS, et al. The annual report to the nation on the status of cancer, 1973-1997, with a special section on colorectal cancer. Cancer. 2000;88:2398-2424.

4. Howe HL, Wingo PA, Thun MJ, et al. Annual report to the nation on the status of cancer (1973 through 1998), featuring cancers with recent increasing trends. J Natl Cancer Inst. 2001;93:824-842.

5. Edwards BK, Howe HL, Ries LA, et al. Annual report to the nation on the status of cancer, 1973-1999, featuring implications of age and aging on U.S. cancer burden. Cancer. 2002;94:2766-2792.

6. Weir HK, Thun MJ, Hankey BF, et al. Annual report to the nation on the status of cancer, 1975-2000, featuring the uses of surveillance data for cancer prevention and control. J Natl Cancer Inst. 2003;95:1276-1299.

7. Jemal A, Clegg LX, Ward E, et al. Annual report to the nation on the status of cancer, 1975-2001, with a special feature regarding survival. Cancer. 2004;101:3-27.

8. Edwards BK, Brown ML, Wingo PA, et al. Annual report to the nation on the status of cancer, 1975-2002, featuring population-based trends in cancer treatment. J Natl Cancer Inst. 2005;97:1407-1427.

9. Howe HL, $\mathrm{Wu} \mathrm{X}$, Ries LA, et al. Annual report to the nation on the status of cancer, 1975-2003, featuring cancer among U.S. Hispanic/Latino populations. Cancer. 2006;107:1711-1742.

10. Fritz A, Percy C, Jack A. International Classification of Diseases for Oncology. Geneva, Switzerland: World Health Organization; 2000.

11. Ries L, Harkins D, Krapcho M, et al. SEER Cancer Statistics Review, 1975-2003. Bethesda, Md: National Cancer Institute; 2006.

12. National Center for Health Statistics. Vital Statistics of the United States, 1950-1999. Volume II. Mortality, Parts A and B. Washington, DC: National Center for Health Statistics, Public Health Service; 2001.

13. World Health Organization. Manual of the International Statistical Classification of Diseases, Injuries, and Causes of Death. Based on the recommendations of the 9th Revision Conference, 1975. Geneva, Switzerland: World Health Organization; 1977.

14. Anderson RN, Minino AM, Hoyert DL, Rosenberg HM. Comparability of cause of death between ICD-9 and ICD10: preliminary estimates. Natl Vital Stat Rep. 2001;49:1-32.

15. Public Health Service. Manual of the International Statistical Classification of Diseases, Injuries, and Causes of Death. Adapted for use in the United States. 8th revision. 1693. Washington, DC: U.S. Department of Health, Education, and Welfare, National Center for Health Statistics, Public Health Service; 1967. 
16. World Health Organization. International Statistical Classification of Diseases and Related Health Problems. 10th revision. Geneva, Switzerland: World Health Organization; 1992.

17. National Cancer Institute-SEER. Policy for calculating Hispanic mortality. Bethesda, Md: National Cancer Institute-SEER Program, 2007. Available at URL: http://seer. cancer.gov/seerstat/variables/mort/origin_recode_1990/vol Accessed March 15, 2007.

18. National Cancer Institute-SEER Program. Statistical resources. U.S. population data 1969-2004. Available at URL: http://seer.cancer.gov/resources Accessed June 7, 2007.

19. Centers for Disease Control and Prevention (CDC). National Center for Health Statistics. National Vital Statistics System. U.S. census populations with bridged race categories. Available at URL: http://www.cdc.gov/nchs/about/major/dvs/ popbridge/popbridge.htm Accessed March 15, 2007.

20. Surveillance Research Program. SEER*Stat software. Bethesda, MD: National Cancer Institute, DCCPS, Surveillance Research Program, Cancer Statistics Branch; 2007. Available at URL: http://www.seer.cancer.gov/seerstat Accessed July 14, 2007.

21. Frost F, Taylor V, Fries E. Racial misclassification of Native Americans in a Surveillance, Epidemiology, and End Results cancer registry. J Natl Cancer Inst. 1992;84:957-962.

22. Partin MR, Rith-Najarian SJ, Slater JS, Korn JE, Cobb N, Soler JT. Improving cancer incidence estimates for American Indians in Minnesota. Am J Public Health. 1999;89: 1673-1677.

23. Kwong S, Perkings C, Snipes K, Wright W. Improving American Indian cancer data in the California Cancer Registry by linkage with the Indian Health Service. J Registry Manage. 1998;25:17-20.

24. Sugarman JR, Holliday M, Ross A, Castorina J, Hui Y. Improving American Indian cancer data in the Washington State Cancer Registry using linkages with the Indian Health Service and tribal records. Cancer. 1996;78(7 suppl): 1564-1568.

25. Becker TM, Bettles J, Lapidus J, et al. Improving cancer incidence estimates for American Indians and Alaska Natives in the Pacific Northwest. Am J Public Health. 2002; 92:1469-1471.

26. Harwell TS, Miller SH, Lemons DL, Helgerson SD, Gohdes D. Cancer incidence in Montana: rates for American Indians exceed those for whites. Am J Prev Med. 2006;30: 493-497.

27. Harwell TS, Hansen D, Moore KR, Jeanotte D, Gohdes D, Helgerson SD. Accuracy of race coding on American Indian death certificates, Montana 1996-1998. Public Health Rep. 2002;117:44-49.

28. Indian Health Service. Indian Health Manual, chapter 2. Available at URL: http://www.ihs.gov/PublicInfo/Publications/IHSManual/2004 Accessed June 26, 2007.

29. Gu D. LinkPlus: a suite of publicly available software programs for collecting and processing cancer registry data. Atlanta: Centers for Disease Control and Prevention, National Center for Chronic Disease Prevention and Health Promotion, U.S. Department of Health and Human Services; 2005. Available at URL: http://www.cdc.gov/cancer/npcr/ tools/registryplus/lp.htm Accessed February 2, 2007.

30. Office of Management and Budget. Revisions to the Standards for the Classification of Federal Data on Race and Ethnicity. Federal Register Notice, October 30, 1997. Available at URL: http://www.whitehouse.gov/omb/fedreg/ 1997standards.html Accessed March 24, 2007.
31. Johnson $\mathrm{CH}$, editor. SEER Program coding and staging manual 2004, revision 1. NIH Pub. No. 04-5581. Bethesda, Md: National Cancer Institute; 2004. Available at URL: http:// seer.cancer.gov/seerstat/variables/seer/yr1973_2003/race ethnicity/ Accessed June 25, 2007.

32. Cobb N, Paisano RE. Patterns of cancer mortality among Native Americans. Cancer. 1998;83:2377-2383.

33. Espey DK, Paisano RE, Cobb N. Cancer Mortality Among American Indians and Alaska Natives: Regional Differences, 1994-1998. Rockville, Md: Indian Health Service; 2003.

34. Espey D, Paisano R, Cobb N. Regional patterns and trends in cancer mortality among American Indians and Alaska Natives, 1990-2001. Cancer. 2005;103:1045-1053.

35. Denny CH, Holtzman D, Cobb N. Surveillance for health behaviors of American Indians and Alaska Natives. Findings from the Behavioral Risk Factor Surveillance System, 1997-2000. MMWR Surveill Summ. 2003;52:1-13.

36. Indian Health Service. IHS area offices and facilities. Available at URL: http://www.ihs.gov/FacilitiesServices/Area Offices/AreaOffices_index.asp, 2003 Accessed May 20, 2006.

37. U.S. Department of Health and Human Services. Tracking Healthy People 2010. Volume 2007, 2000. Available at URL: http://www.healthypeople.gov Accessed May 20, 2007.

38. Howe HL, Jamison M, Havener L, Chen VW, Ries LAG. Site-specific comparison of Summary Stage 1977 and Summary Stage 2000 coding, vol 2006. Available at URL: http://www.naaccr.org/index.asp?Col_SectionKey11\&Col_ ContentID397 Accessed July 6, 2007.

39. Klein R, Schoenborn C.Age adjustment using the 2000 projected U.S. population. In: National Center for Health Statistics, editor. Healthy People 2010 Statistical Notes. Hyattsville, Md: National Center for Health Statistics; 2001.

40. Ogunwole SU. We the People: American Indians and Alaska Natives in the United States Census 2000 Special Reports (CENSR-28). Volume 2007. Washington, DC: U.S. Census Bureau; 2006.

41. Kim HJ, Fay MP, Feuer EJ, Midthune DN. Permutation tests for joinpoint regression with applications to cancer rates. Stat Med. 2000;19:335-351.

42. Clegg LX, Feuer EJ, Midthune DN, Fay MP, Hankey BF. Impact of reporting delay and reporting error on cancer incidence rates and trends. J Natl Cancer Inst. 2002;94: 1537-1545.

43. Research Triangle Institute. SUDAAN User's Manual. Professional Software for Survey Data Analysis. 9th ed. Research Triangle Park, NC: Research Triangle Institute; 2003.

44. Schenker N, Gentleman JF. On judging the significance of differences by examining the overlap between confidence intervals. Am Statistician. 2001;55:182-186.

45. Seattle Indian Health Board-Urban Indian Health Institute. The Health Status of Urban American Indians and Alaska Natives: An Analysis of Select Vital Records and Census Data Sources, 2004. Available at URL: http:// www.uihi.net/Public\%20Documents1/UIHI\%20Publications/2004HealthStatusReport.pdf Accessed May 18, 2007.

46. Swan J, Breen N, Coates RJ, Rimer BK, Lee NC. Progress in cancer screening practices in the United States: results from the 2000 National Health Interview Survey. Cancer. 2003;97:1528-1540.

47. Vogelaar I, van Ballegooijen M, Schrag D, et al. How much can current interventions reduce colorectal cancer mortality in the U.S.? Mortality projections for scenarios of risk-factor modification, screening, and treatment. Cancer. 2006;107:1624-1633. 
48. Gross CP, Andersen MS, Krumholz HM, McAvay GJ, Proctor D, Tinetti ME. Relation between Medicare screening reimbursement and stage at diagnosis for older patients with colon cancer. JAMA. 2006;296:2815-2822.

49. Robertson RH, Burkhardt JH, Powell MP, Eloubeidi MA, Pisu M, Weissman NW. Trends in colon cancer screening procedures in the U.S. Medicare and Tricare populations: 1999-2001. Prev Med. 2006;42:460-462.

50. Mandel JS, Bond JH, Church TR, et al. Reducing mortality from colorectal cancer by screening for fecal occult blood. Minnesota Colon Cancer Control Study. $N$ Engl J Med. 1993;328:1365-1371.

51. Winawer S, Fletcher R, Rex D, et al. Colorectal cancer screening and surveillance: clinical guidelines and rationale-update based on new evidence. Gastroenterology. 2003; 124:544-560.

52. Phillips KA, Liang SY, Ladabaum U, et al. Trends in colonoscopy for colorectal cancer screening. Med Care. 2007; $45: 160-167$.

53. Jemal A, Ward E, Thun MJ. Contemporary lung cancer trends among U.S. women. Cancer Epidemiol Biomarkers Prev. 2005;14:582-585.

54. Jemal A, Travis WD, Tarone RE, Travis L, Devesa SS. Lung cancer rates convergence in young men and women in the United States: analysis by birth cohort and histologic type. Int J Cancer. 2003;105:101-107.

55. Ries L, Melbert D, Krapcho M, et al. SEER cancer statistics review, 1975-2004 [Based on November 2006 SEER data submission; posted to the SEER web site, 2007]. Bethesda, Md: National Cancer Institute, 2006. Available at URL: http://seer.cancer.gov/csr/1975_2004/ Accessed April 13, 2007.

56. Baade PD, Coory MD, Aitken JF. International trends in prostate-cancer mortality: the decrease is continuing and spreading. Cancer Causes Control. 2004;15:237-241.

57. Oliver SE, May MT, Gunnell D. International trends in prostate-cancer mortality in the "PSA ERA." Int $J$ Cancer. 2001;92:893-898.

58. Barry MJ. Clinical practice. Prostate-specific-antigen testing for early diagnosis of prostate cancer. $N$ Engl J Med. 2001;344:1373-1377.

59. Harris R, Lohr KN. Screening for prostate cancer: an update of the evidence for the U.S. Preventive Services Task Force. Ann Intern Med. 2002;137:917-929.

60. Shaw PA, Etzioni R, Zeliadt SB, et al. An ecologic study of prostate-specific antigen screening and prostate cancer mortality in nine geographic areas of the United States. Am J Epidemiol. 2004;160:1059-1069.

61. Feuer EJ, Mariotto A, Merrill R. Modeling the impact of the decline in distant stage disease on prostate carcinoma mortality rates. Cancer. 2002;95:870-880.

62. Messing EM, Manola J, Sarosdy M, Wilding G, Crawford ED, Trump D. Immediate hormonal therapy compared with observation after radical prostatectomy and pelvic lymphadenectomy in men with node-positive prostate cancer. N Engl J Med. 1999;341:1781-1788.

63. Demers RY, Tiwari A, Wei J, Weiss LK, Severson RK, Montie J. Trends in the utilization of androgen-deprivation therapy for patients with prostate carcinoma suggest an effect on mortality. Cancer. 2001;92:2309-2317.

64. Seidenfeld J, Samson DJ, Aronson N, et al. Relative effectiveness and cost-effectiveness of methods of androgen suppression in the treatment of advanced prostate cancer. Evid Rep Technol Assess (Summ). 1999;4:i-X,1-246,I1-36, passim.
65. Bolla M, Gonzalez D, Warde P, et al. Improved survival in patients with locally advanced prostate cancer treated with radiotherapy and goserelin. $N$ Engl J Med. 1997;337: 295-300.

66. Platz EA, Leitzmann MF, Visvanathan K, et al. Statin drugs and risk of advanced prostate cancer. J Natl Cancer Inst. 2006;98:1819-1825.

67. Centers for Disease Control and Prevention (CDC). Use of Mammograms Among Women Aged $>40$ Years-United States, 2000-2005. MMWR Morb Moral Weekly Rep. 2007; 56:49-51.

68. Jemal A, Ward E, Thun MJ. Recent trends in breast cancer incidence rates by age and tumor characteristics among U.S. women. Breast Cancer Res. 2007;9:R28.

69. Ravdin PM, Cronin KA, Howlader N, et al. The decrease in breast-cancer incidence in 2003 in the United States. $N$ Engl J Med. 2007;356:1670-1674.

70. Breen N, Cronin KA, Meissner HI, et al. Reported drop in mammography: is this cause for concern? Cancer. 2007;109: 2405-2409.

71. Stewart SL, Sabatino SL, Foster SL, Richardson LC. Decline in breast cancer incidence rates in the United States, 19992003. Morb Mortal Wkly Rep. 2007;56:549-553.

72. Swan J, Breen N, Burhansstipanov L, et al. Cancer screening and risk factor rates among American Indians. Am J Public Health. 2006;96:340-350.

73. Mokbel K. Contemporary treatment of ductal carcinoma in situ of the breast. Med Sci Monitor. 2005;11:RA86-RA93.

74. Beral V, Bull D, Green J, Reeves G. Ovarian cancer and hormone replacement therapy in the Million Women Study. Lancet. 2007;369:1703-1710.

75. Bray F, Loos AH, Tognazzo S, La Vecchia C. Ovarian cancer in Europe: cross-sectional trends in incidence and mortality in 28 countries, 1953-2000. Int J Cancer. 2005;113: 977-990.

76. Gnagy S, Ming EE, Devesa SS, Hartge P, Whittemore AS. Declining ovarian cancer rates in U.S. women in relation to parity and oral contraceptive use. Epidemiology. 2000;11: 102-105.

77. Hollingsworth JM, Miller DC, Daignault S, Hollenbeck BK. Rising incidence of small renal masses: a need to reassess treatment effect. J Natl Cancer Inst. 2006;98:1331-1334.

78. Jayson M, Sanders H. Increased incidence of serendipitously discovered renal cell carcinoma. Urology. 1998;51: 203-205.

79. Clarke CA, Glaser SL. Changing incidence of non-Hodgkin lymphomas in the United States. Cancer. 2002;94:2015-2023.

80. Clarke CA, Glaser SL. Epidemiologic trends in HIV-associated lymphomas. Curr Opin Oncol. 2001;13:354-359.

81. Clarke CA, Undurraga DM, Harasty PJ, Glaser SL, Morton LM, Holly EA. Changes in cancer registry coding for lymphoma subtypes: reliability over time and relevance for surveillance and study. Cancer Epidemiol Biomarkers Prev. 2006;15:630-638.

82. Morton LM, Wang SS, Devesa SS, Hartge P, Weisenburger DD, Linet MS. Lymphoma incidence patterns by WHO subtype in the United States, 1992-2001. Blood. 2006;107: 265-276.

83. Davies L, Welch HG. Increasing incidence of thyroid cancer in the United States, 1973-2002. JAMA. 2006;295:21642167.

84. Jemal A, Devesa SS, Hartge P, Tucker MA. Recent trends in cutaneous melanoma incidence among whites in the United States. J Natl Cancer Inst. 2001;93:678-683. 
85. McGlynn KA, Tarone RE, El-Serag HB. A comparison of trends in the incidence of hepatocellular carcinoma and intrahepatic cholangiocarcinoma in the United States. Cancer Epidemiol Biomarkers Prev. 2006;15:1198-1203.

86. London WT, McGlynn KA. Liver cancer. In: Schottenfeld D, Fraumeni J, editors. Cancer Epidemiology and Prevention. New York: Oxford University Press; 2006:763-786.

87. Perz JF, Armstrong GL, Farrington LA, Hutin YJ, Bell BP. The contributions of hepatitis B virus and hepatitis C virus infections to cirrhosis and primary liver cancer worldwide. J Hepatol. 2006;45:529-538.

88. Chen MS Jr. Cancer health disparities among Asian Americans: what we do and what we need to do. Cancer. 2005;104(12 suppl):2895-2902 .

89. Swan J, Edwards BK. Cancer rates among American Indians and Alaska Natives: is there a national perspective? Cancer. 2003;98:1262-1272.

90. Lanier AP, Kelly JJ, Maxwell J, McEvoy T, Homan C. Cancer in Alaska Native people, 1969-2003. Alaska Med. 2006;48:30-59.

91. Kelly JJ, Lanier AP, Alberts S, Wiggins CL. Differences in cancer incidence among Indians in Alaska and New Mexico and U.S. whites, 1993-2002. Cancer Epidemiol Biomarkers Prev. 2006;15:1515-1519.

92. Puukka E, Stehr-Green P, Becker TM. Measuring the health status gap for American Indians/Alaska Natives: getting closer to the truth. Am J Public Health. 2005;95: 838-843.

93. Gilliland FD, Mahler R, Davis SM. Non-ceremonial tobacco use among southwestern rural American Indians: the New Mexico American Indian Behavioural Risk Factor Survey. Tob Control. 1998;7:156-160.

94. Peterson E, Fenaughty A, Eberhart-Phillips J. Tobacco in the Great Land: A Portrait of Alaska's Leading Cause of Death. Anchorage, Alaska: Section of Epidemiology, Division of Public Health, Alaska Department of Health and Social Services; 2004. Available at URL: http://www.epi. hss.state.ak.us/pubs/tobacco04/t04_complete.pdf Accessed May 19, 2007.

95. Key CR. Cancer incidence and mortality in New Mexico, 1973-77. In: Young JL Jr, Percy CL, Asire AI, editors. Surveillance, Epidemiology, and End Results: Incidence and Mortality Data, 1973-77. NCI Monograph 57, NIH Publication No. 81-2330. Bethesda, Md: U.S. Department of Health and Human Services, Public Health Service, National Institutes of Health, National Cancer Institute; 1981.

96. Nutting PA, Freeman WL, Risser DR, et al. Cancer incidence among American Indians and Alaska Natives, 1980 through 1987. Am J Public Health. 1993;83:15891598.

97. Sievers ML. Cigarette and alcohol usage by southwestern American Indians. Am J Public Health Nations Health. 1968; 58:71-82.

98. DeStefano F, Coulehan JL, Wiant MK. Blood pressure survey on the Navajo Indian reservation. Am J Epidemiol. 1979;109:335-345.

99. Samet JM, Kutvirt DM, Waxweiler RJ, Key CR. Uranium mining and lung cancer in Navajo men. $N$ Engl $\mathrm{J} \mathrm{Med.}$ 1984;310:1481-1484.

100. Gilliland FD, Hunt WC, Pardilla M, Key CR. Uranium mining and lung cancer among Navajo men in New Mexico and Arizona, 1969 to 1993. J Occup Environ Med. 2000; 42:278-283.
101. Akhter M, Nishino Y, Nakaya N, et al. Cigarette smoking and the risk of colorectal cancer among men: a prospective study in Japan. Eur J Cancer Prev. 2007;16:102-107.

102. Chao A, Thun MJ, Jacobs EJ, Henley SJ, Rodriguez C, Calle EE. Cigarette smoking and colorectal cancer mortality in the Cancer Prevention Study II. J Natl Cancer Inst. 2000; 92:1888-1896.

103. Zisman AL, Nickolov A, Brand RE, Gorchow A, Roy HK. Associations between the age at diagnosis and location of colorectal cancer and the use of alcohol and tobacco: implications for screening. Arch Intern Med. 2006;166:629-634.

104. Larsson SC, Orsini N, Wolk A. Diabetes mellitus and risk of colorectal cancer: a meta-analysis. J Natl Cancer Inst. 2005;97:1679-1687.

105. Larsson SC, Giovannucci E, Wolk A. Diabetes and colorectal cancer incidence in the cohort of Swedish men. Diabetes Care. 2005;28:1805-1807.

106. Limburg PJ, Vierkant RA, Fredericksen ZS, et al. Clinically confirmed type 2 diabetes mellitus and colorectal cancer risk: a population-based, retrospective cohort study. $A m \mathrm{~J}$ Gastroenterol. 2006;101:1872-1879.

107. Acton KJ, Burrows NR, Moore K, Querec L, Geiss LS, Engelgau MM. Trends in diabetes prevalence among American Indian and Alaska native children, adolescents, and young adults. Am J Public Health. 2002;92:1485-1490.

108. Burrows NR, Geiss LS, Engelgau MM, Acton KJ. Prevalence of diabetes among Native Americans and Alaska Natives, 1990-1997: an increasing burden. Diabetes Care. 2000;23:1786-1790.

109. Acton KJ. The Many Voices of the Special Diabetes Program for Indians: Reflections on the Past, Directions for the Future, 2006. Presentation for the 2006 IHS Division of Diabetes Treatment and Prevention Regional Meetings. Available at URL: http://www.ihs.gov/MedicalPrograms/diabetes/[regional_mtg_kaps2006.asp Accessed June 14, 2007.

110. Schraag J. She'll do-quite well! Pioneering the murky waters of nurse practitioner-led screening colonoscopies [electronic resource]. EndoNurse 2006. Available at URL: http://www.endonurse.com/articles/6clfeat3. Accessed May 10, 2007.

111. Meltzer W. Nurses doing flexible sigmoidoscopy and colonscopy [electronic resource]. Outpatient Surg. Available at URL: http://www.outpatientsurgery.net/2004/os05/ nurses_flexible_sigmoidoscopy_colonoscopy.php Accessed May 10, 2007.

112. Yip R, Limburg PJ, Ahlquist DA, et al. Pervasive occult gastrointestinal bleeding in an Alaska native population with prevalent iron deficiency. Role of Helicobacter pylori gastritis. JAMA. 1997;277:1135-1139.

113. Kaur JS, Roubidoux MA, Sloan J, Novotny P. Can the Gail model be useful in American Indian and Alaska Native populations? Cancer. 2004;100:906-912.

114. Moore LE, Wilson RT, Campleman SL. Lifestyle factors, exposures, genetic susceptibility, and renal cell cancer risk: a review. Cancer Invest. 2005;23:240-255.

115. Farivar-Mohseni H, Perlmutter AE, Wilson S, Shingleton WB, Bigler SA, Fowler JE Jr. Renal cell carcinoma and end stage renal disease. J Urol. 2006;175:2018-2020; discussion 2021.

116. Narva AS. The spectrum of kidney disease in American Indians. Kidney Int. 2003;83(suppl):S3-S7.

117. Shaffer EA. Gallstone disease: epidemiology of gallbladder stone disease. Best Pract Res Clin Gastroenterol. 2006;20: 981-996. 
118. Everhart JE, Yeh F, Lee ET, et al. Prevalence of gallbladder disease in American Indian populations: findings from the Strong Heart Study. Hepatology. 2002;35:1507-1512.

119. Hsing H, Rashid A, Devesa SS, Fraumeni J.Biliary tract cancer. In: Schottenfeld D, Fraumeni J, editors. Cancer Epidemiology and Prevention. New York, NY: Oxford University Press; 2006.

120. Barakat J, Dunkelberg JC, Ma TY. Changing patterns of gallbladder carcinoma in New Mexico. Cancer. 2006;106: 434-440.

121. Wiggins CL, Becker TM, Key CR, Samet JM. Stomach cancer among New Mexico's American Indians, Hispanic whites, and non-Hispanic whites. Cancer Res. 1989;49: 1595-1599.

122. Alberts SR, Kelly JJ, Lanier AP, Sacco F. Occurrence of esophageal and gastric cancer in Alaska Natives, 19692003. Alaska Med. 2006;48:2-11.

123. Correa P. Helicobacter pylori infection and gastric cancer. Cancer Epidemiol Biomarkers Prev. 2003;12:238s-241s.

124. Bernstein CN, McKeown I, Embil JM, et al. Seroprevalence of Helicobacter pylori, incidence of gastric cancer, and peptic ulcer-associated hospitalizations in a Canadian Indian population. Dig Dis Sci. 1999;44:668-674.

125. Gammon M, Schoenberg J, Ahsan H, et al. Tobacco, alcohol, and socioeconomic status and adenocarcinomas of the esophagus and gastric cardia. J Natl Cancer Inst. 1997;89: 1277-1284.

126. Sasazuki S, Sasaki S, Tsugane S. Cigarette smoking, alcohol consumption and subsequent gastric cancer risk by subsite and histologic type. Int J Cancer. 2002;101:560-566.

127. Lagergren J, Bergstrom R, Nyren O. Association between body mass and adenocarcinoma of the esophagus and gastric cardia. Ann Intern Med. 1999;130:883-890.

128. Indian Health Service. Trends in Indian Health, 19981999. Rockville, Md: U.S. Department of Health and Human Services, Indian Health Service; 2000.

129. Bialek S, Redd JT, Lynch ACF, et al. Chronic liver disease among 2 American Indian patient populations in the Southwestern United States: 2000-2003. J Clin Gastroenterol. In press.

130. Rawls RA, Vega KJ. Viral hepatitis in minority America. J Clin Gastroenterol. 2005;39:144-151.

131. Anderson RN, Smith BL. Deaths: leading causes for 2002. Natl Vital Stat Rep. 2005;53:1-89.

132. Dennis TD. Cancer stage at diagnosis, treatment, and survival among American Indians and non-American Indians in Montana. Cancer. 2000;89:181-186.

133. Bleed DM, Risser DR, Sperry S, Hellhake D, Helgerson SD. Cancer incidence and survival among American Indians registered for Indian health service care in Montana, 1982-1987. J Natl Cancer Inst. 1992;84:1500-1505.

134. Brown MO, Lanier AP, Becker TM. Colorectal cancer incidence and survival among Alaska Natives, 1969-1993. Int J Epidemiol. 1998;27:388-396.

135. Lanier AP, Holck P, Kelly J, Smith B, McEvoy T. Alaska Native cancer survival. Alaska Med. 2001;43:61-69, 83.

136. Clegg LX, Li FP, Hankey BF, Chu K, Edwards BK. Cancer survival among US whites and minorities: a SEER (Surveillance, Epidemiology, and End Results) Program population-based study. Arch Intern Med. 2002;162:1985-1993.

137. Frost F, Tollestrup K, Hunt WC, Gilliland F, Key CR, Urbina CE. Breast cancer survival among New Mexico Hispanic, American Indian, and non-Hispanic white women (19731992). Cancer Epidemiol Biomarkers Prev. 1996;5:861-866.
138. Becker SA, Affonso DD, Beard MB. Talking circles: Northern Plains tribes American Indian women's views of cancer as a health issue. Public Health Nurs. 2006;23:2736.

139. Burhansstipanov L. Community-driven Native American cancer survivors' quality of life research priorities. J Cancer Educ. 2005;20(1 suppl):7-11.

140. Burhansstipanov L, Tenney M, Russell S, Bad Wound D, Plomer K. Overview of the Native American Cancer Conference III. Risk factors, outreach and intervention strategies. Cancer. 1996;78(7 suppl):1527-1532.

141. Cunningham-Sabo L, Davis SM. Pathways to health. A health promotion and cancer prevention project for American Indian youth. Alaska Med. 1993;35:275-278, 296.

142. Gorin SS, Heck JE, Cheng B, Smith SJ. Delays in breast cancer diagnosis and treatment by racial/ethnic group. Arch Intern Med. 2006;166:2244-2252.

143. Allgar VL, Neal RD. Delays in the diagnosis of six cancers: analysis of data from the National Survey of NHS Patients: Cancer. Br J Cancer. 2005;92:1959-1970.

144. Chao A, Becker TM, Jordan SW, Darling R, Gilliland FD, Key CR. Decreasing rates of cervical cancer among American Indians and Hispanics in New Mexico (United States). Cancer Causes Control. 1996;7:205-213.

145. Indian Health Service. Indian Health Service fact sheet. Available at URL: http://www.ihs.gov/PublicInfo/PublicAffairs/Welcome_Info/ThisFacts.asp, 2006 Accessed May 8, 2007.

146. Allison MT, Rivers PA, Fottler MD. Future public health delivery models for Native American tribes. Public Health. 2007;121:296-307.

147. Sievers ML, Cohen SL. Lung cancer among Indians of the southwestern United States. Ann Intern Med. 1961;54:912915.

148. Lee BJ. The incidence of cancer among the Indians in the southwest Surg Gynecol Obstet. 1930;50:4:196-199.

149. Palmer EP. Incidence of cancer among Indians of the United States and Canada with specific reference to Arizona. Acta Unio Int Cancrum. 1953;9:373-391.

150. Johnson M.Lung cancer among the Alaska Natives. In: Science in Alaska, Proceedings of the 15th Alaskan Science Conference (1964). Washington, DC: American Association for the Advancement of Science, Alaska Division; 1965:110-114.

151. Waxman AG. Colposcopy training for IHS providers: a strategy for improving cervical cancer screening in Native Americans. IHS Provider. 1992;17:41-43.

152. Waxman AG, Inkret W. Teaching colposcopy on the Navajo Indian Reservation. Colposcopist. 1991;23:1-2.

153. Hampton JW, Keala J, Luce P. Overview of National Cancer Institute networks for cancer control research in Native American populations. Cancer. 1996;78(7 suppl):15451552.

154. Becker TM, Joe JR, Cobb N, et al. Training for cancer control research: a curriculum for Native researchers. J Cancer Edu. 1999;14:233-237.

155. Kaur JS, Dignan M, Burhansstipanov L, Baukol P, Claus C. The "Spirit of Eagles" legacy. Cancer. 2006;107(8 suppl): 1987-1994.

156. Becker TM, Lambert L, Puukka E, Stehr-Green P, Johnson CJ. Survival after cancer diagnosis among North-west American Indians/Alaska Natives. J Registry Manage. 2005; 32:76-78. 
157. Given LS, Black B, Lowry G, Huang P, Kerner JF. Collaborating to conquer cancer: a comprehensive approach to cancer control. Cancer Causes Control. 2005;16(Suppl 1): 3-14.

158. Gomez SL, Glaser SL. Misclassification of race/ethnicity in a population-based cancer registry (United States). Cancer Causes Control. 2006;17:771-781.

159. Clegg LX, Reichman ME, Hankey BF, et al. Quality of race, Hispanic ethnicity, and immigrant status in population-based cancer registry data: implications for health disparity studies. Cancer Causes Control. 2007;18:177-187.

160. Link MW, Battaglia MP, Frankel MR, Osborn L, Mokdad $\mathrm{AH}$. Address-based versus random-digit-dial surveys: com- parison of key health and risk indicators. Am J Epidemiol. 2006;164:1019-1025.

161. Wilson-Stronks A, Galvez E. Hospitals, Language and Culture: A Snapshot of the Nation. The Joint Commission, 2007. Available at URL: http://www.jointcommission.org/ NR/rdonlyres/E64E5E89-5734-4D1D-BB4D-C4ACD4BF8BD3/ 0/hlcpaper.pdf Accessed May 10, 2007.

162. Rosenberg HM, Maurer JD, Sorlie PD, et al. Quality of death rates by race and Hispanic origin: a summary of current research, 1999. Vital Health Stat 2. 1999;128:1-13.

163. Centers for Disease Control and Prevention (CDC). Tobacco use among adults-United States, 2005. MMWR Morb Mortal Wkly Rep. 2006;55:1145-1148. 